\title{
Dose-dependent and disease-modifying effects of striatal infusion of cholesterol
}

\section{in Huntington's disease}

Giulia Birolini ${ }^{1,2 \ddagger}$, Marta Valenza ${ }^{1,2 \ddagger *}$, Eleonora Di Paolo ${ }^{1,2 \ddagger}$, Elena Vezzoli ${ }^{1,2, \dagger}$, Francesca Talpo $^{3}$, Claudia Maniezzi ${ }^{3}$, Claudio Caccia ${ }^{4}$, Valerio Leoni ${ }^{5}$, Vittoria D. Bocchi ${ }^{1,2}$, Paola Conforti $^{1,2}$, Elisa Sogne ${ }^{6}$, Lara Petricca ${ }^{7}$, Cristina Cariulo ${ }^{7}$, Margherita Verani $^{7}$, Andrea Caricasole $^{7}$, Andrea Falqui ${ }^{6}$, Gerardo Biella ${ }^{3}$, Elena Cattaneo ${ }^{1,2 *}$

${ }^{1}$ Department of Biosciences, University of Milan, via G. Celoria 26, 20133, Milan, Italy.

${ }^{2}$ Istituto Nazionale di Genetica Molecolare "Romeo ed Enrica Invernizzi" via F. Sforza 35, 20122, Milan, Italy.

${ }^{3}$ Department of Biology and Biotechnologies, University of Pavia, Via Adolfo Ferrata, 9, 27100, Pavia, Italy.

${ }^{4}$ Unit of Medical Genetics and Neurogenetics. Fondazione I.R.C.C.S. Istituto Neurologico Carlo Besta, Via Celoria 11, 20131 Milan, Italy

${ }^{5}$ School of Medicine and Surgery, University of Milano-Bicocca, Via Cadore 48, 20900, Monza and Laboratory of Clinical Pathology, Hospital of Desio, ASST-Monza, Italy

${ }^{6} \mathrm{King}$ Abdullah University of Science and Technology (KAUST), Biological and Environmental Science \& Engineering (BESE) Division, NABLA Lab, Thuwal, Saudi Arabia.

${ }^{7}$ Neuroscience Unit, Translational and Discovery Research Department, IRBM S.p.A, Via Pontina km 30.600, 00071, Pomezia, Rome, Italy.

Present address: Department of Biomedical Sciences for Health, University of Milan, Via G. Colombo 71, 20133, Milan, Italy.

co-first authors

*To whom correspondence should be addressed: elena.cattaneo@unimi.it, marta.valenza@unimi.it. 


\section{Abstract}

A variety of pathophysiological mechanisms are implicated in Huntington's disease (HD). Among them, reduced cholesterol biosynthesis has been detected in the HD mouse brain from pre-symptomatic stages, leading to diminished cholesterol synthesis, particularly in the striatum. In addition, systemic injection of cholesterol-loaded brain-permeable nanoparticles ameliorates synaptic and cognitive function in a transgenic mouse model of HD. To identify an appropriate treatment regimen and gain mechanistic insights into the beneficial activity of exogenous cholesterol in the HD brain, we employed osmotic mini-pumps to infuse three escalating doses of cholesterol directly into the striatum of HD mice in a continuous and ratecontrolled manner. All tested doses prevented cognitive decline, while amelioration of disease-related motor defects was dose-dependent. In parallel, we found morphological and functional recovery of synaptic transmission involving both excitatory and inhibitory synapses of striatal medium spiny neurons. The treatment also enhanced endogenous cholesterol biosynthesis and clearance of mutant Huntingtin aggregates. These results indicate that cholesterol infusion to the striatum can exert a dose-dependent, disease-modifying effect and may be therapeutically relevant in HD.

\section{Keywords}

Cholesterol / Huntington's disease / aggregates / synapses / behavior 


\section{Introduction}

The brain is the most cholesterol-rich organ, accounting for about $25 \%$ of the whole body's cholesterol $(1,2)$. Its biosynthesis occurs through a stepwise cascade involving several enzymes under transcriptional regulation by sterol regulatory element binding protein 2 (SREBP2) transcription factor (3). In the adult brain, a small amount of cholesterol continues to be synthesized locally, where it regulates multiple processes including synapse formation and maintenance, synaptic vesicle (SV) recycling, and optimal release of neurotransmitters for downstream intracellular signaling pathways (4-7). Consequently, dysregulation of brain cholesterol homeostasis is linked to several chronic neurological and neurodegenerative diseases $(8,9)$. Among these conditions is Huntington's disease (HD), an adult-onset disorder characterized by motor, cognitive, and psychiatric features.

The basis of HD is expansion of a CAG trinucleotide repeat in the gene encoding the Huntingtin protein (HTT) (10). In HD, the striatal medium spiny neurons (MSNs) and cortical pyramidal neurons projecting to the striatum are primarily affected and degenerate $(11,12)$. One of the underlying pathophysiological mechanisms is disruption of brain cholesterol biosynthesis. This compromised process is manifested in reduced mRNA levels of key enzymes in the cholesterol synthesis pathway in HD cells, HD mouse models, and postmortem brain from HD patients (13-17). Also evident is a reduction in cholesterol precursors, in particular lathosterol and lanosterol, as judged by isotopic-dilution mass spectrometry (IDMS) in HD cells (18) and in seven rodent HD models (19-22); moreover, striatal level of lathosterol is inversely correlated with CAG repeat number (22). In addition, the striatum of knock-in zQ175 mice (22) shows reduced synthesis of new cholesterol after administration of deuterated water in vivo at the pre-symptomatic stage (22) and decreased cholesterol at late 
time points, as measured by gas chromatography-mass spectrometry (GC-MS). Finally, levels of the brain-derived cholesterol catabolite 24S-hydroxy-cholesterol (24S-OHC) are decreased in brain and blood from HD mice (20-22), post-mortem caudate (23), plasma of HD patients $(24,25)$, as well as in pre-HD manifesting patients who are close to the disease onset $(26)$.

All of these findings support the idea that the primary event of cholesterol dysfunction in the HD brain is decreased synthesis, followed by reduced conversion of cholesterol into 24S-OHC, ultimately leading to reduced cholesterol content at the late-symptomatic stages (22). In a recent study in two HD animal models (R6/2 and zQ175 mice), enhancement of cholesterol catabolism in the striatum via neuronal over-expression of cholesterol 24hydroxylase (Cyp46A1) increased striatal levels of 24S-OHC and endogenous cholesterol biosynthesis and rescued several disease phenotypes $(23,27)$. Despite conflicting data regarding the measurement of striatal cholesterol in $\mathrm{R} 6 / 2$ and $z Q 175$ mice $(23,27)$, this strategy proved to be of therapeutic relevance in targeting cholesterol biosynthesis in HD brain.

We previously reported that systemic administration of brain-permeable polymeric nanoparticles loaded with cholesterol (g7-NPs-chol) reversed synaptic alterations and prevented cognitive defects in a HD transgenic mouse model (28). This work provided the first proof-of-concept that cholesterol delivery to the HD brain is beneficial, but the low cholesterol content of g7-NPs-chol did not allow for full characterization of a target therapeutic dose or its effects on motor and cognitive capacity.

Here we sought to evaluate the dose-dependent effects of cholesterol infusion on molecular, functional, and behavioral parameters. For this purpose, we took advantage of osmotic mini-pumps to infuse three escalating doses of cholesterol directly into the striatum 
of HD mice, in a continuous and rate-controlled manner. In this model, all three doses prevented cognitive defects, and the highest dose attenuated also disease-related motor phenotypes. In parallel with these behavioral benefits, we detected morphological and functional recovery of synaptic transmission that involved both excitatory and inhibitory synapses on striatal MSNs. Striatal infusion of cholesterol in HD mice also increased levels of the brain-specific cholesterol catabolite $24 \mathrm{~S}-\mathrm{OHC}$ and enhanced endogenous cholesterol biosynthesis, restoring the primary cholesterol defect in HD. At the cellular level, we show that striatal infusion of cholesterol reduced muHTT aggregates by reducing lysosome accumulation. 


\section{Results}

Striatal infusion of cholesterol prevents motor and cognitive deficits in HD mice

To identify the target therapeutic dose of cholesterol to administer, we infused three escalating doses of cholesterol - $15 \mu \mathrm{g}$ (chol-low), $185 \mu \mathrm{g}$ (chol-medium), and $369 \mu \mathrm{g}$ (cholhigh) - directly into one hemi-striatum of the R6/2 transgenic model of HD (29). For this purpose, we used miniature infusion osmotic pumps implanted subcutaneously on the back and connected to a catheter. We targeted the striatum as the most affected brain region in HD and the earliest and most obvious site of decreased cholesterol biosynthesis (22). Mice were operated at age 7 weeks, and motor and cognitive tests were performed over a 4-week infusion period (Fig 1A).

Before testing HD mice and to reduce the number of animals in the main study without compromising statistical power, we performed a pilot experiment with healthy wildtype (wt) mice to assess the behavioral influence of osmotic mini-pump implantation and 4 weeks of high-dose cholesterol administration. Mini-pumps filled with artificial cerebrospinal fluid (ACSF) or high-dose cholesterol were implanted in wt mice, and behavioral tests were performed. Coordination, motor activity, and memory recognition were similar among unoperated wt, wt ACSF, and wt chol-high mice (Appendix Fig S1A-F). Using GC-MS, we verified increased cholesterol content in the infused striatum and ipsilateral cortex of wt cholhigh mice compared to wt ACSF animals (Appendix Fig S1G and H). These results allowed us to include only unoperated wt mice as controls in subsequent studies.

To visualize the spread of exogenous cholesterol, we tested an analogue of cholesterol tagged with a fluorescent bodipy group at carbon 24 (bodipy-chol), using the experimental paradigm described in Fig 1A. After a 4-week infusion period, bodipy-chol covered 
$39.7 \% \pm 5.9 \%$ of the infused hemi-striatum of R6/2 mice, whereas we found no signal in the contralateral hemisphere (Fig 1B).

For maximum solubility and diffusion of the exogenous cholesterol (30), we used water-soluble methyl- $\beta$-cyclodextrin $(\mathrm{M} \beta \mathrm{CD})$-balanced cholesterol. To exclude any potential effect of $\mathrm{M} \beta C \mathrm{CD}$, we performed motor and cognitive tests in an additional control group, comparing R6/2 ACSF and R6/2 mice with mini-pumps containing ACSF and the equivalent quantity of $M \beta C D$ to be used with chol-high (R6/2 ACSF-M $\beta C D)$. The presence of M $\beta C D$ in ACSF did not influence outcomes in the motor and cognitive tasks (Appendix Fig S2).

We next tested three doses of exogenous cholesterol in R6/2 mice. We used GC-MS to quantify cholesterol content in the striatum and cortex of R6/2 mice and verify the success of chronic cholesterol infusion. Compared to animals implanted with osmotic mini-pumps filled with ACSF, R6/2 mice infused with the three doses of cholesterol showed a dosedependent increase in cholesterol content in the striatum (Fig 1C). The increase was significant with the chol-medium and chol-high doses (Fig 1C). Of note, striatal cholesterol content was decreased in late-symptomatic R6/2 and R6/2 ACSF mice compared to wt mice (Fig 1C), supporting previous findings (21). A significant increase in cholesterol content was also observed in the ipsilateral cortex of R6/2 chol-high groups (Appendix Fig S3A) but not in the contralateral striatum and cortex of these animals compared to R6/2 ACSF mice (Appendix Fig S3B and C). These results demonstrate the efficiency of osmotic mini-pumps in releasing exogenous cholesterol around the site of infusion and partially into the surrounding cortex in HD animals.

Compared to wt mice, R6/2 ACSF animals showed a progressive deterioration in fine motor coordination, as assessed by an accelerating rotarod test, from the early-symptomatic 
(8 weeks of age) to late-symptomatic stages (10 weeks of age) (Fig 1D). In contrast, R6/2 chol-high mice presented a partial but significant amelioration in rotarod performance at 10 weeks compared to R6/2 chol-medium and R6/2 chol-low groups (Fig 1D).

To further test motor abilities, we evaluated spontaneous locomotor activity in the activity cage test. R6/2 ACSF mice exhibited a severe hypokinetic phenotype with disease progression (Fig 1E). Of note, global activity deficits were normalized in R6/2 chol-high mice, while the low and medium dose of cholesterol did not produce any effect (Fig 1E). Other parameters, such as total distance traveled (Fig 1F), mean velocity (Fig 1G), and stereotyped movements (Fig 1H) significantly improved in R6/2 chol-high mice compared to R6/2 ACSF mice. By comparing among R6/2 groups treated with the three doses of cholesterol, we identified a dose-dependent effect, with a progressive increase in all activityrelated values from low to medium to high doses of cholesterol (Appendix Table S1).

An ANOVA multiple comparison test revealed a significant decrease in the number of vertical movements (rearings) in all R6/2 groups (Fig 1I). However, when we compared only the R6/2 ACSF and R6/2 chol-high groups, we found a significant increase in rearings in cholesterol-treated $\mathrm{R} 6 / 2$ animals ( $\mathrm{p}=0.0419$, unpaired t-test), suggesting a mild but significant effect of exogenous cholesterol on rearings.

As a measure of anxiety-like behavior, we also evaluated the time that mice spent exploring the periphery or center area of the arena during the activity cage test (Fig 1L). R6/2 animals spent more time in the periphery compared to wt mice, indicating anxiety-related behavior. R6/2 chol-high mice spent more time in the center compared to R6/2 ACSF mice, with high-chol HD animals performing similarly to the wt group (Fig 1M; Appendix Table S1), indicating a normalization of anxiety-related behavior. 
To assess if striatal infusion of cholesterol influences cognitive abilities, we used the novel object recognition test (NORT). Long-term memory declined during disease progression in R6/2 ACSF mice, with a marked impairment in the ability to discriminate novel and familiar objects at age 11 weeks (Fig 1N). R6/2 mice in all cholesterol-dose groups performed similarly to wt mice (Fig 1N). Finally, principal component analysis (PCA) of all values related to motor and cognitive tests for chol-high animals identified two distinguishable groups (wt and R6/2 ACSF) that separated in the first principal component, with the R6/2 chol-high mice displaying a greater overlap with wt group than R6/2 ACSF mice (Fig 1O).

Taken together, these results indicate an overall behavioral recovery in HD mice after striatal infusion of cholesterol.

Striatal infusion of cholesterol rescues excitatory synaptic defects in HD mice

Cholesterol is involved in synaptic function (31), and functionality and morphology of excitatory and inhibitory synapses are both altered in $\operatorname{HD}(32,33)$. For this reason, we adopted a combination of techniques to explore the effects of cholesterol on synaptic function and morphology. The analyses were performed in R6/2 chol-high mice and relevant controls.

We first compared whole-cell patch-clamp recordings of striatal MSNs from brain slices of wt, R6/2 ACSF, and R6/2 chol-high mice (Fig 2A). The membrane capacitance, which is proportional to cell size, was significantly lower in R6/2 ACSF compared to wt MSNs and unaffected in R6/2 chol-high mice (Appendix Table S2). Input resistance, reflecting the number of ion channels expressed by the cell, was significantly increased in 
both R6/2 ACSF and R6/2 chol-high compared to wt cells, but unaffected by cholesterol administration (Appendix Table S2).

To evaluate the effect of cholesterol on excitatory transmission, we recorded spontaneous excitatory postsynaptic currents (sEPSC) at a holding potential of -70 $\mathrm{mV}$ (Fig 2B). We did not find any significant differences in the average amplitude of sEPSCs between groups (Fig 2C). In agreement with previous studies (32), we found a significant reduction in frequency of sEPSCs in R6/2 MSNs compared to wt MSNs (Fig 2D). Of note, striatal infusion of cholesterol led to a significant increase in the frequency of sEPSCs in R6/2 cholhigh compared to R6/2 ACSF mice, partially rescuing this defect (Fig 2D).

To identify the structural bases underlying the functional recovery of excitatory synapses after striatal infusion of cholesterol, we undertook a series of morphological studies by electron microscopy. We employed the combination of focused ion beam milling and scanning electron microscopy (FIB/SEM) followed by the 3D reconstruction of complete synaptic junctions in large volumes of tissue (Fig 2E and F). The high spatial resolution of the FIB/SEM images and long series of serial sections allowed for classification of all synapses as asymmetric or symmetric using morphological criteria (34), providing the actual number of synapses per volume of the striatal region. Fig $2 \mathrm{~F}$ shows an example of the $3 \mathrm{D}$ reconstruction of excitatory synapses (in yellow) in a large portion of the tissue blocks used for the analysis $(10 \mu \mathrm{m} \times 5 \mu \mathrm{m} \times 10 \mu \mathrm{m})$ from wt, R6/2, R6/2 ACSF, and R6/2 chol-high mice. The density of excitatory synapses was reduced in the striatal neurons of R6/2 compared to wt mice, but cholesterol infusion did not rescue this defect (Fig 2G). We then tested whether cholesterol could influence synaptic parameters at the active site of excitatory synapses. Using transmission electron microscopy (TEM), we visualized the SVs to quantify their density (Fig 
2H). The number of total and docked SVs was reduced in R6/2 and R6/2 ACSF mice compared to wt mice (Fig 2I). These structural defects were rescued by striatal infusion of cholesterol in R6/2 chol-high mice (Fig 2L and M). Post-synaptic density area and length were not altered in R6/2 groups compared to wt mice (Appendix Fig S4).

Collectively, these findings demonstrate that cholesterol partially rescues excitatory synaptic transmission by enhancing the formation and/or release of SVs at the pre-synaptic site, but not by increasing the number of excitatory synapses.

\section{Striatal infusion of cholesterol rescues GABAergic inhibitory synaptic defects in HD mice}

To test the effect of exogenous cholesterol at the inhibitory synapses, we recorded spontaneous inhibitory synaptic currents (sIPSCs) in brain slices from wt, R6/2 ACSF, and R6/2 chol-high mice at a holding potential of $0 \mathrm{mV}$ (Fig 3A). The average amplitude of sIPSCs was similar between wt and R6/2 ACSF MSNs and was unaffected by cholesterol (Fig 3B). However, the average frequency of sIPSCs was significantly increased in R6/2 ACSF compared to wt cells (Fig 3C). Of note, striatal infusion of cholesterol led to a significant reduction in the average frequency of sIPSCs, bringing this parameter close to what we observed in wt MSNs (Fig 3C) and indicating that exogenous cholesterol contributes to restoring GABAergic inhibitory synaptic defects.

To identify the structural changes underlying the functional recovery of inhibitory synaptic transmission after striatal infusion of cholesterol, we first analyzed the number of inhibitory synapses per volume of striatal tissue, looking at the serial sections obtained by FIB/SEM. We identified symmetric junctions by the presence of a thin post-synaptic density and performed 3D reconstruction for all groups (Fig 3D). The density of inhibitory synapses 
was significantly increased in striatal neurons in both R6/2 and R6/2 ACSF mice compared to wt mice (Fig 3E), in agreement with the electrophysiological findings of increased frequency. Cholesterol striatal infusion reduced the density of inhibitory synapses, rescuing the morphological defect (Fig 3E). TEM analysis of inhibitory synapses showed no alterations in SV density in R6/2 and R6/2 chol-high mice compared to wt animals (Appendix Fig S5).

These findings indicate that striatal infusion of cholesterol acts differentially on excitatory and inhibitory synapses and rescues alterations in inhibitory synaptic transmission by reducing the number of inhibitory synapses.

\section{Striatal infusion of cholesterol does not rescue myelin defects in HD mice}

Cholesterol influences myelin membrane biogenesis and the functionality of mature myelin (35). To evaluate whether striatal infusion of cholesterol counteracts myelin deficits in HD mice, we examined myelin in the striatum and corpus callosum of wt, R6/2, R6/2 ACSF, and R6/2 chol-high mice at age 12 weeks. The G-ratio of myelinated axons, a measure of myelin sheath thickness as evaluated by electron microscopy, was increased in both the striatum and corpus callosum of all R6/2 groups compared to wt mice (Appendix Fig S6A-F), indicating thinner myelin sheaths in HD mice even after striatal infusion of cholesterol. Periodicity, a measure of myelin compaction calculated as the mean distance between two major dense lines, was similar in the striatum and in the corpus callosum among all groups (Appendix Fig S6G-I). These data suggest the presence of a thinner myelin sheath in the striatum and corpus callosum of R6/2 mice and that cholesterol treatment did not rescue this defect. 
The synthesis of new cholesterol and production of its neuronal-specific catabolite $24 \mathrm{~S}-\mathrm{OHC}$ are closely related (36). To maintain constant levels of cholesterol in the brain, any excess of cholesterol is catabolized into 24S-OHC that can cross the blood-brain barrier and enter the circulation $(24,26,37)$.

Fig 4A shows a schematic representation of the enzymes involved in cholesterol biosynthesis and catabolism and how they are affected in HD. In this study, we first measured 24S-OHC level by ID-MS and found reductions in the contralateral and ipsilateral striatum of R6/2 ACSF compared to wt mice (Fig 4B). 24S-OHC level was increased in the infused striatum of R6/2 chol-high mice compared to R6/2 ACSF mice, with higher levels compared to wt mice (Fig 4B). Student's t-test analysis revealed a significant increase in 24S-OHC level in the infused striatum of wt mice treated with the high dose of cholesterol compared to wt ACSF mice, suggesting a genotype-independent effect on 24S-OHC level (Appendix Fig S7A). The low dose of cholesterol did not affect striatal level of $24 \mathrm{~S}-\mathrm{OHC}$ in either wt or R6/2 mice (Appendix Fig s7A and B).

Exogenous cholesterol might operate in negative feedback on endogenous cholesterol biosynthesis, which is already compromised in HD mice. A robust deficit in levels of the key cholesterol precursors lanosterol and lathosterol was found in the striatum of R6/2 and R6/2 ACSF mice compared to wt animals (Fig 4C, 4E), further validating previous results $(20,21)$. Unexpectedly, we also found a significant increase in striatal levels of lanosterol, lathosterol, and desmosterol in R6/2 chol-high mice compared R6/2 or R6/2 ACSF animals (Fig 4C-E), indicating enhancement of endogenous cholesterol biosynthesis following striatal cholesterol infusion. This increase was specific for the infused striatum and was not observed in the contralateral striatum of the same mice (Fig 4C-E). Increased levels of all cholesterol 
precursors were also found in wt mice treated with the high dose of cholesterol compared to wt ACSF mice (Appendix Fig S7C, S7E, S7G), whereas we observed no changes in wt or R6/2 mice treated with the low dose of cholesterol (Appendix Fig S7C-H).

Translocation into the nucleus of the N-terminal (active) fragment of SREBP2 triggers expression of genes involved in cholesterol biosynthesis (38). We sought to assess whether nuclear translocation of SREBP2 mediates the increase in endogenous cholesterol biosynthesis after striatal cholesterol infusion. For this purpose, we performed immunofluorescence staining with a specific antibody that targets the N-terminal fragment of this protein (3), in brain slices of R6/2 chol-high mice. As shown in Fig 4F, we found a marked increase in nuclear distribution of SREBP2 in the infused striatum compared to the contralateral striatum of R6/2 chol-high mice, as confirmed by the relative quantification (Fig 4G). Specifically, by coupling the antibody against SREBP2 with a neuronal or an astrocytic marker (NeuN and GFAP, respectively), we found that the increased nuclear localization of SREBP2 was specific for glial cells (Fig 4H; Appendix Fig S8 and 9), the major producers of cholesterol in the adult brain.

Taken together, these findings highlight that the high dose of cholesterol enhances 24S-OHC availability. This availability in turn may promote endogenous cholesterol biosynthesis through increased activity of SREBP2 in glial cells.

\section{Striatal infusion of cholesterol induces clearance of muHTT aggregates in HD mice}

A hallmark of HD is the presence of intracellular aggregates of muHTT (39-42). To test whether striatal infusion of cholesterol influences muHTT aggregation, we employed different methods to visualize and quantify different forms of muHTT during the process of 
aggregation. We first performed immunofluorescence staining on brain sections of R6/2 ACSF and R6/2 chol-high mice by using the EM48 antibody, which is specific for the expanded polyQ tract prone to aggregate (Fig 5A). The number and size of EM48-positive aggregates (size aggregates $\approx 2 \mu \mathrm{m}$ ) was similar in the striatum of both hemispheres in R6/2 ACSF mice but significantly reduced in the infused striatum compared to the contralateral striatum in R6/2 chol-high mice (Fig 5B and C; Appendix Fig S10A and B). Evidence of reduced muHTT aggregates in cortical tissues of R6/2 mice, however, was variable among the animals (Appendix Fig S10C and D), likely depending on a heterogeneous diffusion of cholesterol into the cortex. We did not observe fewer aggregates in the hippocampus of the same animals (Appendix Fig S10E and F).

Double immunofluorescence staining with EM48 antibody in combination with an antibody against DARPP32 (MSN marker) or GFAP (astrocyte marker) allowed us to count the number of muHTT nuclear aggregates in the striatum of R6/2 chol-high mice in different cell types. In the infused compared to the contralateral striatum of R6/2 chol-high mice, the number of nuclear aggregates was reduced 6-fold in neurons (Fig 5D and E) and 2-fold in astrocytes (Fig 5F and G).

To investigate the morphology and localization of muHTT aggregates after striatal infusion of cholesterol, we employed electron microscopy using pre-embedded immunogold labeling for EM48 to visualize muHTT in striatal neurons of wt, R6/2, R6/2 ACSF, and R6/2 chol-high mice. Immunogold-labeled HTT fragments were found either as protofibril-like structures of about $300 \mathrm{~nm}$ or dispersed in the cytoplasm and nucleus of striatal neurons from R6/2 ACSF mice (Fig 5H). In contrast, muHTT was found dispersed and never composed in a fibril network in striatal neurons from R6/2 chol-high animals (Fig 5H). 
We next sought to apply a more reliable quantitative measure of aggregation and to detect the early phases of aggregation process $(43,44)$. For this purpose, we employed a timeresolved Förster resonance energy transfer (TR-FRET)-based immunoassay (43) to quantify aggregated muHTT oligomers and total/soluble muHTT (Fig 5I) in striatal tissues from R6/2 ACSF and R6/2 chol-high mice. First, we checked the feasibility of the assay in striatal samples of wt and R6/2 mice. As shown by the fluorescence ratios, the 4C9-4C9 combination was muHTT aggregate-specific, and the 2B7-MW1 combination recognized total muHTT, allowing for detection of aggregated or total muHTT, respectively, in R6/2 samples (Fig 5L and M). TR-FRET detection of aggregated muHTT (4C9-4C9 combination) did not differ between R6/2 chol-high and R6/2 ACSF mice (Fig 5N). When we used the TR-FRET assay to quantify total muHTT (2B7-MW1 combination), we found a significant decrease in total muHTT level in the striatum of R6/2 chol-high compared to R6/2 ACSF mice (Fig 5O). Collectively, these findings demonstrate that striatal infusion of cholesterol counteracts different forms of muHTT aggregates and might therefore contribute to reduced toxicity in HD mice.

\section{Striatal infusion of cholesterol reverses lysosomal accumulation in HD mice}

We next sought to test whether striatal infusion of cholesterol can stimulate clearance pathways involving autophagy or lysosomal activity. For this purpose, we performed immunofluorescence staining on brain sections of wt, R6/2 ACSF, and R6/2 chol-high mice with antibodies against p62, a protein involved in the recognition and delivery of substrates to autophagosomes, and against the lysosomal-associated membrane protein LAMP1. p62 (red signal) was present in round bodies in the perinuclear area of wt cells but was present 
primarily as cellular dots in the contralateral and infused striatum of R6/2 ACSF and R6/2 chol-high mice (Fig 6A). Quantification analysis revealed an increase in p62 dots in all R6/2 animal groups compared to wt mice (Fig 6B), suggesting a high basal autophagy in the presence of muHTT, which cholesterol treatment did not significantly influence.

In contrast, immunofluorescence staining for LAMP1 (Fig 6C; green signal) and relative quantification (Fig 6D) revealed increased LAMP1 density in the striatum of R6/2 ACSF mice and in the contralateral striatum of R6/2 chol-high compared to wt mice, suggesting an accumulation of lysosomes in HD cells. Of note, LAMP1 density was restored to physiological levels in the infused striatum of R6/2 chol-high mice (Fig 6C). Colocalization of LAMP1 and bodipy in the striatum of R6/2 mice (Fig 6E) suggests that cholesterol may act directly on lysosomes to enhance muHTT clearance.

Taken together, these results suggest that striatal infusion of cholesterol in HD mice could restore the degradative capacity of lysosomes and counteract muHTT aggregates by reducing lysosome accumulation in HD cells. 


\section{Discussion}

In this work, we identified the therapeutic dose of cholesterol that can prevent both motor and cognitive defects in HD mice and ameliorate synaptic transmission while reducing muHTT aggregate load in the brain. Moreover, we showed that all tested doses of infused cholesterol prevented cognitive decline. In particular, the lower dose of cholesterol used here $(15 \mu \mathrm{g})$ is similar to that employed in our previous work in which we delivered cholesterol via braintargeted polymeric nanoparticles (28). The success in preventing mouse cognitive decline in both studies using this cholesterol level is in line with reports highlighting a link between cholesterol and cognitive impairments in adult patients $(9,45)$. In contrast, only the highest dose of cholesterol we used here could also counteract progression of motor defects, suggesting that restoration of motor circuit function may require a higher cholesterol dose.

Cholesterol infusion can exert these beneficial effects by several mechanisms. One is improving the function of residual synaptic circuits. In fact, we showed here that striatal infusion of cholesterol restored both glutamatergic activation and GABAergic inhibition in MSNs of HD mice. Similarly, exogenous cholesterol increased the number of docked vesicles of glutamatergic synapses, accounting for the increasing probability of vesicle release demonstrated through partial renormalization of glutamatergic spontaneous synaptic current frequency. Furthermore, exogenous cholesterol reduced the number of GABAergic inhibitory synapses, as also demonstrated by a reduced frequency of spontaneous inhibitory currents. The magnitude of rescue was more evident for inhibitory transmission/synapses, suggesting circuit-specific signaling mechanisms in which cholesterol may act differently. Specific proteins involved in inhibitory transmission might bind cholesterol for their function, exerting a major effect on this circuit with respect to the excitatory one. The high dose of cholesterol 
tested here, however, was not sufficient to fully rescue excitatory transmission and additional pathways or molecules might be more critical in restoring it.

Exogenous cholesterol may also act by partnering specifically with cellular proteins and influencing cell physiology. A recent proteome-wide mapping of cholesterol-interacting proteins in mammalian cells detected more than 250 proteins that bind cholesterol. These proteins are involved in vesicular transport, degradation pathways, and membrane structure and dynamics, and many of them are linked to neurological disorders (46). Among them, several membrane receptors bind cholesterol in cholesterol-enriched lipid rafts at the plasma membrane, and their interaction determines their function (47-50). Once infused, exogenous cholesterol might renormalize the stoichiometry between plasma proteins and receptors at the neuronal plasma membrane and rescue the impaired intracellular and receptor signaling in HD.

Cholesterol supplementation in animal models of Pelizaeus-Merzbacher disease and of multiple sclerosis results in a permissive environment for myelin repair, preventing disease progression $(51,52)$. Changes in myelin also occur in different HD animal models $(53,54)$ and in patients showing pre-HD signs (55). In those studies, over-expression of muHTT in primary oligodendrocytes was accompanied by reduced expression of cholesterol biosynthesis genes and myelin-binding protein in vitro (54), and muHTT interfered with oligodendrocyte maturation in vivo (56). However, striatal infusion of cholesterol failed to promote myelin repair in the R6/2 HD mouse model used here. Although restoration of myelin defects in this rapid, aggressive HD model was not observed under our experimental conditions, cholesterol administration may normalize myelin phenotypes in less aggressive HD murine models such as the YAC128 and knock-in mice $(53,56)$. 
In this study, we also found that striatal infusion of the high dose of cholesterol restored the primary defect of brain cholesterol biosynthesis in HD mice. Cholesterol biosynthesis, as judged by cholesterol precursor levels $(20,21)$ or its synthesis rate $(22)$, is significantly reduced in the striatum of HD mice before disease onset, as we confirm here. The significant increase in levels of cholesterol precursors, along with increased nuclear translocation of SREBP2 mainly in astrocytes, is consonant with an enhanced endogenous cholesterol biosynthesis in the striatum of R6/2 chol-high mice. This outcome is specific for the infused striatum and the highest dose of cholesterol, possibly indicating that excess exogenous cholesterol is converted into $24 \mathrm{~S}-\mathrm{OHC}$ in neurons that in turn stimulate endogenous synthesis in astrocytes $(57,58)$. Accordingly, the level of $24 \mathrm{~S}-\mathrm{OHC}$ was also increased in the infused striatum of R6/2 chol-high mice in this work, supporting evidence that synthesis and catabolism are closely related in the disease state, as well, as previously reported (22). This connection is in agreement with two recent studies showing that adenoassociated virus over-expressing Cyp46A1, the neuronal-specific enzyme for cholesterol conversion to $24 \mathrm{~S}-\mathrm{OHC}$, increased lanosterol and desmosterol levels in the striatum of R6/2 mice and zQ175 mice $(23,27)$.

The increase in cholesterol precursors may also explain the reduction that we observed in muHTT aggregates in R6/2 mice. Lanosterol reverses protein aggregation in cataracts (59), suppresses the aggregation and cytotoxicity of misfolded proteins linked to neurodegenerative diseases (60), and promotes autophagy in Parkinson's disease models (61). In our study, clearance of muHTT in R6/2 chol-high mice may have been secondary to stimulation of mTORC1 activity (17), leading to increased autophagy (62). Several studies have established links between mTORC1 activation and cholesterol metabolism. For 
example, the expression of the active form of the mTORC1 regulator, Rheb, in the HD mouse brain ameliorates aberrant cholesterol homeostasis and increases autophagy (17). In addition, mTORC1 activation increases nuclear translocation of SREBP2 and sterol synthesis $(63,64)$. Moreover, an increase in lysosomal cholesterol has been reported to activate mTORC1 (65), and cholesterol is reduced in HD lysosomes (66). Of note, we showed here that exogenous cholesterol localizes in lysosomes and reduces lysosome accumulation, leading to muHTT clearance. How exactly the increased nuclear translocation of SREBP2 and decreased muHTT aggregates observed here are linked to mTORC1 activity and lysosomes is currently unknown. Further mechanistic studies are needed to test this hypothesis.

The fact that, using the TR-FRET assay, we found no significant reduction in aggregated muHTT suggests that cholesterol is not sufficient to degrade soluble muHTT oligomers. However, using the same assay with a different Ab combination, we identified a significant decrease in total muHTT protein levels in R6/2 chol-high mice. Coupled with the significant reduction in aggregate number and size (assessed by immunofluorescence) and absence of amyloid-like fibers (by EM) in R6/2 chol-high mice, this result supports the hypothesis that cholesterol influences muHTT aggregation in vivo and that its targeted administration to the brain might be useful for reducing muHTT toxicity in HD.

In conclusion, we demonstrate a dose-dependent, disease-modifying effect of striatal infusion of cholesterol in HD mice. This work and our previous findings (28) support the hypothesis that reduced cholesterol biosynthesis contributes to disease pathogenesis and that cholesterol delivery to the HD brain is beneficial. A second generation of brain-permeable nanoparticles has been recently developed (67) that allows delivery of higher cholesterol 
bioRxiv preprint doi: https://doi.org/10.1101/2020.05.13.092742; this version posted May 15, 2020. The copyright holder for this preprint (which

was not certified by peer review) is the author/funder, who has granted bioRxiv a license to display the preprint in perpetuity. It is made available under aCC-BY-NC-ND 4.0 International license.

content to the brain. This advance may promote progress toward the goal of achieving the therapeutic dose identified here by means of systemic injection. 


\section{Materials and Methods}

\section{Colony management}

All the in vivo experiments were carried out in accordance with Italian Governing Law (D.lgs 26/2014; Authorization n.324/2015-PR issued May 6, 2015 by Ministry of Health); the NIH Guide for the Care and Use of Laboratory Animals (2011 edition) and EU directives and guidelines (EEC Council Directive 2010/63/UE).

Our R6/2 colony lifespan was approximately of 13 weeks and it was maintained through the male line exclusively (29). Mice were weaned and then genotyped at 3 weeks of age (+/- 3 days). Transgenic R6/2 males were paired with non-carrier females (B6CBAF1/J, purchased from Charles River). CAG repeat length and changes that could affect strain productivity, general behavior, litter size, pup survival, genotype frequency, phenotype were constantly monitored with a range between 200-250 CAGs. Mice were housed under standard conditions $\left(22 \pm 1{ }^{\circ} \mathrm{C}, 60 \%\right.$ relative humidity, 12 hours light/dark schedule, 3-4 mice/cage, with free access to food and water). After PCR genotyping (29), male and female mice were included and randomly divided into experimental groups. Littermates were included as controls.

\section{Surgical implantation of osmotic mini-pumps}

Avertin 100\% was prepared diluting $5 \mathrm{~g}$ of 2,2,2-Tribromoethanol (Sigma Aldrich, \#T48402$25 \mathrm{G}$ ) in $5 \mathrm{~mL}$ of 2-methyl-2-butanol (Sigma Aldrich, \#240486). Mice were deeply anesthetized using $15 \mu \mathrm{L}$ of Avertin 2.5\% per gram of body weight. Once responses to tail/toe pinches and intactness of the ocular reflex were assessed, scalp was shaved and mice were placed into a stereotaxic apparatus (2-Biological Instrument). A subcutaneous pocket was made on the back of the animals, in the midscapular area, to insert the osmotic mini- 
pump (Alzet, pump model 1004, \#0009922). The brain infusion microcannula (brain infusion kit ${ }^{\circ} 3$, Alzet, $\# 0008851$ ), connected to the mini-pump through a catheter, was stereotaxically implanted into mice right striatum (stereotaxic coordinates $1.75 \mathrm{~mm}$ mediolateral, $0.5 \mathrm{~mm}$ anteroposterior, $3 \mathrm{~mm}$ dorsoventral; from Paxinos $\mathrm{G}$ and Watson $\mathrm{C}$. The Rat Brain in Stereotaxic Coordinates. Academic Press, San Diego).

Following surgery, mice were removed from the stereotaxic apparatus and placed on a warm cover to awaken from anesthesia. The mini-pump infused at constant rate $(0.11 \mu \mathrm{L} / \mathrm{h})$ for 28 days a solution of artificial cerebrospinal fluid (ACSF); or methyl- $\beta$-cyclodextrin (Sigma Aldrich, \#M7439-1G) diluted in ACSF; or water-soluble methyl- $\beta$-cyclodextrin (M $\beta C D)$ balanced cholesterol (Sigma Aldrich, \#C4951-30MG) supplemented with $5 \mu \mathrm{M}$ free cholesterol, diluted in ACSF. ACSF was prepared mixing two solutions (A and B) in a 1:1 ratio. Solution A was prepared by diluting 8,66 g of $\mathrm{NaCl}$ (Sigma Aldrich, \#53014), 0,224 $\mathrm{g}$ of KCl (Sigma Aldrich, \#P9333), 0,206g of CaCl2 2H2O (Sigma Aldrich, \#C3881) and 0,163 $\mathrm{g}$ of $\mathrm{MgCl} 2 \mathrm{H} 2 \mathrm{O}$ (Sigma Aldrich, \#M9272) in $500 \mathrm{~mL}$ of sigma water. Solution B was prepared by diluting 0,214 g of Na2HPO4 7H2O (Sigma Aldrich, \#59390) and 0,027 g of NaH2PO4 H2O (Sigma Aldrich, \#59638) in $500 \mathrm{~mL}$ of sigma water.

Assessment of post-operative pain and distress was performed using a specific table for pain scoring based on behavioral indicators of well-being and monitoring mice body weight (68).

\section{Behavioral tests}

Mice behavior was evaluated from pre-symptomatic stages (5-6 weeks of age) until latesymptomatic stages of the disease (10-11 weeks of age). Animals were assigned randomly 
and sex was balanced in the various experimental groups. All the behavioral analyses were performed in blind.

Rotarod: motor coordination and balance were evaluated on the Rotarod test. Mice were first trained to walk on a rotating bar at constant speed of $4 \mathrm{rpm}$ (apparatus model 47600, Ugo Basile), for $300 \mathrm{sec} .1$ hour after this training phase, mice motor performance was evaluated in an accelerating task (from 4 to $40 \mathrm{rpm}$ ) over a 300 sec-period. For three consecutive days, mice performed three daily trials, with an inter-trial interval of $30 \mathrm{~min}$. Latency to fall was recorded for each trial and averaged.

Activity Cage: spontaneous locomotor activity was evaluated by the activity cage test, in presence of a low-intensity white light source. The animal was placed in the center of the testing, transparent, arena $(25 \mathrm{~cm} \times 25 \mathrm{~cm})(2$ Biological Instrument) and allowed to freely move for an hour. Following 15 minutes of habituation, both horizontal and vertical motor activities were assessed by an automated tracking system (Actitrack software, 2Biological Instrument) connected to infrared sensors surrounding the arena. Total distance travelled, mean velocity speed, stereotyped movements and numbers of rearings were evaluated. The \% of time that mice explored the periphery or the center area of the was evaluated as a measure of anxiety-like behavior.

Novel Object Recognition (NOR) test: long-term memory was evaluated by the NOR test, using a grey-colored, non-reflective arena $(44 \times 44 \times 44 \mathrm{~cm})$. All phases of the test were conducted with a low-intensity white light source. In a first habituation phase, mice were placed into the empty arena for $10 \mathrm{~min}$. The habituation phase was followed by the familiarization one, in which two identical objects $\left(\mathrm{A}^{\prime}\right.$ and $\left.\mathrm{A}^{\prime \prime}\right)$ were presented to each animal for $10 \mathrm{~min}$. Twenty-four hours later, during the testing phase, the same animals were exposed 
to one familiar object $\left(\mathrm{A}^{\prime \prime}\right)$ and a new object $(\mathrm{B})$ for $10 \mathrm{~min}$. A measure of the spontaneous recognition memory was represented by the index of discrimination, calculated as (time exploring the novel object-time exploring the familiar object)/(time exploring both objects $) \times 100$. Mice exploring less than $7 \mathrm{sec}$. were excluded from the analysis due to their inability to perform the task.

\section{PCA Analysis}

Principal component analysis (PCA) was performed using the R package ade4 (69).

Gas chromatography-mass spectrometry (GC-MS) analysis for neutral sterols and $24 S$ hydroxycholesterol

To a screw-capped vial sealed with a Teflon-lined septum were added $50 \mu \mathrm{L}$ of homogenates together with $1000 \mathrm{ng}$ of D4-lathosterol (CDN Isotopes, Canada), $100 \mathrm{ng}$ of D6-lanosterol (Avantipolar Lipids, USA), 400 ng of D7-24S-hydroxycholesterol (Avantipolar Lipids, USA), and $50 \mu \mathrm{g}$ of D6-cholesterol (CDN Isotopes,Canada) as internal standards, $50 \mu \mathrm{L}$ of butylated hydroxytoluene (BHT) $(5 \mathrm{~g} / \mathrm{L})$ and $25 \mu \mathrm{L}$ of EDTA $(10 \mathrm{~g} / \mathrm{L})$. Argon was flushed through to remove air. Alkaline hydrolysis was allowed to proceed at room temperature $\left(22^{\circ} \mathrm{C}\right)$ for $1 \mathrm{~h}$ in the presence of $1 \mathrm{M}$ ethanolic potassium hydroxide solution under magnetic stirring. After hydrolysis, the neutral sterols (cholesterol, lathosterol, and lanosterol) and oxysterols $(24 \mathrm{~S}-\mathrm{OHC})$ were extracted three times with $5 \mathrm{ml}$ of hexane. The organic solvents were evaporated under a gentle stream of argon and converted into trimethylsilyl ethers with BSTFA-1\% TMCS (Cerilliant, USA) at $70{ }^{\circ} \mathrm{C}$ for $60 \mathrm{~min}$. Analysis was performed by gas chromatography - mass spectrometry (GC-MS) on a Clarus 600 gas chromatograph (Perkin 
Elmer, USA) equipped with Elite-5MS capillary column $(30 \mathrm{~m}, 0.32 \mathrm{~mm}, 0.25 \mu \mathrm{m}$. Perkin

Elmer, USA) connected to Clarus 600C mass spectrometer (Perkin Elmer, USA). The oven temperature program was as follows: initial temperature $180^{\circ} \mathrm{C}$ was held for $1 \mathrm{~min}$, followed by a linear ramp of $20{ }^{\circ} \mathrm{C} / \mathrm{min}$ to $270{ }^{\circ} \mathrm{C}$, and then a linear ramp of $5{ }^{\circ} \mathrm{C} / \mathrm{min}$ to $290{ }^{\circ} \mathrm{C}$, which was held for $10 \mathrm{~min}$. Helium was used as carrier gas at a flow rate of $1 \mathrm{~mL} / \mathrm{min}$ and $1 \mu \mathrm{L}$ of sample was injected in splitless mode. Mass spectrometric data were acquired in selected ion monitoring mode. Peak integration was performed manually and sterols were quantified against internal standards, using standard curves for the listed sterols (70).

\section{Electrophysiological analysis}

Experiments were performed on submerged brain slices obtained from adult mice (12 weeks of age) after 4 weeks-long infusion of ACSF or cholesterol directly into the striatum. Animals were anesthetized by inhalation of isoflurane and decapitated. The head was rapidly submerged in ice-cold $\left(\sim 4^{\circ} \mathrm{C}\right)$ and oxygenated $\left(95 \% \mathrm{O}_{2}-5 \% \mathrm{CO}_{2}\right)$ cutting solution containing: Sucrose 70 mM, NaCl 80 mM, KCl 2.5 mM, NaHCO 326 mM, Glucose 15 mM, $\mathrm{MgCl}_{2} 7 \mathrm{mM}, \mathrm{CaCl}_{2} 1 \mathrm{mM}$ and $\mathrm{NaH}_{2} \mathrm{PO}_{4} 1.25 \mathrm{mM}$. Striatal coronal slices (300- $\mu \mathrm{m}$-thick) were cut using a vibratome (DTK-1000, Dosaka EM, Kyoto, Japan) and allowed to equilibrate for at least 1 hour in a chamber filled with oxygenated ACSF containing: $\mathrm{NaCl}$ $125 \mathrm{mM}, \mathrm{KCl} 2.5 \mathrm{mM}, \mathrm{NaHCO}_{3} 26 \mathrm{mM}$, Glucose $15 \mathrm{mM}, \mathrm{MgCl}_{2} 1.3 \mathrm{mM}, \mathrm{CaCl}_{2} 2.3 \mathrm{mM}$ and $\mathrm{NaH}_{2} \mathrm{PO}_{4} 1.25 \mathrm{mM}$. The slices collected from the hemisphere ipsilateral to the infusion site were transferred to a submerged-style recording chamber at room temperature $(\sim 23$ $25^{\circ} \mathrm{C}$ ) and were continuously perfused at $1.4 \mathrm{ml} / \mathrm{min}$ with ACSF. The chamber was mounted 
on an E600FN microscope (Nikon) equipped with $4 \mathrm{X}$ and 40X water-immersion objectives (Nikon) and connected to a near-infrared CCD camera for cells visualization.

Data were obtained from striatal projection medium spiny neurons (MSNs) using the wholecell patch-clamp technique in both voltage- and current-clamp mode. The patch pipette was produced from borosilicate glass capillary tubes (Hilgenberg $\mathrm{GmbH}$ ) using a horizontal puller (P-97, Sutter instruments) and filled with an intracellular solution containing: Csmethanesulphonate $120 \mathrm{mM}, \mathrm{KCl} 5 \mathrm{mM}, \mathrm{CaCl}_{2} 1 \mathrm{mM}, \mathrm{MgCl}_{2} 2 \mathrm{mM}$, EGTA $10 \mathrm{mM}$, Na 2 ATP 4 mM, Na ${ }_{3}$ GTP $0.3 \mathrm{mM}$, Hepes $8 \mathrm{mM}$ and lidocaine N-ethylbromide $5 \mathrm{mM}$ (added to inhibit firing by blocking intracellularly the voltage-sensitive $\mathrm{Na}^{+}$channels) (pH adjusted to 7.3 with $\mathrm{KOH}$ ). Spontaneous excitatory postsynaptic currents (sEPSCs), mediated by the activation of ionotropic glutamate receptors, were recorded from MSNs at a holding potential of $-70 \mathrm{mV}$, whereas spontaneous inhibitory postsynaptic currents (sIPSCs), elicited by the activation of $\mathrm{GABA}_{\mathrm{A}}$ receptors, were assessed at a holding potential of $0 \mathrm{mV}$. The signals were amplified with a MultiClamp 700B amplifier (Molecular Devices) and digitized with a Digidata 1322 computer interface (Digitata, Axon Instruments Molecular Devices, Sunnyvale, CA). Data were acquired using the software Clampex 9.2 (Molecular Devices, Palo Alto, CA, U.S.A.), sampled at $20 \mathrm{kHz}$ and filtered at $2 \mathrm{kHz}$.

The off-line detection of spontaneous postsynaptic currents (sPSCs) were performed manually using a custom-made software in Labview (National Instruments, Austin, TX, U.S.A.). The amplitudes of sPSCs obeyed a lognormal distribution. Accordingly, the mean amplitude was computed as the peak of the lognormal function used to fit the distribution. Intervals (measured as time between two consecutive sPSCs) for spontaneous events were distributed exponentially and the mean interval was computed as the tau $\left(\tau_{\text {interval }}\right)$ value of the 
mono-exponential function that best fitted this distribution. The reciprocal of $\tau(1 / \tau)$ is the mean of the instantaneous frequencies of sPSCs. Furthermore, the analysis of the membrane capacitance $\left(\mathrm{C}_{\mathrm{m}}\right)$ and the input resistance $\left(\mathrm{R}_{\text {in }}\right)$ was performed using Clampfit 10.2 (Molecular Devices, Palo Alto, CA, U.S.A.). $\mathrm{C}_{\mathrm{m}}$ was estimated from the capacitive current evoked by a $10 \mathrm{mV}$ pulse, whereas $\mathrm{R}_{\text {in }}$ was calculated from the linear portion of the I-V relationship obtained by measuring steady-state voltage responses to hyperpolarizing and depolarizing current steps.

\section{Immunohistochemistry analysis}

Mice were anesthetized by intraperitoneal injection of Avertin $2.5 \%$ and transcardially perfused with PFA 4\%. Brains were post-fixed overnight in the same solution at $4{ }^{\circ} \mathrm{C}$ and then in $30 \%$ sucrose to prevent ice crystal damage during freezing in OCT.

Immunohistochemistry was performed on $15 \mu \mathrm{m}$ coronal sections. Epitopes were demasked at $98^{\circ} \mathrm{C}$ with $\mathrm{NaCitrate} 10 \mathrm{mM}$ and then slices were incubated with the following primary antibodies for 3h at RT: rabbit anti-SREBP2 (1:2000; gift by T. Osborne) (3), anti-DARPP32 (1:100; Cell Signalling, 2306), mouse anti-NeuN (1:100; Millipore, MAB377); rabbit antiGFAP (1:250; Dako, Z0334), rabbit anti-Huntingtin clone EM48 (1:100; Millipore, MAB5374), rabbit anti-p62 (1:100; Abcam, AB109012) or rat anti-LAMP1 (1:50; Santa Cruz, SC19992). Anti-rabbit Alexa Fluor 568-conjugated goat secondary antibodies (1:500;

Invitrogen), anti-rabbit Alexa Fluor 633-conjugated goat secondary antibodies (1:500; Invitrogen) or anti-mouse Alexa Fluor 488-conjugated goat secondary antibodies (1:500; Invitrogen) were used for detection (1h at RT). Sections were counterstained with the nuclear 
dye Hoechst 33258 (1:10.000, Invitrogen) and then mounted under cover slips using Vectashield (Vector Laboratories).

\section{Image acquisition and quantification}

Confocal images were acquired with a LEICA SP5 laser scanning confocal microscope. Laser intensity and detector gain were maintained constant for all images and 3 to 10 -z steps images were acquired.

To count aggregates in the different brain areas 34 images/mice taken from three R6/2-ACSF and three R6/2-chol mice were made at $40 \times$. For the striatum 18 images/animal were analyzed from 9 sections throughout the entire striatum. For the cortex, 10 images for each animal were analyzed from 3 sections and for the hippocampus, 6 images for each animal/condition were analyzed from 3 sections. To quantify the number of aggregates, ImageJ software was used to measure the fluorescence. Images were divided into three-color channels and the same global threshold was set. In both R6/2-ACSF and R6/2-chol mice, the total number of aggregates in the infused hemisphere was normalized to the total number of aggregates in the contralateral hemisphere. To count the number of aggregates in the nucleus of DARPP32 or GFAP positive cells, the NIS software was used.

To quantify the amount of SREBP2 inside the nucleus, images were acquired at $40 \mathrm{X}$ and were segmented using the NIS software. A threshold was applied to both channels and the intensity ratio of SREBP2/Hoechst was measured.

To count the dots of p62 and LAMP1 in the different brain areas 20 images/mice taken from three R6/2-ACSF and three R6/2-chol mice were made at 40×. For the striatum 10 images/animal were analyzed from 3 sections in the middle of the striatum. For the cortex, 10 
images for each animal were analyzed from 3 sections. To quantify the number of dots, ImageJ software was used to measure the fluorescence. Images were divided into three-color channels and the same global threshold was set. In both R6/2-ACSF and R6/2-chol mice, the total number of dots in the infused hemisphere was normalized to the total number of dots in the contralateral hemisphere.

\section{Electron microscopy}

Sample preparation: mice were anesthetized by intraperitoneal injection of $10 \mathrm{mg} / \mathrm{ml}$ Avertin (Sigma) and transcardially perfused using a fixative solution of: $2.5 \%$ glutaraldehyde (\#16220 Electron Microscopy Sciences (EMS), Hartfield, PA), and 2\% paraformaldehyde (P16148 EMS) in sodium cacodylate buffer 0.15 M (pH 7.4) (\#12300 EMS). Brains were removed and post-fixed for additional 24 hours at $4^{\circ} \mathrm{C}$. Brains were cut in $100 \mu \mathrm{m}$-thick coronal slices by using a Leica VT1000S vibratome. Sections were collected in sodium cacodylate buffer 0.1 $\mathrm{M}$ and striatum and corpus callosum were manually dissected for staining and embedding. Samples were then washed with cold sodium cacodylate buffer $0.1 \mathrm{M}$ and then postfixed in a reduced osmium solution (i.e., 1.5\% potassium ferrocyanide (\#20150 EMS) with 2\% osmium tetroxide (\#19170 EMS) in 0.15 M cacodylate buffer, for 1 hour in ice. After the first heavy metal incubation, the tissues were washed with $\mathrm{ddH}_{2} \mathrm{O}$ at room temperature and then placed in the $0.22 \mu \mathrm{m}$-Millipore-filtered $1 \%$ thiocarbohydrazide (TCH) (\#21900 EMS) in $\mathrm{ddH}_{2} \mathrm{O}$ solution for 20 minutes, at room temperature. Tissues were then rinsed again in $\mathrm{ddH}_{2} \mathrm{O}$ and incubated in $2 \%$ osmium tetroxide in $\mathrm{ddH}_{2} \mathrm{O}$ for 30 minutes, at room temperature. After several washings at room temperature in $\mathrm{ddH}_{2} \mathrm{O}$, they were then placed in $1 \%$ uranyl acetate (aqueous), overnight at $4^{\circ} \mathrm{C}$. Samples were washed, and then incubated en-bloc in Walton's 
lead aspartate solution (0.066 gr lead nitrate (\#17900 EMS) dissolved in $10 \mathrm{ml}$ of $0.003 \mathrm{M}$ aspartic acid solution, $\mathrm{pH} 5.5)$ at $60^{\circ} \mathrm{C}$ for 30 minutes. The tissues were still washed, and then dehydrated with an ethanol series and finally placed in anhydrous ice-cold acetone for 10 minutes. Infiltration was performed with acetone (\#179124 Sigma-Aldrich) - Durcupan ACM ${ }^{\circledR}(\# 14040$ EMS) mixture with 3:1 volume ratio for 2 hours, then 1:1 overnight. The tissues were left for 2 hours in pure resin and then embedded in Durcupan $A C M \circledast$ resin, and placed in a $60^{\circ} \mathrm{C}$ oven for 48 hours for polymerization.

TEM imaging. Ultrathin sections $70 \mathrm{~nm}$-thick were prepared by an UltraCut E ultramicrotome (Reichert) and collected on TEM copper grids, which were then observed by a LEO 912AB microscope (Carl Zeiss), equipped with a thermionic W electron source and operating at an acceleration voltage of $100 \mathrm{kV}$. For quantitative analyses, images with a resolution of 1024x1024 pixels, were acquired using a bottom mount Esivision CCD-BM/1K system (ProScan Camera). Quantitative measurements were performed by ImageJ $1.47 \mathrm{v}$, and measuring the following parameters: SVs number per area unit $\left(\mu \mathrm{m}^{2}\right)$, number of docked vesicles per active zone (AZ) length $(\mu \mathrm{m})$ and PSD area $\left(\mathrm{nm}^{2}\right)$ and PSD length $(\mathrm{nm})$. For myelin analyses we measured the G-ratio, as the diameter of the axon / outer diameter of the myelinated fiber (of at least 300 myelinated axons in 3 mice group) and the myelin periodicity that was measured as the mean distance between two major dense lines, in at least 45 randomly chosen myelin sheaths in 3 mice group.

FIB-SEM imaging and ion cutting. The following procedure was used to mount specimens with the aim to minimize theirs electrical charging during the FIB-SEM imaging and ion cutting. Resin blocs were mounted on aluminium specimen pins and trimmed with a glass knife using an ultramicrotome, to expose the tissue on all four sides. Silver paint (\#16031 
TedPella, Redding, US) was used to electrically ground the edges of the tissue block to the aluminium pin. The entire specimen was then coated with a thin layer of gold by means of a Cressington 208-HR sputter coater (Cressington Scientific Instruments, Watford, UK) equipped with a pure gold target (TedPella, Redding, US), to finely mount it into the SEM chamber in view of the FIB-SEM imaging. The samples 3D ultrastructural imaging was performed by using a ThermoScientific Helios G4 Dual Beam (Eindhoven, NL) being this instrument constituted by the combination of a high-resolution SEM equipped with a Schottky field emission gun and a focused gallium ion beam. First, the region of interest was chosen on the surface of the tissue block, then a protective layer of platinum was deposited on top of the area to be imaged using a gallium ion beam with $30 \mathrm{kV}$ of acceleration voltage. Initially, a rough cross-section was milled by a $9.1 \mathrm{nA}$ ion beam current, and used as window for SEM imaging. The exposed surface of this cross-section was finely polished by progressively lowering the ion beam current down to $0.44 \mathrm{nA}$ and keeping the acceleration voltage at $30 \mathrm{kV}$. Afterward, layers from the finely polished cross-section were successively milled by the gallium ion beam, again using a current of $0.44 \mathrm{nA}$ and an acceleration voltage of $30 \mathrm{kV}$. To remove each layer, the ion beam was continuously moved closer to the surface of the cross-section by increments of $25 \mathrm{~nm}$. After each slice ion cutting, the milling process was automatically paused, and the newly exposed surface was imaged with a $2 \mathrm{kV}$ acceleration voltage and $0.2 \mathrm{nA}$ electron beam current using the through-the-lens backscattered electron detector (TLD-BSE). The slicing and imaging processes were continuously repeated, and a long series of images were acquired in a automated procedure. SEM images of $2048 \times 1768$ pixels were acquired with voxel size of $(3 \times 3 \times 25)$ and $(4 \times 4 \times 25)$ $\mathrm{nm}$, depending on the SEM magnification chosen. 
$3 D$ reconstruction, rendering and analysis. Serial SEM images were assembled into volume files aligned using the FiJi software (71) plugin called linear stack alignment with SIFT (72). Following the images acquisition, recording and alignment, the 3D shape of samples peculiar features (in our case excitatory and inhibitory synapses) was reconstructed layer by layer by careful segmentation. For performing the latter, and the 3D model generation, electron microscopy image stacks were then converted to 8-bit greyscale tiff format images and manually segmented using AMIRA software package (ThermoScientific, Eindhoven, NL). Three-dimensional structures in image stacks containing hundreds or thousands of 2D orthoslices were traced individually in each plane and automatically surface rendered. The excitatory and inhibitory synapse density ( ${ }^{\circ}$ of synapse/ $\left.\mu \mathrm{m} 3\right)$ was finally measured by using Ilastik-0.5.12 software.

Sample preparation for pre-embedding immunogold labeling. Mice were anesthetized by intraperitoneal injection of $10 \mathrm{mg} / \mathrm{ml}$ Avertin (Sigma) and transcardially perfused using $\mathrm{pH}$ shift formaldehyde (73): 4\% paraformaldehyde (P16148 EMS) 0.1 M sodium acetate buffer, $\mathrm{pH}$ 6.0, followed by the same fixatives in $0.1 \mathrm{M}$ sodium carbonate buffer, $\mathrm{pH} 10.5$. Brains were removed and post-fixed for additional 24 hours at $4{ }^{\circ} \mathrm{C}$ and $100 \mu \mathrm{m}$-thick coronal slices were cut by using a Leica VT1000S vibratome. Sections were collected in $0.1 \mathrm{M}$ sodium carbonate buffer, $\mathrm{pH} 10.5$ and striatum was manually dissected. Striatal sections were incubated with mouse monoclonal antibodies (EM48) 1:50 (MAB5374-Millipore) that reacts with human huntingtin protein (both native and recombinant protein) in PBS containing 1\% NGS 48 hours at $4^{\circ} \mathrm{C}$. After rinsing in PBS, samples were incubated with goat anti-mouse secondary antibodies (1:50) conjugated to $10 \mathrm{~nm}$ gold particles (Jakson ImmunoResearch) in PBS with $2 \%$ NGS overnight at $4^{\circ} \mathrm{C}$. After rinsing in PBS, sections were osmicated in $1 \%$ 
OsO4 in dd $22 \mathrm{O}$, and stained overnight in $2 \%$ aqueous uranyl acetate. All sections used for electron microscopy (EM) were dehydrated in ascending concentrations of ethanol and Acetone/Eponate 12 (1:1) and embedded in Eponate 12 (\#14120 EMS). Ultrathin sections (70 $\mathrm{nm}$ ) were cut using an UltraCut E ultramicrotome (Reichert) and placed on TEM copper grids. Thin sections were counterstained with $1 \%$ aqueous uranyl acetate for 5 min followed by $1 \%$ lead citrate in $\mathrm{ddH} 2 \mathrm{O}$ for 2 min and examined using a LEO 912AB microscope (Carl Zeiss), equipped with a thermionic $\mathrm{W}$ electron source and operating at an acceleration voltage of $100 \mathrm{kV}$. Images were acquired at a resolution of $1024 \times 1024$ pixels using a bottom mount Esivision CCD-BM/1K system (ProScan Camera).

Sample preparation for post-embedding immunogold labeling. Mice were anesthetized by intraperitoneal injection of $10 \mathrm{mg} / \mathrm{ml}$ Avertin (Sigma) and transcardially perfused using $\mathrm{pH}$ shift formaldehyde (73): 4\% paraformaldehyde (P16148 EMS) 0.1 M sodium acetate buffer, $\mathrm{pH}$ 6.0, followed by the same fixatives in $0.1 \mathrm{M}$ sodium carbonate buffer, $\mathrm{pH} 10.5$. Brains were removed and post-fixed for additional 24 hours at $4{ }^{\circ} \mathrm{C}$ and $100 \mu \mathrm{m}$-thick coronal slices were cut by using a Leica VT1000S vibratome. Sections were collected in $0.1 \mathrm{M}$ sodium carbonate buffer, $\mathrm{pH} 10.5$ and striatum was manually dissected and post-fixed with 1\% OsO4 in ddH2O, and stained with $0.5 \%$ uranyl acetate. Samples were dehydrated in ascending concentrations of ethanol and Acetone/Eponate 12 (1:1) and embedded in Eponate 12 (\#14120 EMS). Striatal sections were cut in a UltraCut E ultramicrotome (Reichert). Formvar carbon-coated nickel grids with $70 \mathrm{~nm}$ ultrathin sections were processed for GABA immunolabeling. After 5 min incubation in TBST pH 7.6, grids were incubated with rabbit antiserum against GABA (Sigma A2052, 1:500 in TBST) overnight at RT in a moist chamber. After the incubation, grids were washed 3 x 10 min TBST pH 7.6, followed by 
TBST pH 8.2 for $5 \mathrm{~min}$. Grids were incubated for $2 \mathrm{~h}$ in goat anti-rabbit IgG conjugated to 12 nm colloidal gold (Jakson ImmunoResearch) diluted 1:20 in TBST pH 8.2. They were then washed twice in TBST pH 7.6, rinsed in deionized water. After that, the grids were contraststained with $1 \%$ aqueous uranyl acetate for 5 min followed by $1 \%$ lead citrate in ddH2O for 2 min. Sections were examined using a LEO 912AB microscope (Carl Zeiss), equipped with a thermionic $\mathrm{W}$ electron source and operating at an acceleration voltage of $100 \mathrm{kV}$. Images were acquired at a resolution of $1024 \times 1024$ pixels using a bottom mount Esivision CCDBM/1K system (ProScan Camera).

\section{FRET analysis}

TR-FRET assays were performed as described previously (74). Briefly, $15 \mu 1$ of each homogenate was transferred to a low volume 384 well plate (Greiner) in serial dilutions starting from a defined concentration $(4 \mu \mathrm{g} / \mu \mathrm{l}), 3 \mu \mathrm{l}$ of antibody cocktail was then added. HTT aggregates were measured with 4C9-Tb/4C9-Alexa647, using $1.93 \mathrm{ng} / \mu \mathrm{l}$ of $4 \mathrm{C} 9-\mathrm{Tb}$ and 2 ng/ $\mu 1$ of 4C9-Alexa647 labelled antibodies. Total HTT level was measured with 2B7Tb/MW1-D2, using $1 \mathrm{ng} / \mu \mathrm{l}$ of 2B7-Tb and $10 \mathrm{ng} / \mu 1$ of MW1-D2 labelled antibody. TRFRET measurements were routinely performed following overnight incubation at $4^{\circ} \mathrm{C}$ using an EnVision Reader (Perkin Elmer). Values were collected as the background subtracted ratio between fluorescence emission at $665 \mathrm{~nm}$ and $615 \mathrm{~nm}$ where the background signal corresponds to the ratio (665/615) measured for the antibodies in lysis buffer. The points in the graphs correspond to the averages of the background subtracted fluorescence ratio relative to the sample. The dilution points of each sample were fitted in a 4 parameters function that 
describes the curves. The obtained values were also expressed as (1/IC50) per $\mu \mathrm{g}$ of total protein for both assays.

\section{Statistics}

Prism 6 (GraphPad software) was used to perform all statistical analyses. Data are presented as means \pm standard error of the mean (s.e.m.). Grubbs' test was applied to identify outliers. For each set of data to be compared, we determined whether data were normally distributed or not to select parametric or not parametric statistical tests. The specific statistical test used is indicated in the legend of all results figures. Differences were considered statistically if the p-value was less than 0.05 . To pre-determine sample sizes, we used G-power analysis based on pilot or previous studies. Appendix Table S3 summarizes all the trials and read-outs performed. 


\section{Acknowledgments}

The authors acknowledge the scientific and technical assistance of Dr. Chiara Cordiglieri, responsible of the INGM Imaging Facility (Istituto Nazionale Genetica Molecolare - INGM, Milan, Italy); Dr. Alex Costa and the NOLIMITS advanced imaging facility established by the University of Milan.

The authors also acknowledge Prof. Timothy F. Osborne (Department of Medicine, Johns Hopkins University, Baltimore, Maryland, USA), who supplied the antibody anti-SREBP2. This work was supported by Telethon Foundation, Italy (\# GGP17102), the EU projects Neuromics (FP7 \#305121) and JPND Research CircProt (643417) to E.C. and by KAUST Baseline funding to A.F.. 


\section{Author contributions (based on CRediT model)}

E.D.P., M.V. and E.C. conceived the study; E.D.P. and G.B. performed in vivo experiments, including surgical implantation of osmotic-minipumps and behavioral analysis; G.B. performed immunostaining experiments and provided confocal images and quantification; E.V. prepared samples for the TEM and FIB-SEM imaging and performed the TEM imaging; A.F. and E.S. performed the FIB-SEM imaging; E.V. and A.F. analyzed the TEM and FIBSEM data; C.M., F.T., and G.R.B. performed and analyzed the electrophysiological recordings; C. Caccia and V.L. performed mass spectrometry analyses; L.P., C. Cariulo, M. Verani, and A.C. performed TR-FRET experiments; V.D.B. performed the PCA analysis; P.C. provided reagents/tools and suggestions for experiments regarding muHTT clearance and autophagy; M. Valenza and G.B. collected study data and performed statistical analyses; M. Valenza and E.C. oversaw and coordinated responsibility for all research activities and their performance and provided experimental advice throughout the work. E.C. secured the funding, the collaborations and the execution of the entire project. M. Valenza, G.B., and E.C. wrote the paper that has been edited and reviewed by all authors.

\section{Conflict of interest}

All authors declare no conflict of interest 


\section{The paper explained}

PROBLEM. Cholesterol is fundamental for several activities of the brain. Peripheral cholesterol is not able to reach this organ due to the presence of the blood-brain barrier, thus the majority of cholesterol found in brain is synthetized locally. De novo synthesis of cholesterol is reduced in the Huntington's disease (HD) brain before the clinical disease onset and strategies aimed at providing cholesterol to the brain may be beneficial. However, the identification of the therapeutic dose of cholesterol that must reach the brain to have a maximum benefit on the multiple disease phenotypes is still unknown and needs to be qualified for a translational perspective.

RESULTS: Here we infused three escalating doses of cholesterol in the brain of HD mice by the use of osmotic-mini-pumps and identified the dose that is able to reverse both cognitive and motor abnormalities. We found that cognitive decline was prevented by all the three doses tested, while motor dysfunction was reversed in HD mice only with the highest dose. Moreover, exogenous cholesterol acted at multiple levels by normalizing a plethora of disease-related dysfunctions including those related to synapse function and morphology and aggregation of mutated Huntingtin.

IMPACT: Our work highlights the therapeutic dose of exogenous cholesterol capable of improving behavioral, synaptic and neuropathological abnormalities in HD. This knowledge creates a solid foundation for developing new therapeutic strategies based on cholesterol to fight this disease. 


\section{References}

1. J. M. Dietschy, S. D. Turley, Cholesterol metabolism in the central nervous system during early development and in the mature animal, J. Lipid Res. 45, 1375-1397 (2004).

2. J. M. Dietschy, Central nervous system: Cholesterol turnover, brain development and neurodegeneration, Biol. Chem. 390, 287-293 (2009).

3. Y. K. Seo, T. Jeon, H. K. Chong, J. Beisinger, T. F. Osborne, Genome-wide Localization of SREBP-2 in Hepatic Chromatin Predicts a Role in Autophagy, 13, 367-375 (2012).

4. D. H. Mauch, K. Nägier, S. Schumacher, C. Göritz, E. C. Müller, A. Otto, F. W. Pfrieger, CNS synaptogenesis promoted by glia-derived cholesterol, Science (80). 294, 1354-1357 (2001).

5. J. Rohrbough, K. Broadie, Lipid regulation of the synaptic vesicle cycle, Nat. Rev. Neurosci. 6, 139-150 (2005).

6. K. Fukui, H. A. Ferris, C. R. Kahn, Effect of cholesterol reduction on receptor signaling in neurons, J. Biol. Chem. 290, 26383-26392 (2015).

7. P. A. Postila, T. Róg, A Perspective: Active Role of Lipids in Neurotransmitter Dynamics, Mol. Neurobiol., 910-925 (2019).

8. M. Valenza, E. Cattaneo, Emerging roles for cholesterol in Huntington's disease, Trends Neurosci. 34, 474-486 (2011).

9. M. G. Martin, T. Ahmed, A. Korovaichuk, C. Venero, S. A. Menchón, I. Salas, S. Munck, O. Herreras, D. Balschun, C. G. Dotti, Constitutive hippocampal cholesterol loss underlies poor cognition in old rodents, EMBO Mol. Med. 6, 902-917 (2014).

10. F. Saudou, S. Humbert, The Biology of Huntingtin, Neuron 89, 910-926 (2016). 
11. C. Zuccato, M. Valenza, E. Cattaneo, Molecular mechanisms and potential therapeutical targets in Huntington's disease, Physiol. Rev. 90, 905-981 (2010).

12. U. Rüb, K. Seidel, H. Heinsen, J. P. Vonsattel, W. F. den Dunnen, H. W. Korf, Huntington's disease (HD): the neuropathology of a multisystem neurodegenerative disorder of the human brain, Brain Pathol. 26, 726-740 (2016).

13. S. Sipione, D. Rigamonti, M. Valenza, C. Zuccato, L. Conti, J. Pritchard, C. Kooperberg, J. M. Olson, E. Cattaneo, Early transcriptional profiles in huntingtin-inducible striatal cells by microarray analyses, Hum. Mol. Genet. 25, 210-210 (2002).

14. M. Valenza, D. Rigamonti, D. Goffredo, C. Zuccato, S. Fenu, L. Jamot, A. Strand, A. Tarditi, B. Woodman, M. Racchi, C. Mariotti, S. Di Donate, A. Corsini, G. Bates, R. Pruss, J. M. Olson, S. Sipione, M. Tartari, E. Cattaneo, Dysfunction of the cholesterol biosynthetic pathway in Huntington's disease, J. Neurosci. 25, 9932-9939 (2005).

15. M. Valenza, M. Marullo, E. Di Paolo, E. Cesana, C. Zuccato, G. Biella, E. Cattaneo, Disruption of astrocyte-neuron cholesterol cross talk affects neuronal function in Huntington's disease, Cell Death Differ. 22, 690-702 (2015).

16. A. Bobrowska, G. Donmez, A. Weiss, L. Guarente, G. Bates, SIRT2 ablation has no effect on tubulin acetylation in brain, cholesterol biosynthesis or the progression of Huntington's disease phenotypes in vivo., PLoS One 7 (2012).

17. J. H. Lee, L. Tecedor, Y. H. Chen, A. M. Monteys, M. J. Sowada, L. M. Thompson, and B. L. Davidson, Reinstating aberrant mTORC1 activity in Huntington's disease mice improves disease phenotypes, Neuron 85, 303-315 (2015).

18. J. J. Ritch, A. Valencia, J. Alexander, E. Sapp, L. Gatune, G. R. S., S. Sinha, Cally M. Scherber, S. Zeitlin, G. Sadri-Vakili, D. Irimia, M. DiFiglia, K. B. Kegel, Multiple 
Phenotypes in Huntington Disease Mouse Neural Stem Cells James, Mol. Cell. Neurosci. 50, 70-71 (2012).

19. M. Valenza, V. Leoni, A. Tarditi, C. Mariotti, I. Björkhem, S. Di Donato, E. Cattaneo, Progressive dysfunction of the cholesterol biosynthesis pathway in the R6/2 mouse model of Huntington's disease, Neurobiol. Dis. 28, 133-142 (2007).

20. M. Valenza, J. B. Carroll, V. Leoni, L. N. Bertram, I. Björkhem, R. R. Singaraja, S. Di Donato, D. Lutjohann, M. R. Hayden, E. Cattaneo, Cholesterol biosynthesis pathway is disturbed in YAC128 mice and is modulated by huntingtin mutation, Hum. Mol. Genet. 16, $2187-2198$ (2007).

21. M. Valenza, V. Leoni, J. M. Karasinska, L. Petricca, J. Fan, J. Carroll, M. A. Pouladi, E. Fossale, H. P. Nguyen, O. Riess, M. MacDonald, C. Wellington, S. DiDonato, M. Hayden, E. Cattaneo, Cholesterol defect is marked across multiple rodent models of Huntington's disease and is manifest in astrocytes, J. Neurosci. 30, 10844-10850 (2010).

22. M. Shankaran, E. Di Paolo, V. Leoni, C. Caccia, C. Ferrari Bardile, H. Mohammed, S. Di Donato, S. Kwak, D. Marchionini, S. Turner, E. Cattaneo, M. Valenza, Early and brain region-specific decrease of de novo cholesterol biosynthesis in Huntington's disease: A crossvalidation study in Q175 knock-in mice, Neurobiol. Dis. 98, 66-76 (2017).

23. L. Boussicault, S. Alves, A. Lamazière, A. Planques, N. Heck, L. Moumné, G. Despres, S. Bolte, A. Hu, C. Pagès, L. Galvan, F. Piguet, P. Aubourg, N. Cartier, J. Caboche, S. Betuing, CYP46A1, the rate-limiting enzyme for cholesterol degradation, is neuroprotective in Huntington's disease, Brain 139, 953-970 (2016).

24. V. Leoni, C. Mariotti, S. J. Tabrizi, M. Valenza, E. J. Wild, S. M. D. Henley, N. Z. Hobbs, M. L. Mandelli, M. Grisoli, I. Björkhem, E. Cattaneo, S. Di Donato, Plasma 24S- 
hydroxycholesterol and caudate MRI in pre-manifest and early Huntington's disease, Brain 131, 2851-2859 (2008).

25. V. Leoni, C. Mariotti, L. Nanetti, E. Salvatore, F. Squitieri, A. R. Bentivoglio, M. Bandettini del Poggio, S. Piacentini, D. Monza, M. Valenza, E. Cattaneo, S. Di Donato, Whole body cholesterol metabolism is impaired in Huntington's disease, Neurosci. Lett. 494, 245-249 (2011).

26. V. Leoni, J. D. Long, J. A. Mills, S. Di Donato, J. S. Paulsen, Plasma 24Shydroxycholesterol correlation with markers of Huntington disease progression, Neurobiol. Dis. 55, 37-43 (2013).

27. R. Kacher, A. Lamazière, N. Heck, V. Kappes, C. Mounier, G. Despres, Y. Dembitskaya, E. Perrin, W. Christaller, S. Sasidharan Nair, V. Messent, N. Cartier, P. Vanhoutte, L. Venance, F. Saudou, C. Néri, J. Caboche, S. Betuing, CYP46A1 gene therapy deciphers the role of brain cholesterol metabolism in Huntington's disease, Brain 142, 2432-2450 (2019).

28. M. Valenza, J. Y. Chen, E. Di Paolo, B. Ruozi, D. Belletti, C. Ferrari Bardile, V. Leoni, C. Caccia, E. Brilli, S. Di Donato, M. M. Boido, A. Vercelli, M. A. Vandelli, F. Forni, C. Cepeda, M. S. Levine, G. Tosi, E. Cattaneo, Cholesterol-loaded nanoparticles ameliorate synaptic and cognitive function in H untington's disease mice, EMBO Mol. Med. 7, 1547$1564(2015)$.

29. L. Mangiarini, K. Sathasivam, M. Seller, B. Cozens, A. Harper, C. Hetherington, M. Lawton, Y. Trottier, H. Lehrach, S. W. Davies, G. P. Bates, Exon 1 of the HD Gene with an Expanded CAG Repeat Is Sufficient to Cause a Progressive Neurological Phenotype in Transgenic Mice, Cell 87, 493-506 (1996). 
30. T. Loftsson, P. Jarho, M. Másson, T. Järvinen, Cyclodextrins in drug delivery, Expert Opin. Drug Deliv. 2, 335-351 (2005).

31. F. W. Pfrieger, Cholesterol homeostasis and function in neurons of the central nervous system, Cell. Mol. Life Sci. 60, 1158-1171 (2003).

32. C. Cepeda, R. S. Hurst, C. R. Calvert, E. Hernández-Echeagaray, O. K. Nguyen, E. Jocoy, L. J. Christian, M. A. Ariano, M. S. Levine, Transient and progressive electrophysiological alterations in the corticostriatal pathway in a mouse model of Huntington's disease, $J$. Neurosci. 23, 961-969 (2003).

33. C. Cepeda, A. J. Starling, N. Wu, O. K. Nguyen, B. Uzgil, T. Soda, V. M. André, M. A. Ariano, M. S. Levine, Increased GABAergic function in mouse models of Huntington's disease: Reversal by BDNF, J. Neurosci. Res. 78, 855-867 (2004).

34. A. Merchán-Pérez, J. R. Rodriguez, L. Alonso-Nanclares, A. Schertel, J. DeFelipe, Counting synapses using FIB/SEM microscopy: A true revolution for ultrastructural volume reconstruction, Front. Neuroanat. 3, 1-14 (2009).

35. G. Saher, S. K. Stumpf, Cholesterol in myelin biogenesis and hypomyelinating disorders, Biochim. Biophys. Acta - Mol. Cell Biol. Lipids 1851, 1083-1094 (2015).

36. E. G. Lund, C. Xie, T. Kotti, S. D. Turley, J. M. Dietschy, D. W. Russell, Knockout of the cholesterol 24-hydroxylase gene in mice reveals a brain-specific mechanism of cholesterol turnover, J. Biol. Chem. 278, 22980-22988 (2003).

37. I. Björkhem, D. Lütjohann, O. Breuer, A. Sakinis, Å. Wennmalm, Importance of a Novel Oxidative Mechanism for Elimination of Brain Cholesterol, J. Biol. Chem. 272, 30178-30184 (1997). 
38. M. S. Brown, J. L. Goldstein, The SREBP pathway: Regulation of cholesterol metabolism by proteolysis of a membrane-bound transcription factor, Cell 89, 331-340 (1997).

39. M. Difiglia, E. Sapp, K. O. Chase, S. W. Davies, G. P. Bates, J. P. Vonsattel, N. Aronin, Aggregation of huntingtin in neuronal intranuclear inclusions and dystrophic neurites in brain, Science (80). 277, 1990-1993 (1997).

40. C. A. Gutekunst, S. H. Li, H. Yi, J. S. Mulroy, S. Kuemmerle, R. Jones, D. Rye, R. J. Ferrante, S. M. Hersch, X. J. Li, Nuclear and neuropil aggregates in Huntington's disease: Relationship to neuropathology, J. Neurosci. 19, 2522-2534 (1999).

41. M. L.C. Maat-Schieman, J. C. Dorsman, M. A. Smoor, S. Siesling, S. Van Duinnen, J. J.G.M. Verschuuren, J. T. den Dunnen, Distribution of inclusions in neuronal nuclei and dystrophic neurites in Huntington Disease brain, J. Neuropathol. Exp. Neurol. 58, 129-137 (1394).

42. M. E. S. Herndon, C. L. Hladik, P. Shang, D. K. Burns, J. Raisanen, and C. L. White, Neuroanatomical Profile of Polyglutamine Immunoreactivity in Huntington Disease Brains, $J$. Neuropathol. Exp. Neurol. 68, 250-261 (2009).

43. B. Baldo, P. Paganetti, S. Grueninger, D. Marcellin, L. S. Kaltenbach, D. C. Lo, M. Semmelroth, A. Zivanovic, D. Abramowski, D. Smith, G. P. Lotz, G. P. Bates, A. Weiss, TRFRET-based duplex immunoassay reveals an inverse correlation of soluble and aggregated mutant huntingtin in Huntington's disease, Chem. Biol. 19, 264-275 (2012).

44. A. Weiss, R. Andre, S. J. Tabrizi, A. Weiss, U. Träger, E. J. Wild, S. Grueninger, R. Farmer, C. Landles, R. I. Scahill, N. Lahiri, S. Haider, D. Macdonald, C. Frost, G. P. Bates, G. Bilbe, R. Kuhn, R. Andre, S. J. Tabrizi, Mutant huntingtin fragmentation in immune cells tracks Huntington's disease progression, J. Clin. Invest. 122, 3731-3736 (2012). 
45. M. Segatto, L. Leboffe, L. Trapani, V. Pallottini, Cholesterol Homeostasis Failure in the Brain: Implications for Synaptic Dysfunction and Cognitive Decline, Curr. Med. Chem. 21, 2788-2802 (2014).

46. B. F. Hulce, Jonathan J.; Cognetta, Armand B.; Niphakis, Micah J.; Tully, Sarah E. and Cravatt, Proteome-wide Mapping of Cholesterol-Interacting Proteins in Mammalian Cells, Nat. Methods 10, 259-264 (2013).

47. S. Oddi, E. Dainese, F. Fezza, M. Lanuti, D. Barcaroli, V. De Laurenzi, D. Centonze, M. MacCarrone, Functional characterization of putative cholesterol binding sequence (CRAC) in human type-1 cannabinoid receptor, J. Neurochem. 116, 858-865 (2011).

48. T. Rahbek-Clemmensen, M. D. Lycas, S. Erlendsson, J. Eriksen, M. Apuschkin, F. Vilhardt, T. N. Jørgensen, F. H. Hansen, U. Gether, Super-resolution microscopy reveals functional organization of dopamine transporters into cholesterol and neuronal activitydependent nanodomains, Nat. Commun. 8 (2017).

49. R. Guixà-González, J. L. Albasanz, I. Rodriguez-Espigares, M. Pastor, F. Sanz, M. MartíSolano, M. Manna, H. Martinez-Seara, P. W. Hildebrand, M. Martín, J. Selent, Membrane cholesterol access into a G-protein-coupled receptor, Nat. Commun. 8 (2017).

50. P. C. Casarotto, M. Girych, S. M. Fred, R. Moliner, G. Enkavi, C. Biojone, C. Cannarozzo, C. A. Brunello, A. Steinzeig, F. Winkel, S. Patil, S. Vestring, T. Serchov, L. Laukkanen, I. Cardon, H. Antila, T. Rog, C. R. Bramham, C. Normann, S. E. Lauri, I. Vattulainen, E. Castrén, Antidepressants act by binding to the cholesterol-interaction site at TRKB neurotrophin receptor, bioRxiv 757989 (2020). 
51. G. Saher, F. Rudolphi, K. Corthals, T. Ruhwedel, K. F. Schmidt, S. Löwel, P. Dibaj, B.

Barrette, W. Möbius, K. A. Nave, Therapy of Pelizaeus-Merzbacher disease in mice by feeding a cholesterol-enriched diet, Nat. Med. 18, 1130-1135 (2012).

52. S. A. Berghoff, N. Gerndt, J. Winchenbach, S. K. Stumpf, L. Hosang, F. Odoardi, T. Ruhwedel, C. Böhler, B. Barrette, R. Stassart, D. Liebetanz, P. Dibaj, W. Möbius, J. M. Edgar, G. Saher, Dietary cholesterol promotes repair of demyelinated lesions in the adult brain, Nat. Commun. 8 (2017).

53. R. T. Yi Teo, X. Hong, L. Yu-Taeger, Y. Huang, L. J. Tan, Y. Xie, X. V. To, L. Guo, R. Rajendran, A. Novati, C. Calaminus, O. Riess, M. R. Hayden, H. P. Nguyen, K. H. Chuang, M. A. Pouladi, Structural and molecular myelination deficits occur prior to neuronal loss in the YAC128 and BACHD models of Huntington disease, Hum. Mol. Genet. 25, 2621-2632 (2016).

54. Z. Xiang, M. Valenza, L. Cui, V. Leoni, H. K. Jeong, E. Brilli, J. Zhang, Q. Peng, W. Duan, S. A. Reeves, E. Cattaneo, D. Krainc, Peroxisome-proliferator-activated receptor gamma coactivator $1 \alpha$ contributes to dysmyelination in experimental models of Huntington's disease, J. Neurosci. 31, 9544-9553 (2011).

55. H. D. Rosas, P. Wilkens, D. H. Salat, N. D. Mercaldo, M. Vangel, A. Y. Yendiki, S. M. Hersch, Complex spatial and temporally defined myelin and axonal degeneration in Huntington disease, NeuroImage Clin. 20, 236-242 (2018).

56. B. Huang, W. Wei, G. Wang, M. A. Gaertig, Y. Feng, W. Wang, X. J. Li, S. Li, Mutant Huntingtin Downregulates Myelin Regulatory Factor- Mediated Myelin Gene Expression and Affects Mature Oligodendrocytes, Neuron 85, 1212-1226 (2015). 
57. B. A. Janowski, M. J. Grogan, S. A. Jones, G. B. Wisely, S. A. Kliewer, E. J. Corey, D. J. Mangelsdorf, Structural requirements of ligands for the oxysterol liver X receptors LXRa and LXRß, Proc. Natl. Acad. Sci. U. S. A. 96, 266-271 (1999).

58. K. Abildayeva, P. J. Jansen, V. Hirsch-Reinshagen, V. W. Bloks, A. H. F. Bakker, F. C. S. Ramaekers, J. de Vente, A. K. Groen, C. L. Wellington, F. Kuipers, and M. Mulder, 24(S)Hydroxycholesterol Participates in a Liver X Receptor- controlled Pathway in Astrocytes That Regulates Apolipoprotein E-mediated Cholesterol Efflux, J. Biol. Chem. 281, 1279912808 (2006).

59. L. Zhao, X. J. Chen, J. Zhu, Y. B. Xi, X. Yang, L. D. Hu, H. Ouyang, S. H. Patel, X. Jin, D. Lin, F. Wu, K. Flagg, H. Cai, G. Li, G. Cao, Y. Lin, D. Chen, C. Wen, C. Chung, Y. Wang, A. Qiu, E. Yeh, W. Wang, X. Hu, S. Grob, R. Abagyan, Z. Su, H. C. Tjondro, X. J. Zhao, H. Luo, R. Hou, J. J. P. Perry, W. Gao, I. Kozak, D. Granet, Y. Li, X. Sun, J. Wang, L. Zhang, Y. Liu, Y. Bin Yan, K. Zhang, Lanosterol reverses protein aggregation in cataracts, Nature 523, 607-611 (2015).

60. A. Upadhyay, A. Amanullah, R. Mishra, A. Kumar, A. Mishra, Lanosterol Suppresses the Aggregation and Cytotoxicity of Misfolded Proteins Linked with Neurodegenerative Diseases, Mol. Neurobiol. 55, 1169-1182 (2018).

61. K. L. Lim, X. H. Ng, L. G. Y. Grace, T. P. Yao, Mitochondrial dynamics and Parkinson’s disease: Focus on parkin, Antioxidants Redox Signal. 16, 935-949 (2012).

62. M. Narita, A. R. J. Young, S. Arakawa, S. A. Samarajiwa, T. Nakashima, S. Yoshida, S. Hong, L. S. Berry, S. Reichelt, M. Ferreira, S. Tavaré, K. Inoki, S. Shimizu, M. Narita, Spatial Coupling of mTOR and Autophagy Augments Secretory Phenotypes, Science (80-). 332, 966-970 (2011). 
63. J. L. Owen, Y. Zhang, S. H. Bae, M. S. Farooqi, G. Liang, R. E. Hammer, J. L. Goldstein, M. S. Brown, Insulin stimulation of SREBP-1c processing in transgenic rat hepatocytes requires p70 S6-kinase, Proc. Natl. Acad. Sci. U. S. A. 109, 16184-16189 (2012).

64. J. L. Yecies and B. D. Manning, Transcriptional Control of Cellular Metabolism by mTOR Signaling, Cancer Res. 71, 2815-2820 (2011).

65. R. Castellano, Brian M.; Thelen, Ashley M.; Moldavski, Ofer; Feltes, McKenna; van der Welle, Reini E. N.; Mydock-McGrane, Laurel; Jiang, Xuntian; van Eijkeren, Robert J.; Davis, Oliver B.; Louie, Sharon M; Perera, Rushika M.; Covey, Douglas; Nomura, Daniel K, Lysosomal Cholesterol Activates mTORC1 via an SLC38A9- Niemann Pick C1 Signaling Complex, Science (80-. ). 355, 1306-1311 (2017).

66. H. Koga, M. Martinez-Vicente, E. Arias, S. Kaushik, D. Sulzer, A. M. Cuervo, Constitutive upregulation of chaperone-mediated autophagy in Huntington's disease, $J$. Neurosci. 31, 18492-18505 (2011).

67. D. Belletti, A. M. Grabrucker, F. Pederzoli, I. Menerath, M. A. Vandelli, G. Tosi, T. J. Duskey, F. Forni, B. Ruozi, Hybrid nanoparticles as a new technological approach to enhance the delivery of cholesterol into the brain, Int. J. Pharm. 543, 300-310 (2018).

68. M. H. Lloyd, S. E. Wolfensohn, Practical use of distress scoring systems in the application of humane endpoints, Int. Conf. Hum. endpoints Anim. Exp. Biomed. Res., 22-25 (1998).

69. S. Pavoine, A. B. Dufour, D. Chessel, From dissimilarities among species to dissimilarities among communities: A double principal coordinate analysis, J. Theor. Biol. 228, 523-537 (2004). 
70. V. Leoni, T. Nury, A. Vejux, A. Zarrouk, C. Caccia, M. Debbabi, A. Fromont, R. Sghaier,

T. Moreau, G. Lizard, Mitochondrial dysfunctions in 7-ketocholesterol-treated $158 \mathrm{~N}$ oligodendrocytes without or with $\alpha$-tocopherol: Impacts on the cellular profil of tricarboxylic cycle-associated organic acids, long chain saturated and unsaturated fatty acids, oxysterols, chole, J. Steroid Biochem. Mol. Biol. 169, 96-110 (2017).

71. J. Schindelin, I. Arganda-Carrera, E. Frise, K. Verena, L. Mark, P. Tobias, P. Stephan, R. Curtis, S. Stephan, S. Benjamin, T. Jean-Yves, J. W. Daniel, H. Volker, E. Kevin, T. Pavel, C. Albert, Fiji - an Open platform for biological image analysis, Nat. Methods 9 (2009).

72. D. G. Lowe, Distinctive image features from scale-invariant keypoints, Int. J. Comput. Vis. 60, 91-110 (2004).

73. A. Berod, F. Pujol, Importance of Fixation in Immunohistochemistry, J. Histochem. Cytochem. 29, 844-850 (1981).

74. A. Weiss, D. Abramowski, M. Bibel, R. Bodner, V. Chopra, M. DiFiglia, J. Fox, K. Kegel, C. Klein, S. Grueninger, S. Hersch, D. Housman, E. Régulier, H. D. Rosas, M. Stefani, S. Zeitlin, G. Bilbe, P. Paganetti, Single-step detection of mutant huntingtin in animal and human tissues: A bioassay for Huntington's disease, Anal. Biochem. 395, 8-15 (2009). 
bioRxiv preprint doi: https://doi.org/10.1101/2020.05.13.092742; this version posted May 15,2020 . The copyright holder for this preprint (which was not certified by peer review) is the author/funder, who has granted bioRxiv a license to display the preprint in perpetuity. It is made available under aCC-BY-NC-ND 4.0 International license.

\section{Figure 1}

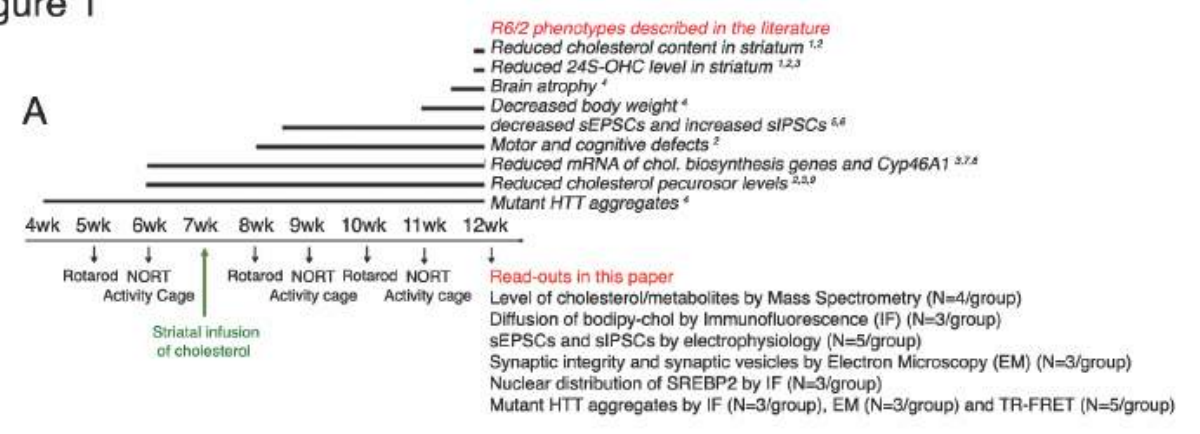

C
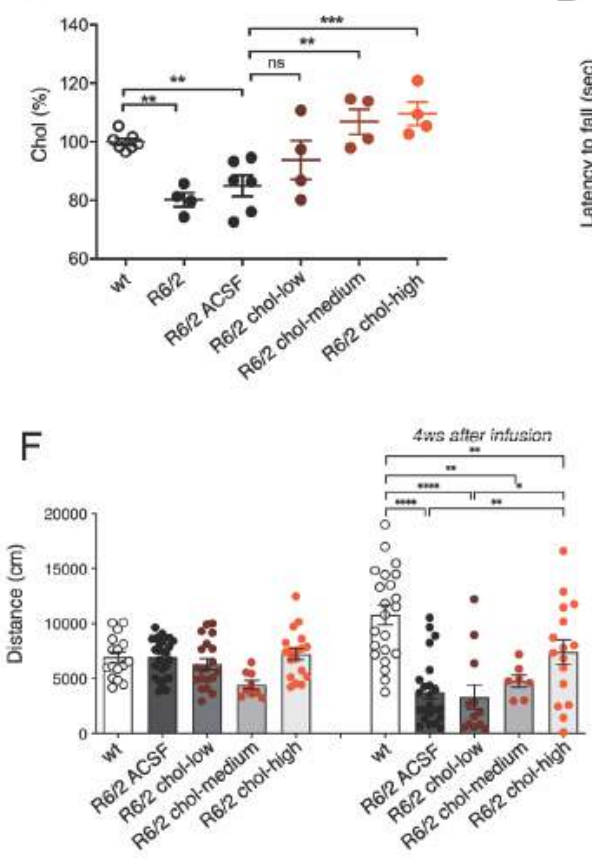

I
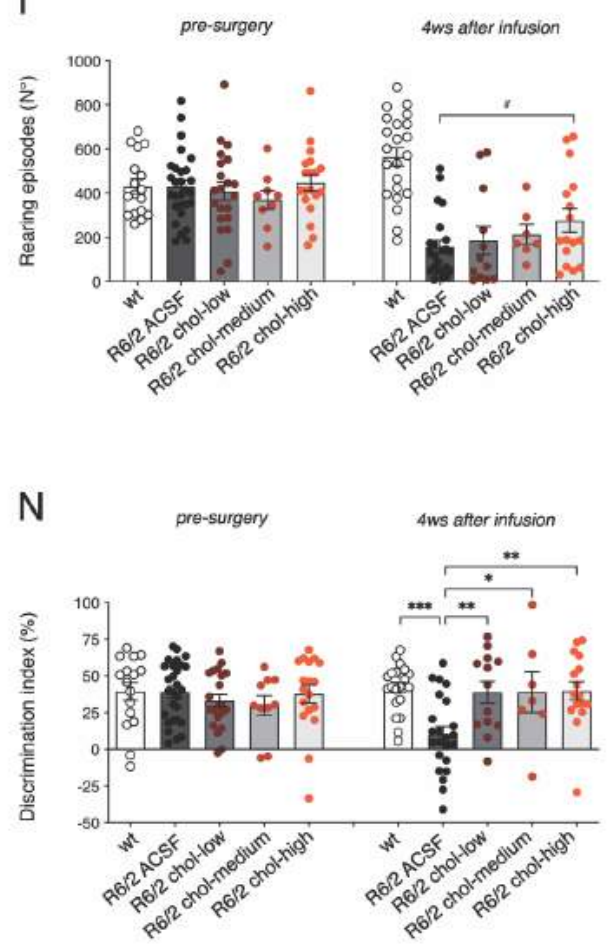

B
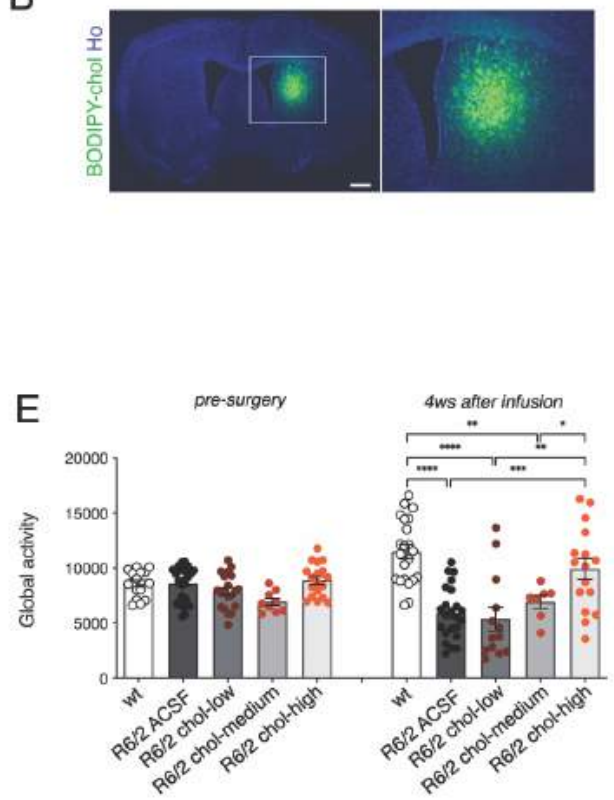

$\mathrm{H}$

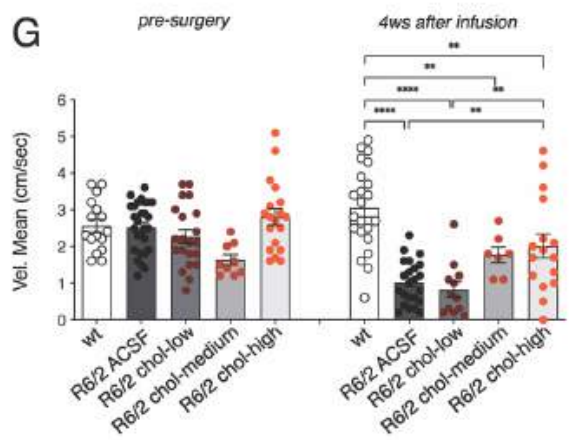

L

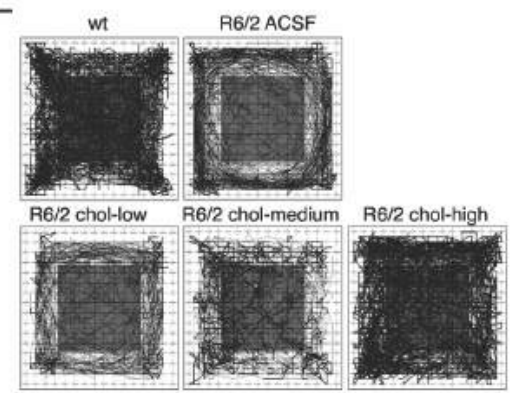

M

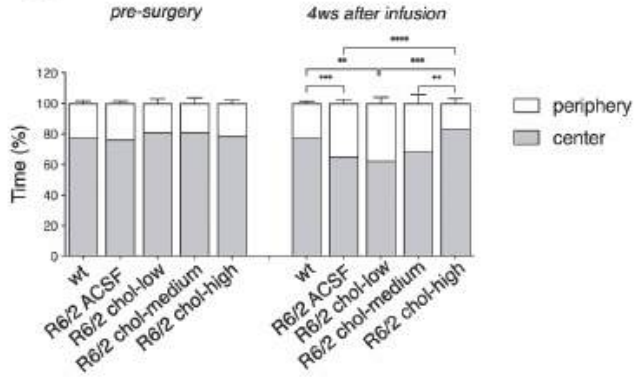

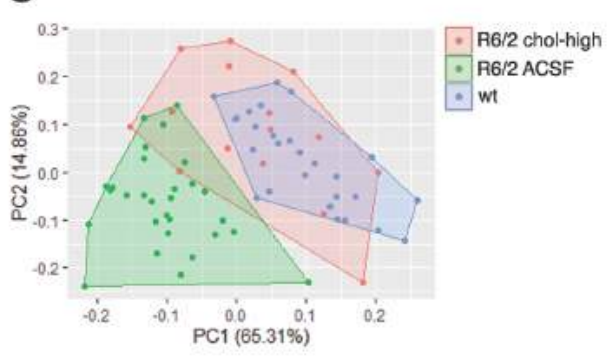


bioRxiv preprint doi: https://doi.org/10.1101/2020.05.13.092742; this version posted May 15, 2020. The copyright holder for this preprint (which was not certified by peer review) is the author/funder, who has granted bioRxiv a license to display the preprint in perpetuity. It is made available under aCC-BY-NC-ND 4.0 International license.

\section{Figure 2}

A

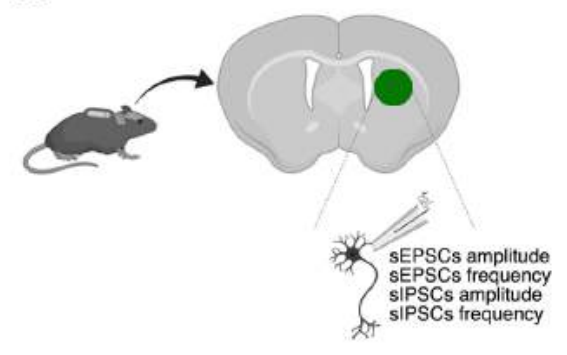

B

wt

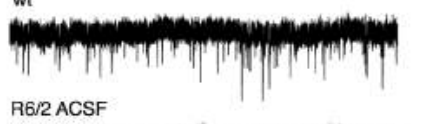

R6/2 ACSF

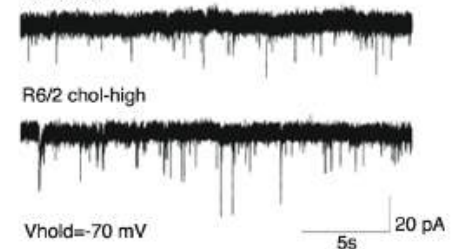

C

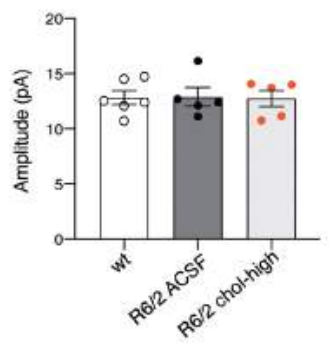

D

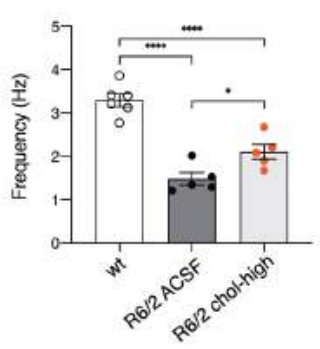

E

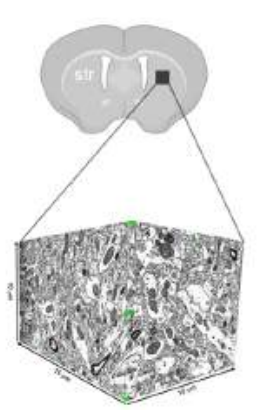

F

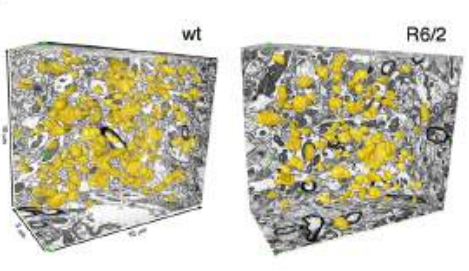

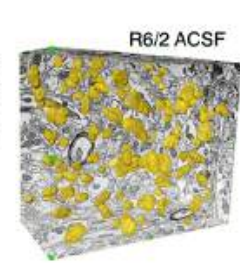

G

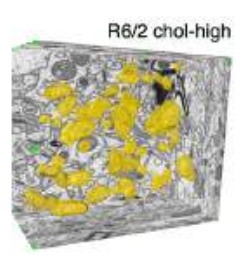

$\mathrm{H}$

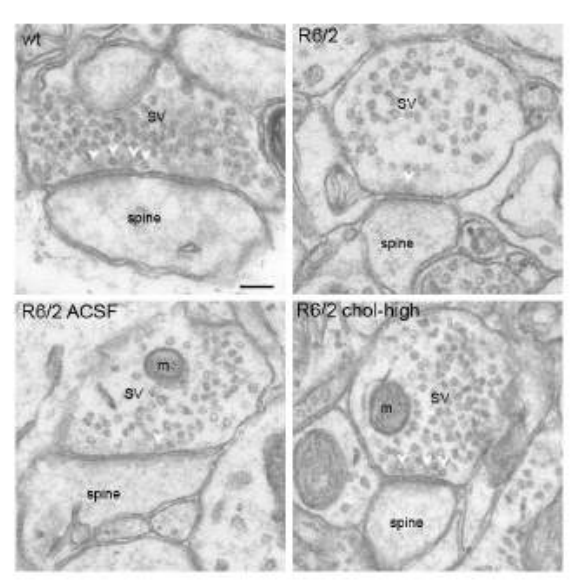

I
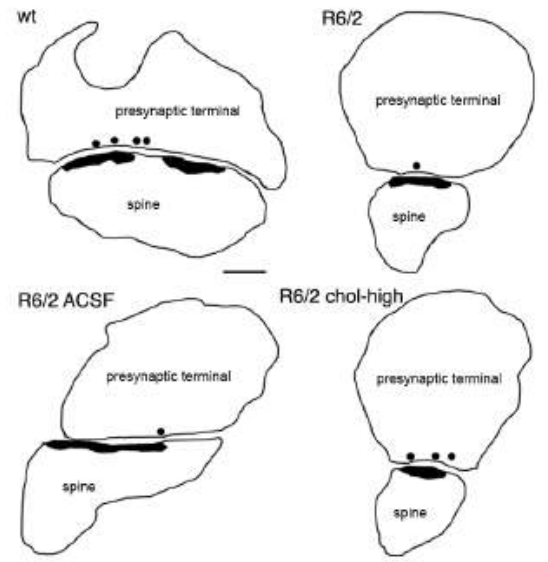

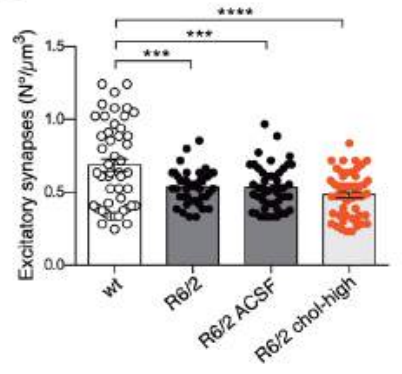

L
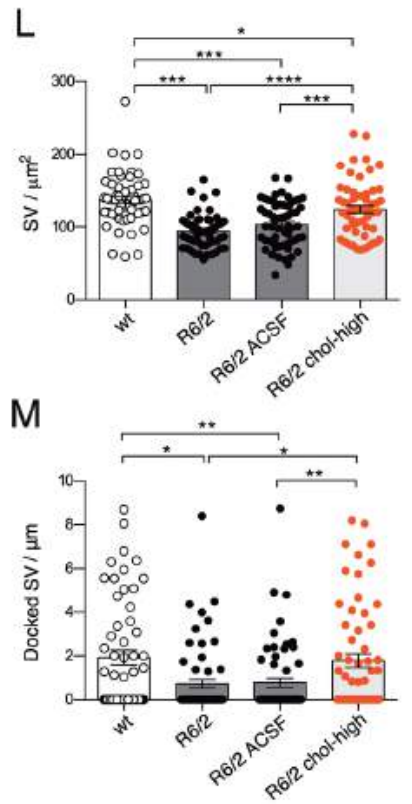
bioRxiv preprint doi: https://doi.org/10.1101/2020.05.13.092742; this version posted May 15, 2020. The copyright holder for this preprint (which was not certified by peer review) is the author/funder, who has granted bioRxiv a license to display the preprint in perpetuity. It is made

Figure 3 available under aCC-BY-NC-ND 4.0 International license.

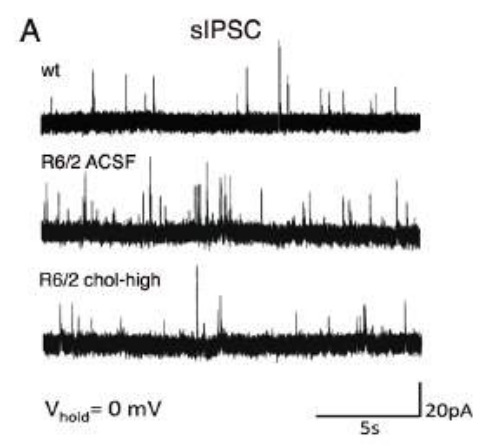

B

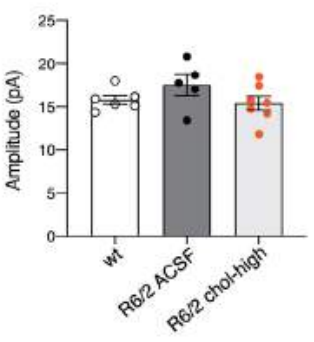

C

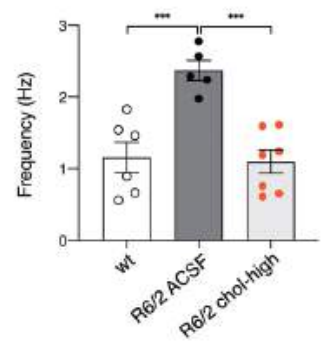

D

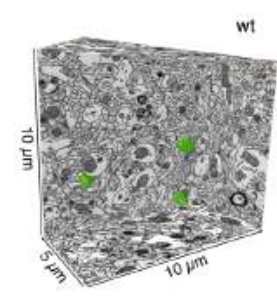

$R 6 / 2$

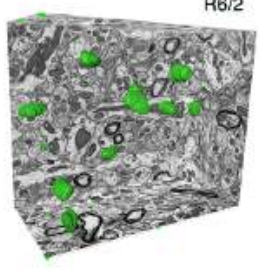

$\mathrm{R} 6 / 2 \mathrm{ACSF}$

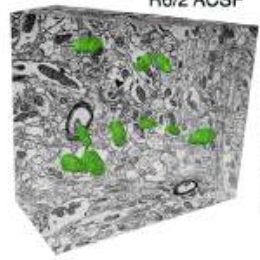

R6/2 chol-high

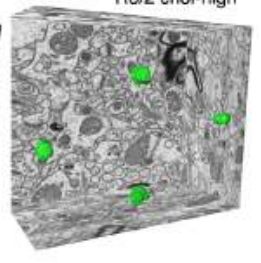

E

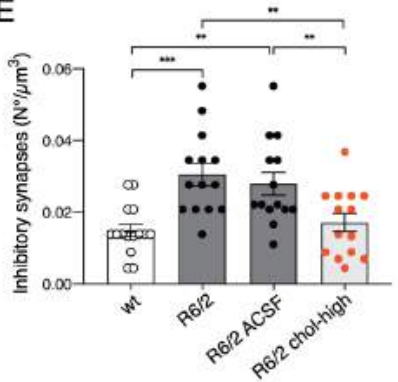


bioRxiv preprint doi: https://doi.org/10.1101/2020.05.13.092742; this version posted May 15, 2020. The copyright holder for this preprint (which

was not certified by peer review) is the author/funder, who has granted bioRxiv a license to display the preprint in perpetuity. It is made available under aCC-BY-NC-ND 4.0 International license.

Figure 4
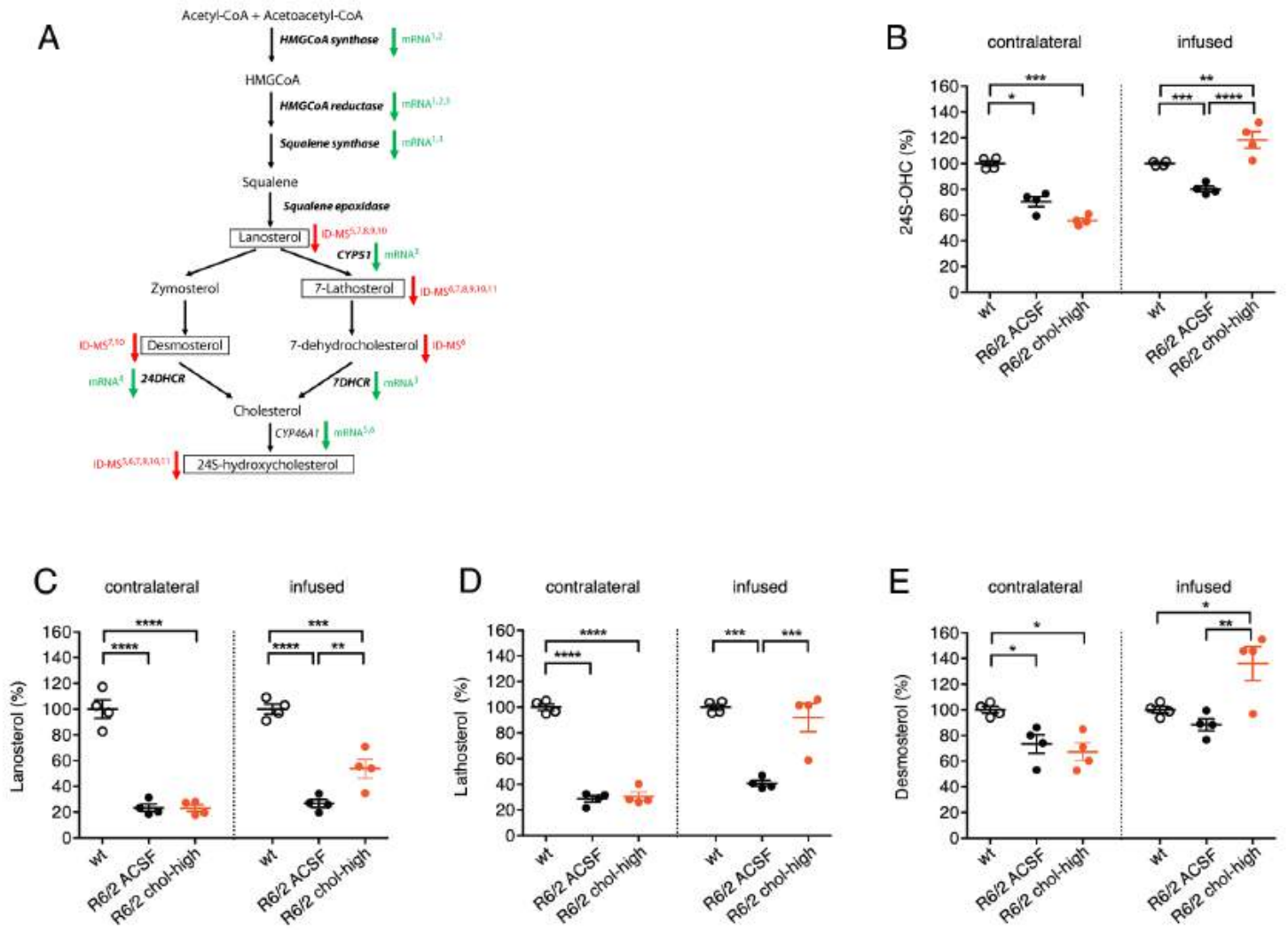

F

R6/2 chol-high (contralateral)

R6/2 chol-high (infused)

G

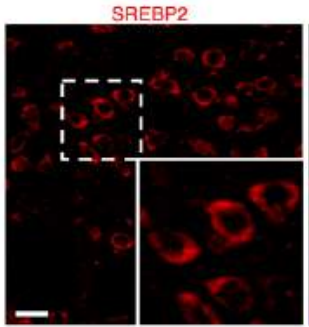

SAERP2 HO

SREBP?

SRERP2

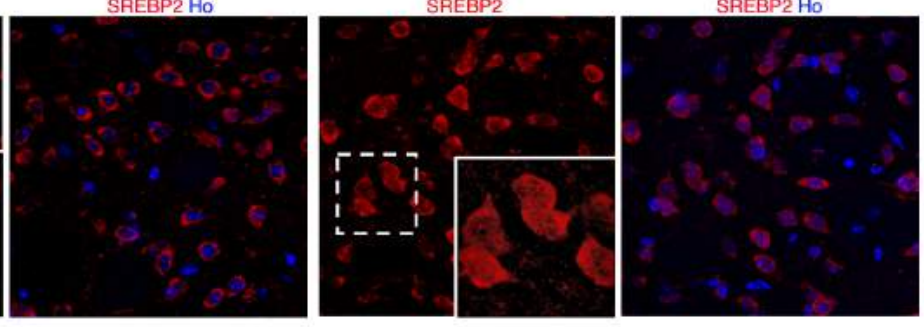

$\mathrm{H}$
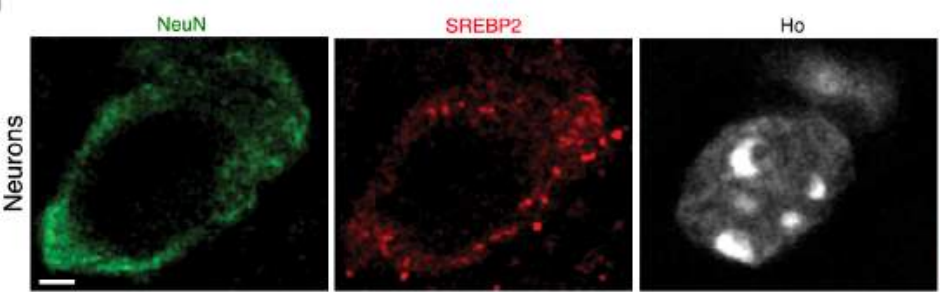

NEUN SREBP2 Ho

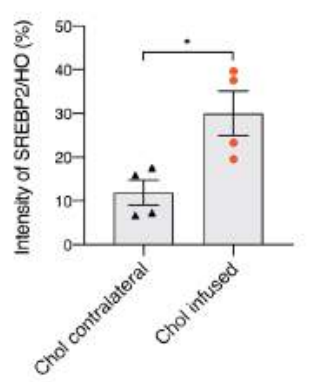

I
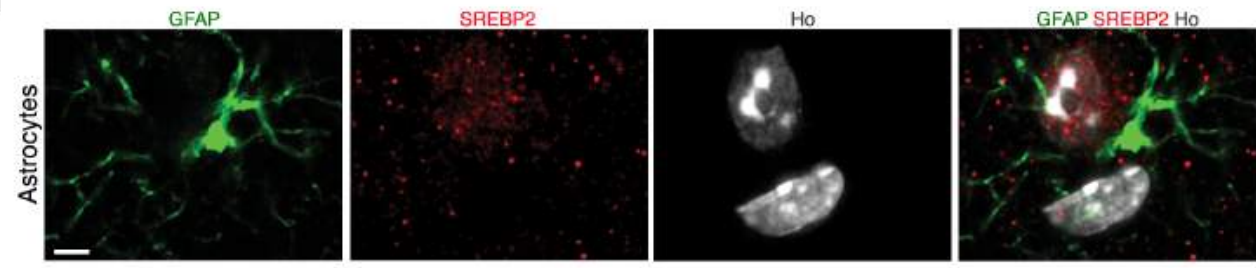
bioRxiv preprint doi: https://doi.org/10.1101/2020.05.13.092742; this version posted May 15,2020 . The copyright holder for this preprint (which was not certified by peer review) is the author/funder, who has granted bioRxiv a license to display the preprint in perpetuity. It is made available under aCC-BY-NC-ND 4.0 International license.

Figure 5

A

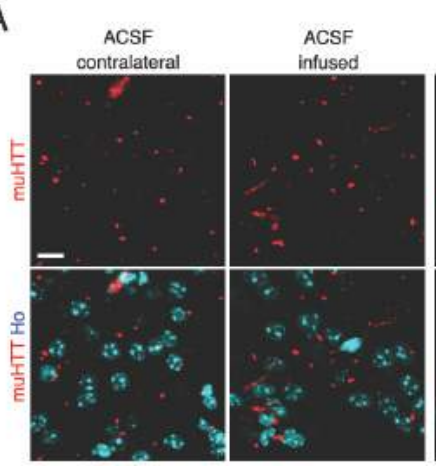

D Chol-high

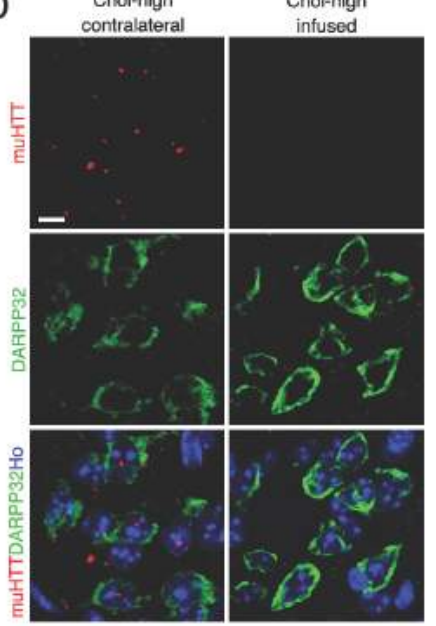

Chol-high
contralateral

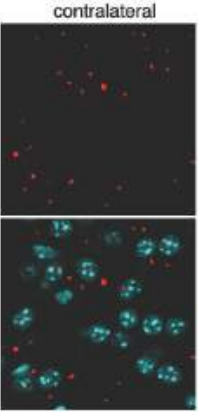

E

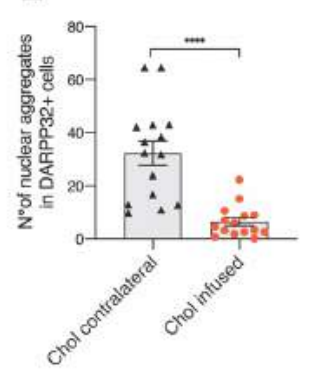

B

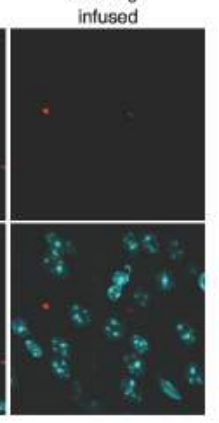

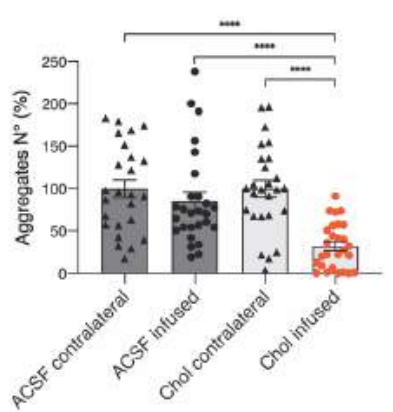

F
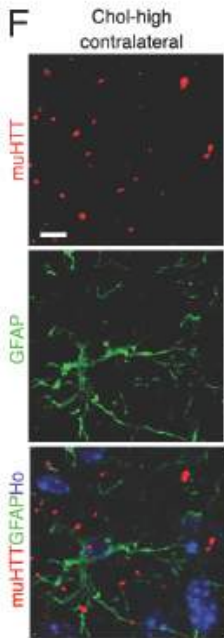

C

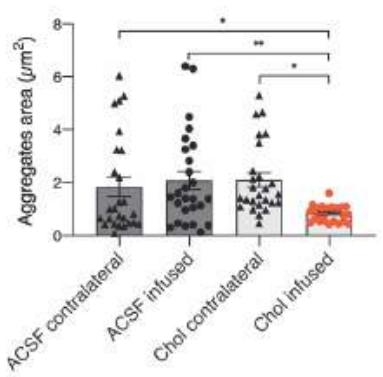

G

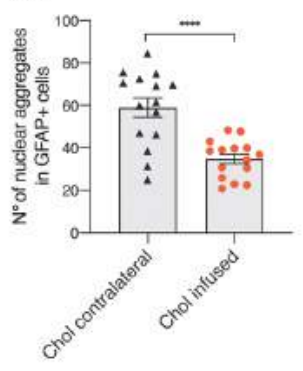

$\mathrm{H}$

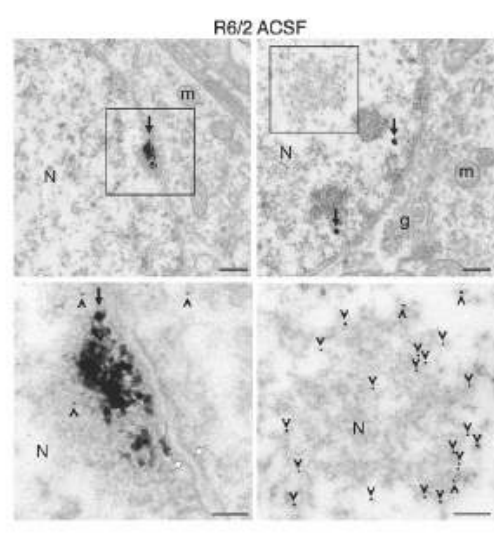

R6/2 chol-high

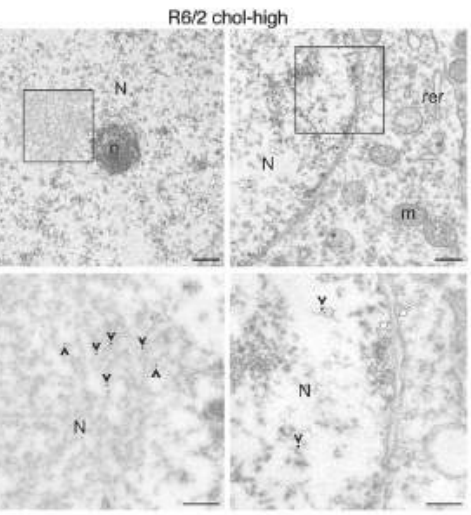

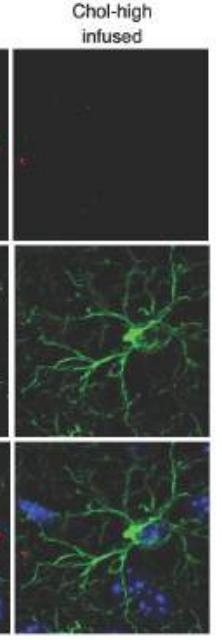

I
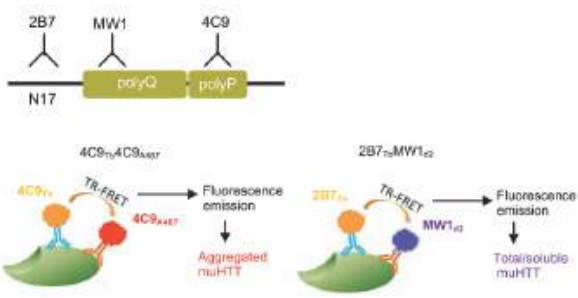

L

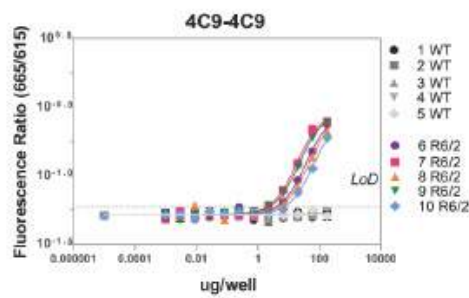

M

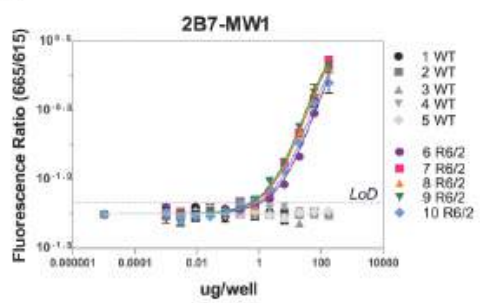

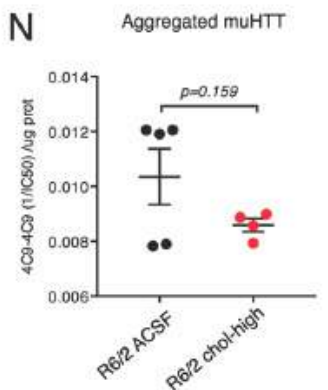

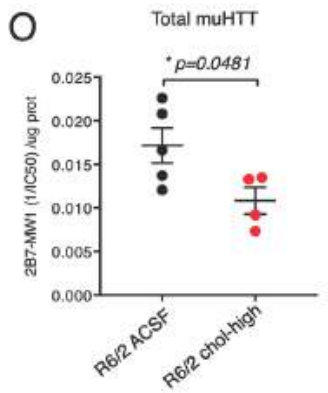


bioRxiv preprint doi: https://doi.org/10.1101/2020.05.13.092742; this version posted May 15, 2020. The copyright holder for this preprint (which was not certified by peer review) is the author/funder, who has granted bioRxiv a license to display the preprint in perpetuity. It is made available under aCC-BY-NC-ND 4.0 International license.

Figure 6

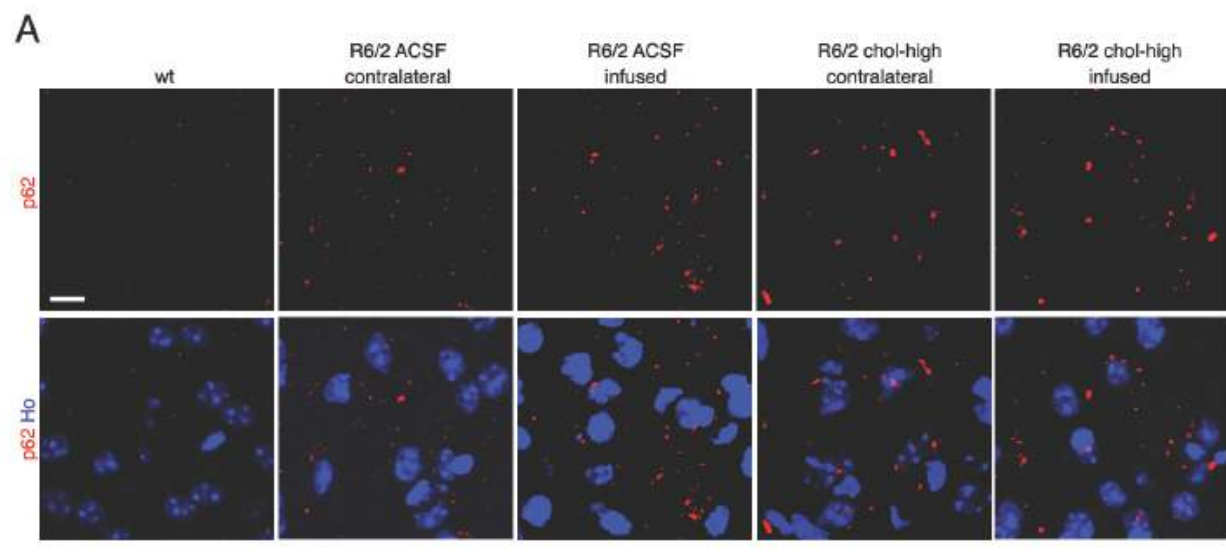

B
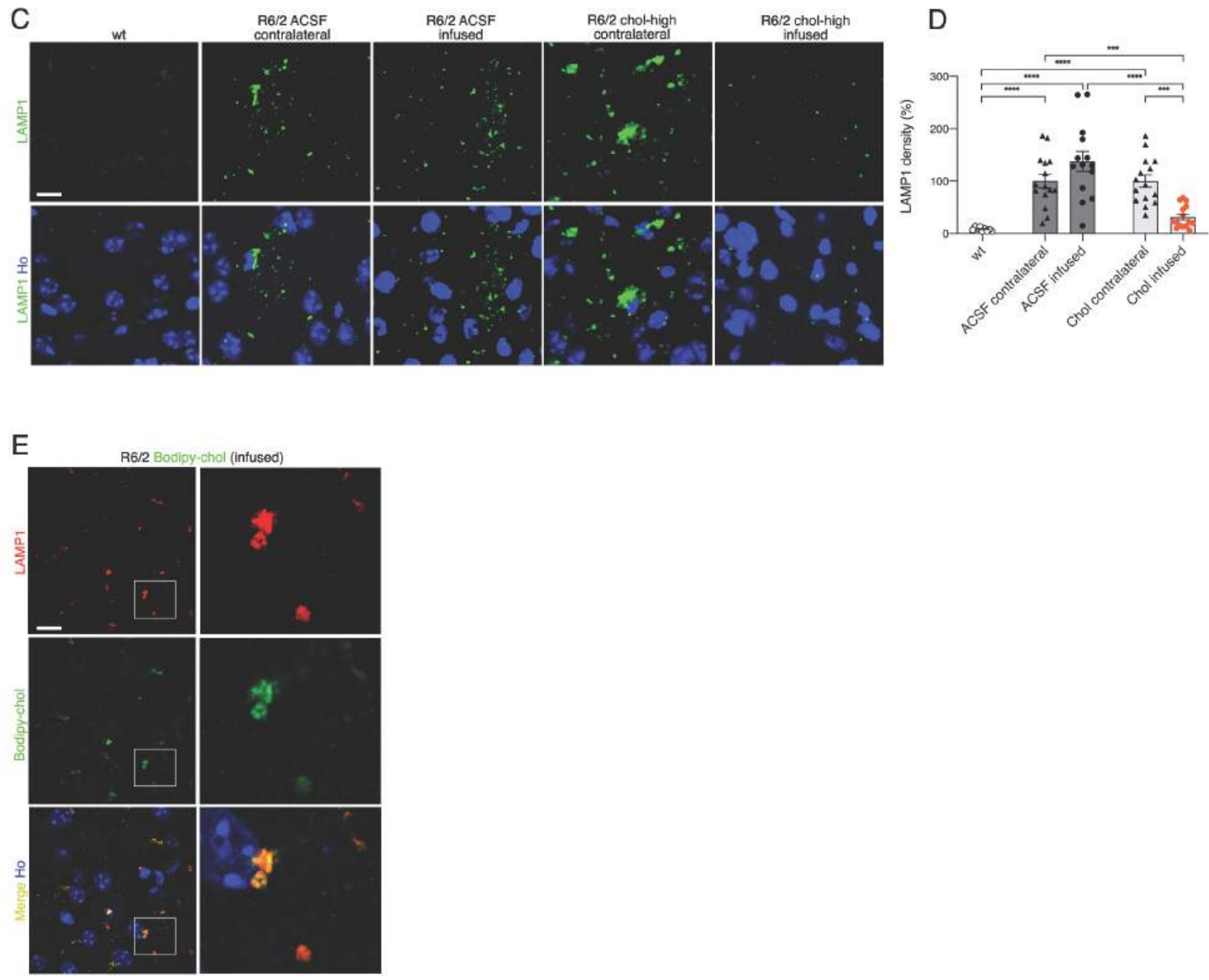


\section{Figure captions}

Fig. 1 Striatal infusion of three escalating doses of cholesterol ameliorates cognitive and motor deficits in HD mice.

(A) Experimental paradigm performed in all the trials: mini-pumps were implanted in the striatum of 7-week-old mice. A battery of behavioral tests was performed before and after mini-pump implantation. In bold, a list of R6/2 phenotypes (above) and read-outs analyzed following cholesterol (chol) infusion (below). References: 1) Valenza, 2010; 2) Valenza, 2015; 3) Boussicault, 2016; 4) Mangiarini, 1996; 5) Cepeda, 2003; 6) Cepeda, 2004; 7) Valenza, 2005; 8) Bobrowska, 2012; 9) Valenza, 2007. (B) Representative large image of a brain slice from R6/2 mice after 4-week striatal infusion of fluorescent cholesterol (bodipychol, green). In the inlet, infused striatum is shown. Hoechst (Ho, blue) was used to counterstain nuclei. Scale bar: $1000 \mu \mathrm{m}$. (C) Cholesterol content measured by mass spectrometry in infused striatum of untreated wt $(\mathrm{N}=7)$ and $\mathrm{R} 6 / 2(\mathrm{~N}=4), \mathrm{R} 6 / 2$ ACSF $(\mathrm{N}=5)$, R6/2 chol-low $(\mathrm{N}=5), \mathrm{R} 6 / 2$ chol-medium $(\mathrm{N}=5)$, and $\mathrm{R} 6 / 2$ chol-high $(\mathrm{N}=5)$ mice at 12 weeks of age after 4-week striatal cholesterol infusion. The low, medium, and high doses respectively correspond to $15 \mu \mathrm{g}, 185 \mu \mathrm{g}$, and $369 \mu \mathrm{g}$ of cholesterol infused in the striatum after 4 weeks. (D) Latency to fall (seconds) from an accelerating rotarod from 5 weeks (presurgery; i.e., before pump implantation) to 10 weeks of age ( 4 weeks after infusion) in wt (N=23-28), R6/2 ACSF (N=30-35), R6/2 chol-low (N=13-22), R6/2 chol-medium ( $\mathrm{N}=8$ 12), and $\mathrm{R} 6 / 2$ chol-high $(\mathrm{N}=17-19)$ mice. The graph shows means \pm standard error for each time point. (E-I) Global motor activity (E), total distance traveled (F), mean velocity (G), stereotyped movements $(\mathrm{H})$, and number of rearings (I) in an open-field test at 6 weeks of age 
(pre-surgery) and 11 weeks of age (4 weeks after infusion) of wt (N=16-22), R6/2 $\operatorname{ACSF}(\mathrm{N}=23-27), \mathrm{R} 6 / 2$ chol-low $(\mathrm{N}=13-20)$, R6/2 chol-medium ( $\mathrm{N}=7-9)$, and $\mathrm{R} 6 / 2$ cholhigh ( $\mathrm{N}=16-18)$ mice. ( $\mathbf{L}-\mathbf{M})$ Representative track plots (L) generated from the open-field test from wt (N=16-22), R6/2 ACSF (N=23-27), R6/2 chol-low (N=13-20), R6/2 cholmedium ( $\mathrm{N}=7-9)$, and $\mathrm{R} 6 / 2$ chol-high $(\mathrm{N}=16-22)$ mice and relative quantification $(\mathrm{M})$ of the time spent in the center and in the periphery (\%) of the arena. (N) Discrimination index (DI; \%) in the novel object recognition test of wt (N=16-21), R6/2 ACSF (N=23-28), R6/2 chollow $(\mathrm{N}=13-21), \mathrm{R} 6 / 2$ chol-medium $(\mathrm{N}=7-10)$, and $\mathrm{R} 6 / 2$ chol-high $(\mathrm{N}=16-18)$ mice at 6 weeks of age (before pump implantation) and 11 weeks of age ( 4 weeks after cholesterol infusion). DI above zero indicates a preference for the novel object; DI below zero indicates a preference for the familiar object. (O) Principal component analysis by combining all the values related to motor and cognitive tasks from wt mice (blue dots), R6/2 ACSF mice (green dots), and R6/2 chol-high mice (red dots). The data in $\mathrm{C}-\mathrm{N}$ are from five independent trials and shown as scatterplot graphs with means \pm standard error. Each dot (E-I) corresponds to the value obtained from each animal. Statistics: one-way ANOVA with Newman-Keuls post-hoc test $(* \mathrm{p}<0.05 ; * * \mathrm{p}<0.01 ; * * * \mathrm{p}<0.001)$

Fig. 2 Striatal infusion of the high dose of cholesterol partially rescues synaptic activity and ultrastructure of excitatory synapses in HD MSNs.

(A) Schematic representation of the electrophysiological parameters analyzed in the infused striatum of 12-week-old mice following 4 weeks of striatal infusion of cholesterol. (B) Spontaneous EPSCs were recorded from striatal MSNs (wt=6; R6/2 ACSF=5; R6/2 cholhigh=5) at a holding potential of $-70 \mathrm{mV}$. (C-D) Average amplitude (B) and average 
frequency (C) of EPSCs from wt, R6/2 ACSF, and R6/2 chol-high MSNs. The data are shown in $\mathrm{C}$ and $\mathrm{D}$ as scatterplot graphs with means \pm standard error. Each dot corresponds to the value from each cell recorded. (E-G) Number of excitatory synapses per volume of striatum by using FIB/SEM followed by $3 \mathrm{D}$ reconstruction. (E-F) Representative FIB-SEM segmentation and reconstruction of excitatory synapses (yellow) in 400 serial sections of striatum for a total volume of $500 \mu \mathrm{m}^{3}$, of wt, R6/2, R6/2 ACSF, and R6/2 chol-high mice. (G) Density of excitatory synapses in at least $1500 \mu \mathrm{m}^{3}$ of striatal tissue from wt, R6/2, R6/2 ACSF, and R6/2 chol-high mice ( $\mathrm{N}=3$ animals/group). (H-I) TEM images $(\mathrm{H})$ and 2D profile (I) of pre-synaptic terminal sections contain SVs and mitochondria (m). Docked vesicles are indicated by a white arrowhead (H) and black circle (I) and are defined as a vesicle with its center located within $20 \mathrm{~nm}$ from the presynaptic membrane. (L-M) Quantification showing the total SVs $/ \mu \mathrm{m}^{2}(\mathrm{~L})$ and the docked SVs/ $\mu \mathrm{m}(\mathrm{M})$ in R6/2, R6/2 ACSF, and wt striatal synapses ( $\mathrm{N}=3$ animals/group). $\mathrm{N}=60$ excitatory synapses/group were counted. Scale bar in $\mathrm{H}$, I: $100 \mathrm{~nm}$. The data in C, D, G, L, and $\mathrm{M}$ are shown as scatterplot graphs with means \pm standard error. Each dot corresponds to the value of each cell recorded $(C$ and $D)$, the number of synapses counted $/ \mu \mathrm{m}^{3}$ in different blocks of striatal tissue $(\mathrm{G})$, and the number of total SVs $/ \mu \mathrm{m}^{2}(\mathrm{~L})$ and docked SVs/ $\mu \mathrm{m}$ of active zone $(\mathrm{M})$ counted in each synapse. Statistics: one-way ANOVA with Newman-Keuls post-hoc test $\left({ }^{*} \mathrm{p}<0.05 ;{ }^{*} \mathrm{p}<0.01 ;{ }^{*} * \mathrm{p}<0.001\right)$.

Fig. 3 Striatal infusion of the high dose of cholesterol rescues synaptic activity and ultrastructure of inhibitory synapses in MSNs of HD mice.

(A) Spontaneous IPSCs were recorded from striatal MSNs (wt=6; R6/2 ACSF=5; R6/2 cholhigh=5) at a holding potential of $0 \mathrm{mV}$. (B-C) Average amplitude (B) and average frequency 
(C) of IPSCs from wt, R6/2 ACSF, and R6/2 chol-high MSNs. The scatterplot graphs in B and $\mathrm{C}$ represent the means \pm standard error, and each dot corresponds to the value from each cell recorded. (D-E) Evaluation of the number of inhibitory synapses per volume of striatum by using FIB/SEM followed by 3D reconstruction. (D) Representative FIB-SEM segmentation and reconstruction of inhibitory synapses (green) in 200 serial sections of striatum for a total volume of $500 \mu \mathrm{m}^{3}$ in wt, R6/2, R6/2 ACSF, and R6/2 chol-high mice. (E) Density of inhibitory synapses in at least $2000 \mu \mathrm{m}^{3}$ of striatal tissue of wt, R6/2, R6/2 ACSF, and $\mathrm{R} 6 / 2$ chol-high mice ( $\mathrm{N}=3$ mice/ group). The data in $\mathrm{B}, \mathrm{C}$, and $\mathrm{E}$ are shown as scatterplot graphs with means \pm standard error. Each dot corresponds to the value of each cell recorded $(B, C)$ and to the number of synapses counted $/ \mu \mathrm{m}^{3}$ in different blocks of tissue for each group of animals ( $\mathrm{N}=3$ animals/group) (E). Statistics: one-way ANOVA with Newman-Keuls post-hoc test $\left({ }^{*} \mathrm{p}<0.05 ; * * \mathrm{p}<0.01 ; * * * \mathrm{p}<0.001\right)$.

Fig. 4 Striatal infusion of the high dose of cholesterol increases endogenous cholesterol catabolism and synthesis in the striatum of HD mice.

(A) Schematic pathway of cholesterol synthesis and cholesterol precursors and catabolites in the brain. Green arrows indicate enzymes with downregulated mRNA in HD, and red arrows indicate cholesterol precursors or metabolites that were decreased per ID-MS; SREBP2dependent genes are in bold. Here, lanosterol, 7-lathosterol, desmosterol, and 24S-OHC (highlighted in the boxes) were measured by ID-MS. References: 1) Bobrowska, 2012; 2) Lee, 2014; 3) Valenza, 2005; 4) Samara, 2014; 5) Boussicault, 2016; 6) Kacher, 2019; 7) Valenza, 2007a; 8) Valenza, 2007b; 9) Shankaran, 2017; 10) Valenza, 2010; 11) Valenza, 2015. (B) 24S-OHC level measured by mass spectrometry in the infused and contralateral 
striatum of wt, R6/2-ACSF, and R6/2 chol-high mice at 12 weeks of age after a 4-week striatal infusion of cholesterol ( $\mathrm{N}=4$ /group). (C-E) Lanosterol (C), lathosterol (D), and desmosterol (E) level measured by mass spectrometry in the infused and contralateral striatum of wt, R6/2 ACSF, and R6/2 chol-high mice at 12 weeks of age after 4-week striatal infusion of cholesterol ( $\mathrm{N}=4$ /group). All values in $\mathrm{B}-\mathrm{E}$ are expressed as \% above the mean of wt, and these data are shown as scatterplots with means \pm standard error. Each dot corresponds to the value obtained from each animal. (F-I) Nuclear localization of endogenous SREBP2 in the striatum of HD mice. Representative confocal image (F) and relative quantification (G) of SREBP2 (red) in the infused and contralateral striatum of $\mathrm{R} 6 / 2$ chol-high mice $(\mathrm{N}=4)$. Hoechst (Ho, blue) was used to counterstain nuclei. Scale bar in F: $10 \mu \mathrm{m}$. Graph in G represents the intensity of SREBP2 normalized on nuclei (\%). Statistics: Student's t-test $\left({ }^{*} \mathrm{p}<0.05 ; * * \mathrm{p}<0.01 ; * * * \mathrm{p}<0.001\right)$. Representative high-magnification confocal images of immunostaining against SREBP2 (red) and NeuN (H) or DARPP32 (I) (green) on coronal sections of brains from R6/2 chol-high mice. A cell in the infused striatum, positive for DARPP32 and GFAP respectively, is shown. Hoechst (Ho, blue) was used to counterstain nuclei. Scale bars in $\mathrm{H}$ and I: $2 \mu \mathrm{m}$.

Fig. 5 Striatal infusion of the high dose of cholesterol rescues muHTT aggregation in the striatum of HD mice.

(A-G) Immunolabeling of muHTT aggregates (red) in R6/2 ACSF and R6/2 chol-high mice ( $\mathrm{N}=3$ /group). Zoom of representative confocal images of immunostaining against muHTT aggregates (red) showing muHTT aggregates positive for EM48 antibody in the infused and contralateral striatum (A) and relative quantification of number (B) and size (C) of 
aggregates. Hoechst (Ho, blue) was used to counterstain nuclei. 18 images/animal were analyzed from 9 sections throughout the entire striatum. Representative confocal images of immunostaining against muHTT (red) and DARPP32 (D) or GFAP (F) (green) showing muHTT aggregates positive for EM48 antibody in the infused striatum in neurons or astrocytes and relative quantification $(\mathrm{E}-\mathrm{G})$. Hoechst (Ho, blue) was used to counterstain nuclei. All values are expressed as \% above the mean of aggregates in the contralateral striatum of R6/2 ACSF or of R6/2 chol-high. The data in B, C, E, and G are shown as scatterplots with means \pm standard error. Each dot corresponds to aggregates counted in all the images from 3 animals. Scale bars: $10 \mu \mathrm{m}$ (A) and $5 \mu \mathrm{m}$ (D, F). Statistics: one-way ANOVA followed by Newman-Keuls multiple comparison tests $\left({ }^{*} \mathrm{p}<0.05 ;{ }^{*} \mathrm{p}<0.01 ; * * * \mathrm{p}<0.001\right)$. (H) EM48 pre-embedding immunogold labeling showing muHTT aggregates in the striatal neuropil of R6/2 ACSF mice and R6/2 chol-high mice treated with ACSF and $500 \mu \mathrm{g}$ of cholesterol. Arrows indicate large muHTT aggregates with a fibrous structure in the nucleus, and arrowheads indicate single 10-nm gold particles in MSN. Nucleus (N), nucleolus (n), mitochondrion (m), rough endoplasmic reticulum (rer), Golgi apparatus (g), and white arrows indicate the nuclear envelope ( $\mathrm{N}=3$ animals/group). Scale bars: $700 \mathrm{~nm}$ and $300 \mathrm{~nm}$. (I-O) Quantification of aggregated and total muHTT in the infused striatum of HD mice after 4week cholesterol infusion by TR-FRET analysis using different antibody pairs. Schematic representation of employed TR-FRET assay (I). Preliminary assessment of the sustainability of the assay in wt and $\mathrm{R} 6 / 2$ striata (N=5/group) using 4C9-4C9 and 2B7-MW1 antibodies in combination to detect, respectively, muHTT aggregates (L) and total muHTT (M). Quantification of muHTT aggregates $(\mathrm{N})$ and total muHTT $(\mathrm{O})$ in the infused striata of R6/2 ACSF and R6/2 chol-high mice. Data in $\mathrm{N}$ and $\mathrm{O}$ are shown as scatterplots with 
means \pm standard error. Each dot corresponds to the value obtained from one striatum. Statistics: student's t-test $(* \mathrm{p}<0.05)$.

Fig. 6 Striatal infusion of the high dose of cholesterol promotes lysosomal clearance and autophagy in the striatum of HD mice.

(A-D) Representative confocal images showing p62 (A, red) or LAMP1 (C, green) in the infused and contralateral striatum on brain coronal sections from wt, R6/2 ACSF, and R6/2 chol-high mice ( $\mathrm{N}=3$ /group). Hoechst (Ho, blue) was used to counterstain nuclei. Quantification of dots for p62 (B) and density for LAMP1 (D) in the contralateral and infused striatum of R6/2 ACSF and R6/2 chol-high mice. 20 images from 3 sections in the middle of the striatum for each animal were acquired and analyzed. The data in B and D are shown as scatterplots with means \pm standard error, and each dot corresponds to the value obtained from each image. Statistics: one-way ANOVA followed by Newman-Keuls multiple comparison tests $(* \mathrm{p}<0.05 ; * * \mathrm{p}<0.01 ; * * * \mathrm{p}<0.001)$. (E) Representative confocal images showing colocalization of LAMP1 (red) and bodipy-chol (green) in the striatum of R6/2 mice infused with bodipy-cholesterol. Scale bars in A, C, E: $10 \mu \mathrm{m}$. 


\section{Supplementary Figure 1}

bioRxiv preprint doi: https://doi.org/10.1101/2020.05.13.092742; this version posted May 15, 2020. The copyright holder for this preprint (which was not certified by peer review) is the author/funder, who has granted bioRxiv a license to display the preprint in perpetuity. It is made

A

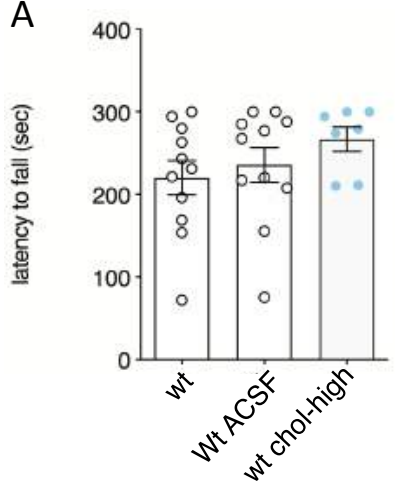

D

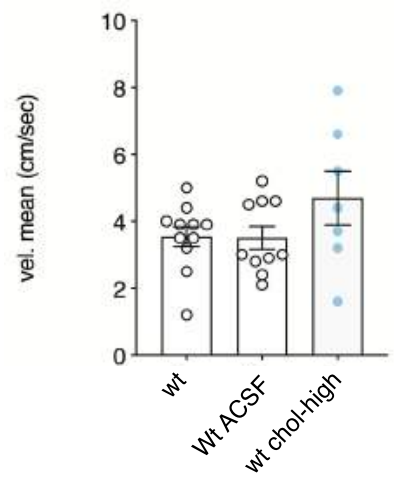

B

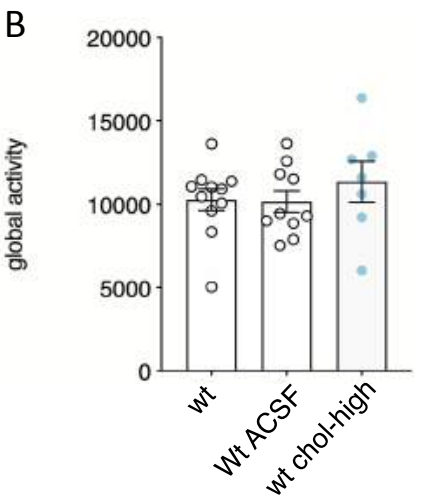

E

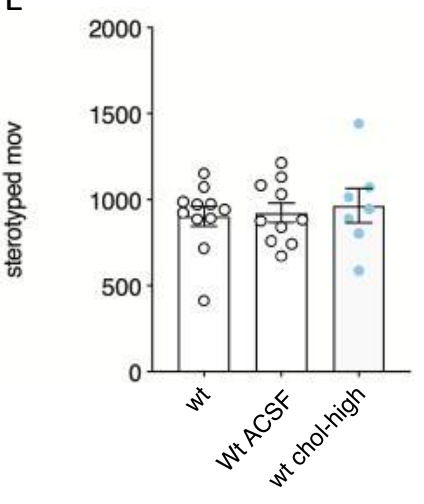

H $\begin{gathered}\text { wt cortex } \\ \text { (ipsilateral) }\end{gathered}$

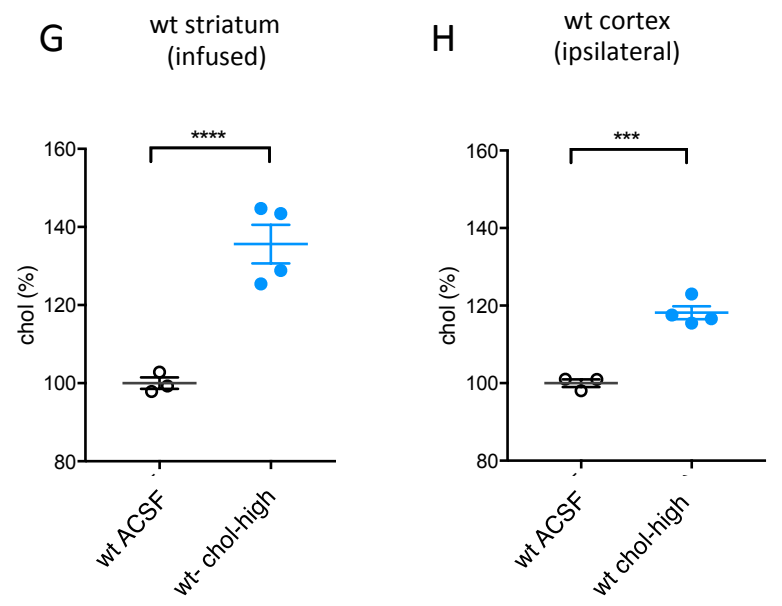

C

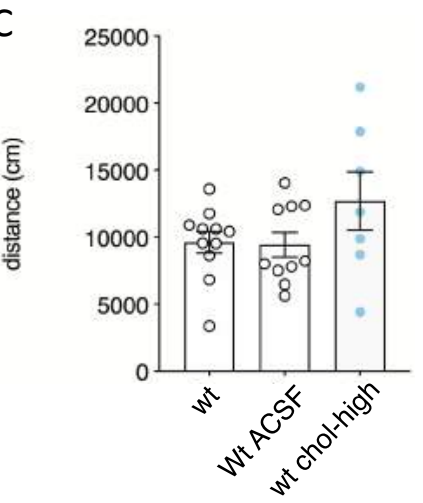

$\mathrm{F}$

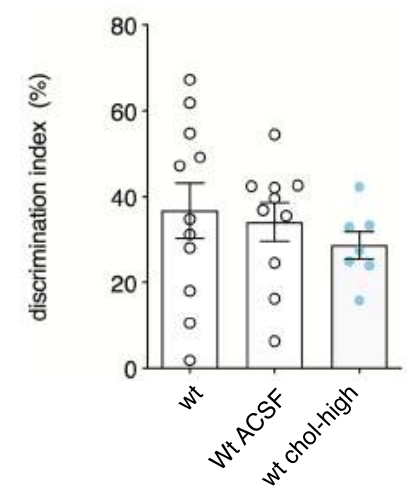




\section{Supplementary Figure 2}

bioRxiv preprint doi: https://doi.org/10.1101/2020.05.13.092742; this version posted May 15, 2020. The copyright holder for this preprint (which was not certified by peer review) is the author/funder, who has granted bioRxiv a license to display the preprint in perpetuity. It is made

A

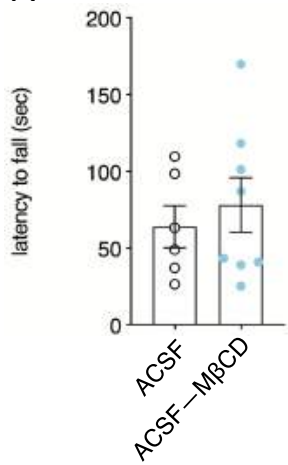

D

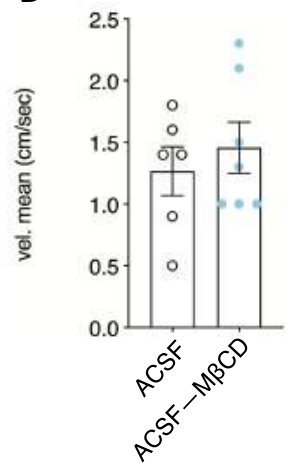

B

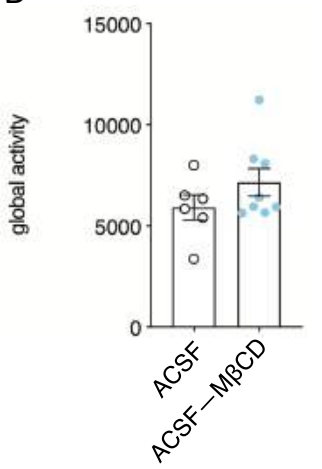

E

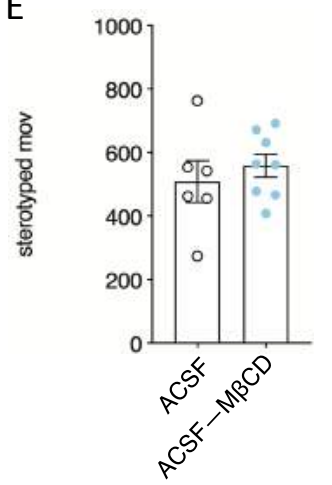

C

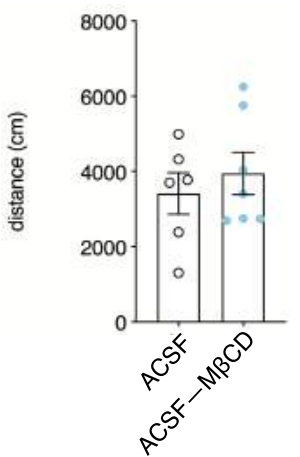

$\mathrm{F}$

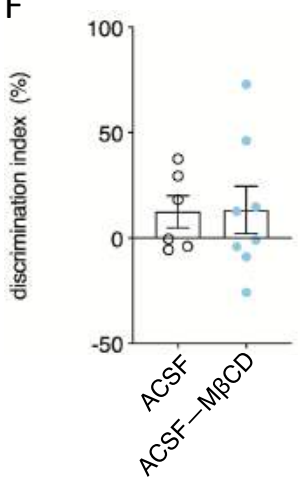




\section{Supplementary Figure 3}

bioRxiv preprint doi: https://doi.org/10.1101/2020.05.13.092742; this version posted May 15, 2020. The copyright holder for this preprint (which was not certified by peer review) is the author/funder, who has granted bioRxiv a license to display the preprint in perpetuity. It is made

A R6/2 cortex

(ipsilateral)

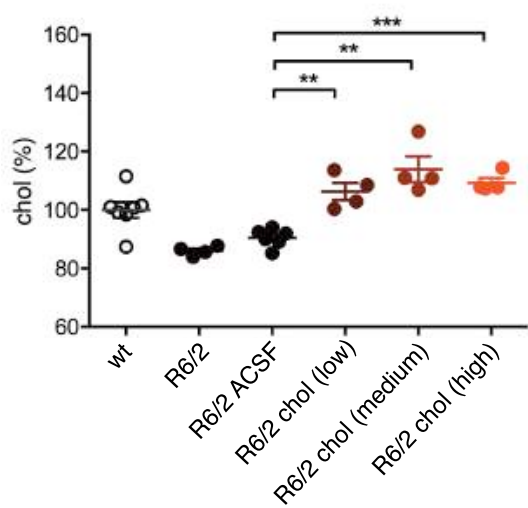

B

$\mathrm{R} 6 / 2$ striatum

(contralateral hemisphere)

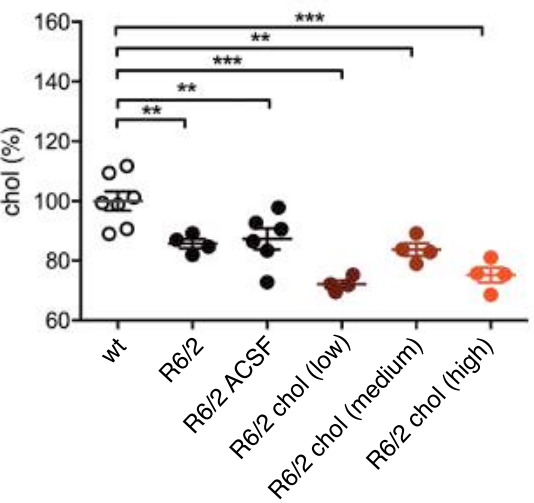

C

R6/2 cortex

(contralateral hemisphere)

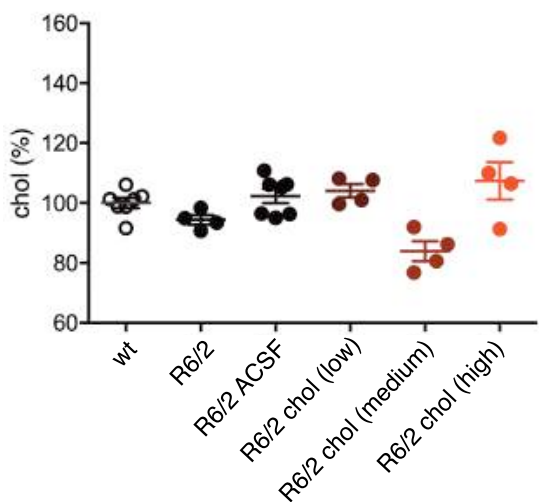




\section{Supplementary Figure 4}

bioRxiv preprint doi: https://doi.org/10.1101/2020.05.13.092742; this version posted May 15, 2020. The copyright holder for this preprint (which was not certified by peer review) is the author/funder, who has granted bioRxiv a license to display the preprint in perpetuity. It is made

A

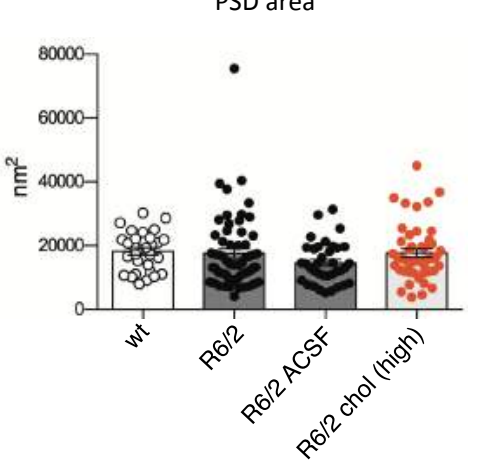

B

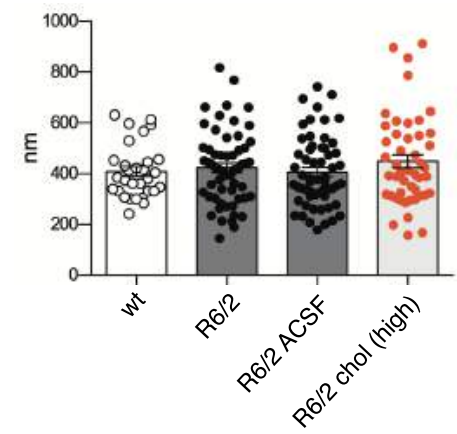




\section{Supplementary Figure 5}

bioRxiv preprint doi: https://doi.org/10.1101/2020.05.13.092742; this version posted May 15, 2020. The copyright holder for this preprint (which was not certified by peer review) is the author/funder, who has granted bioRxiv a license to display the preprint in perpetuity. It is made available under aCC-BY-NC-ND 4.0 International license.

A

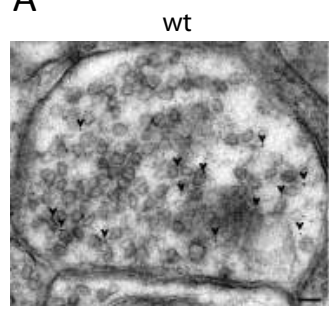

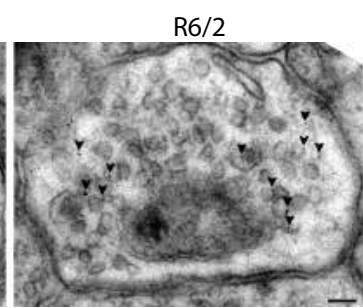

B

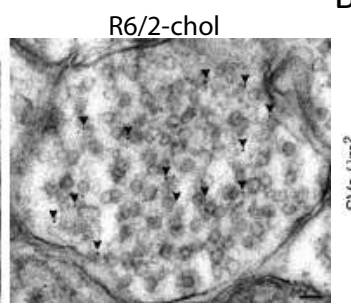

Synaptic vesicles

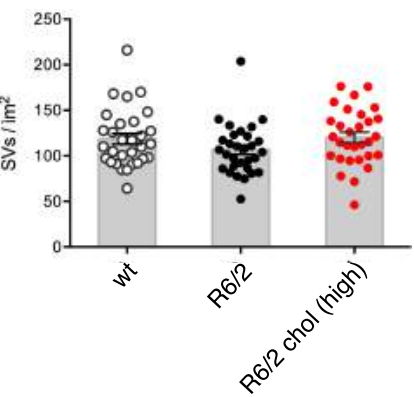




\section{Supplementary Figure 6}

bioRxiv preprint doi: https://doi.org/10.1101/2020.05.13.092742; this version posted May 15, 2020. The copyright holder for this preprint (which was not certified by peer review) is the author/funder, who has granted bioRxiv a license to display the preprint in perpetuity. It is made

A striatum available undeBaCC-BY-NC-ND 4.0 International license.
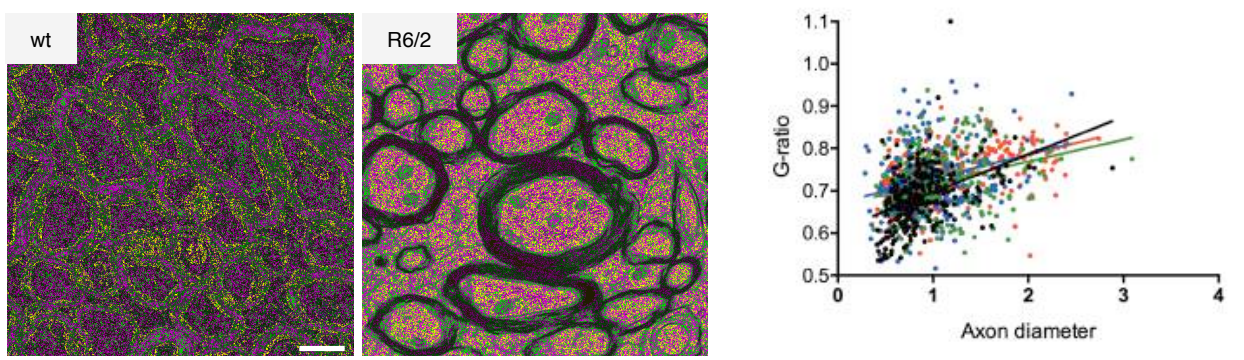

$-\mathrm{wt}$
$-\mathrm{R} 6 / 2$

- R6/2 ACSF

__R6/2 chol-high
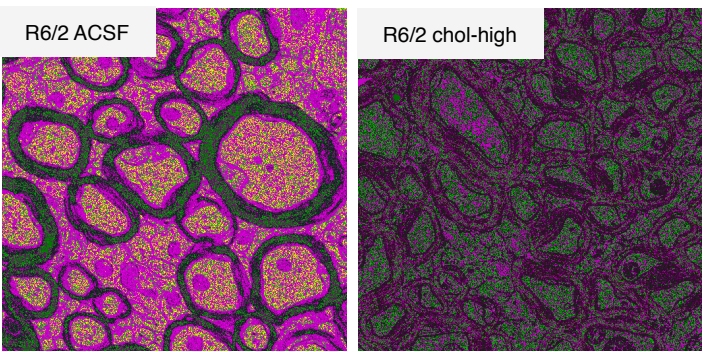

D
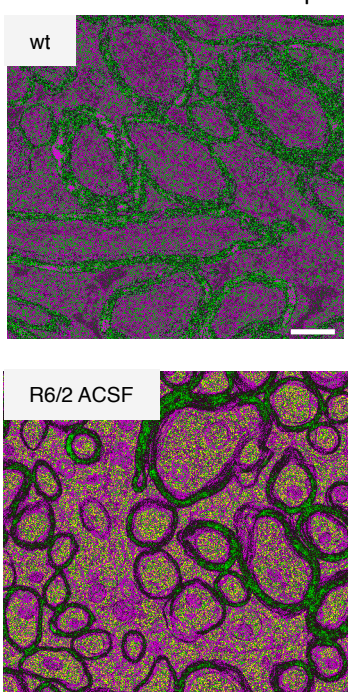

Corpus callosum
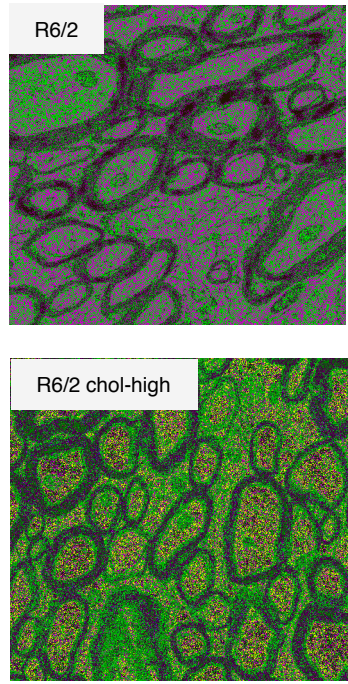

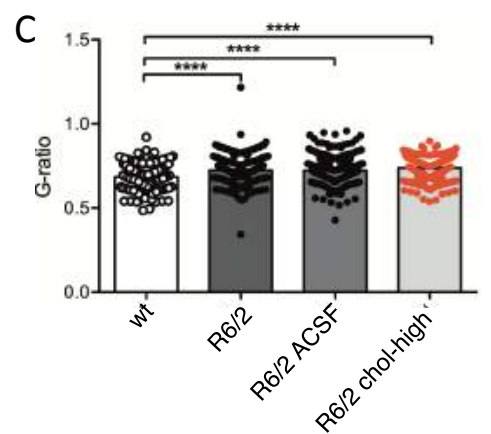

$\mathrm{E}$

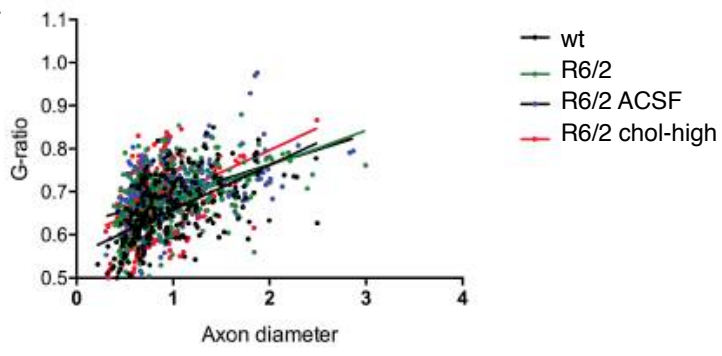

G

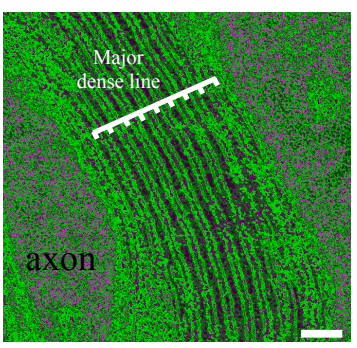

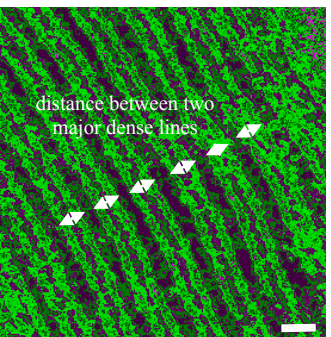

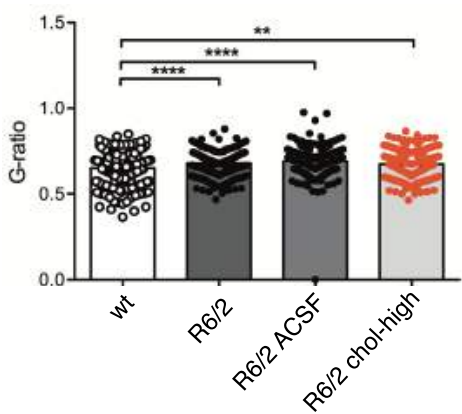

$\mathrm{H}$

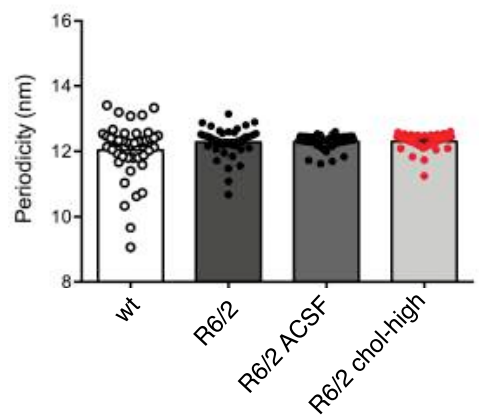

Corpus Callosum

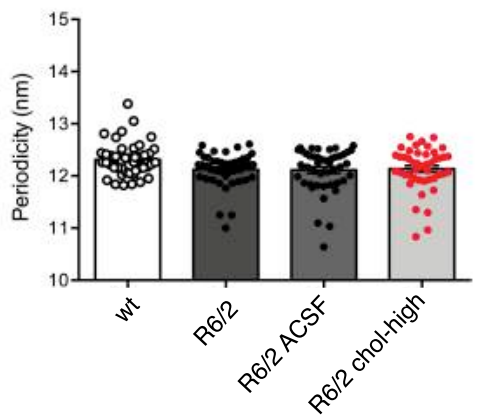




\section{Supplementary Figure 7}

bioRxiv preprint doi: https://doi.org/10.1101/2020.05.13.092742; this version posted May 15, 2020. The copyright holder for this preprint (which was not certified by peer review) is the author/funder, who has granted bioRxiv a license to display the preprint in perpetuity. It is made available under aCC-BY-NC-ND 4.0 International license.

A

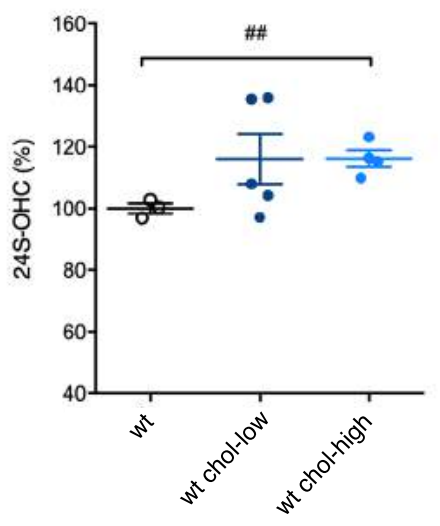

C

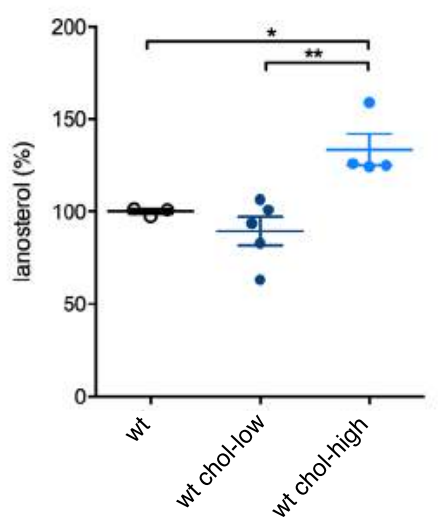

$\mathrm{E}$

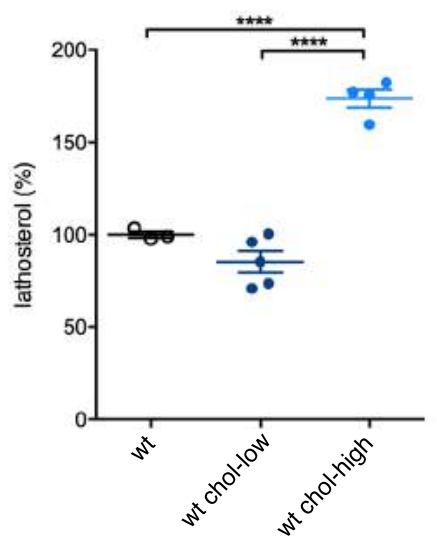

G

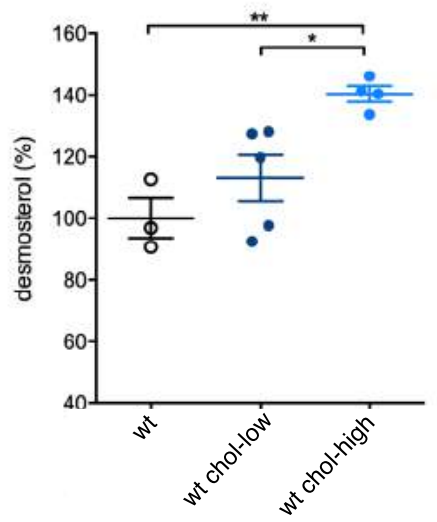

B

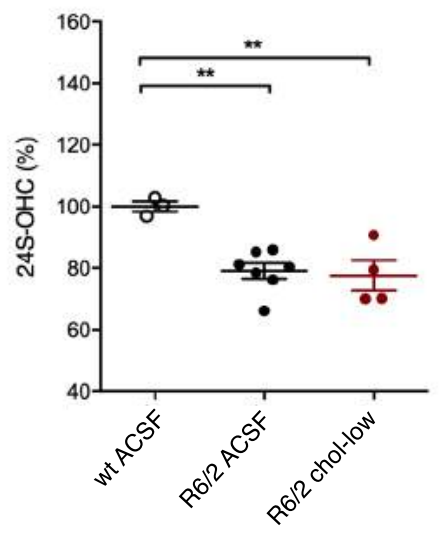

D

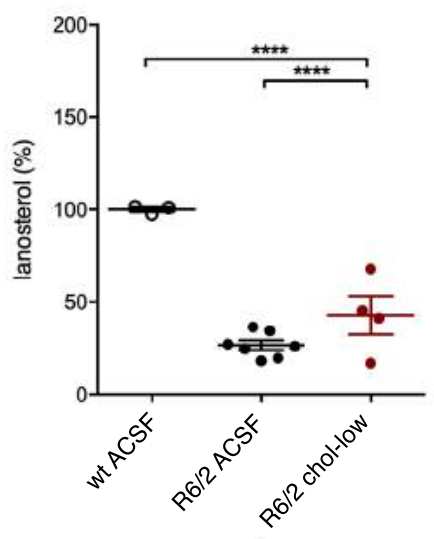

F

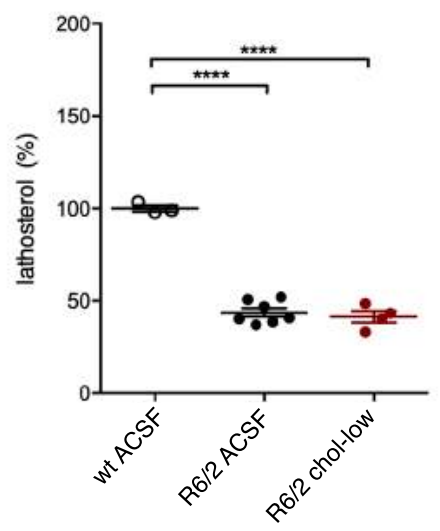

$\mathrm{H}$

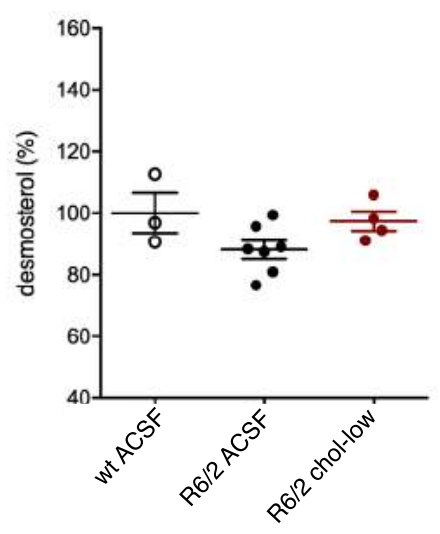




\section{Supplementary Figure 8}

bioRxiv preprint doi: https://doi.org/10.1101/2020.05.13.092742; this version posted May 15, 2020. The copyright holder for this preprint (which was not certified by peer review) is the author/funder, who has granted bioRxiv a license to display the preprint in perpetuity. It is made available under aCC-BY-NC-ND 4.0 International license.
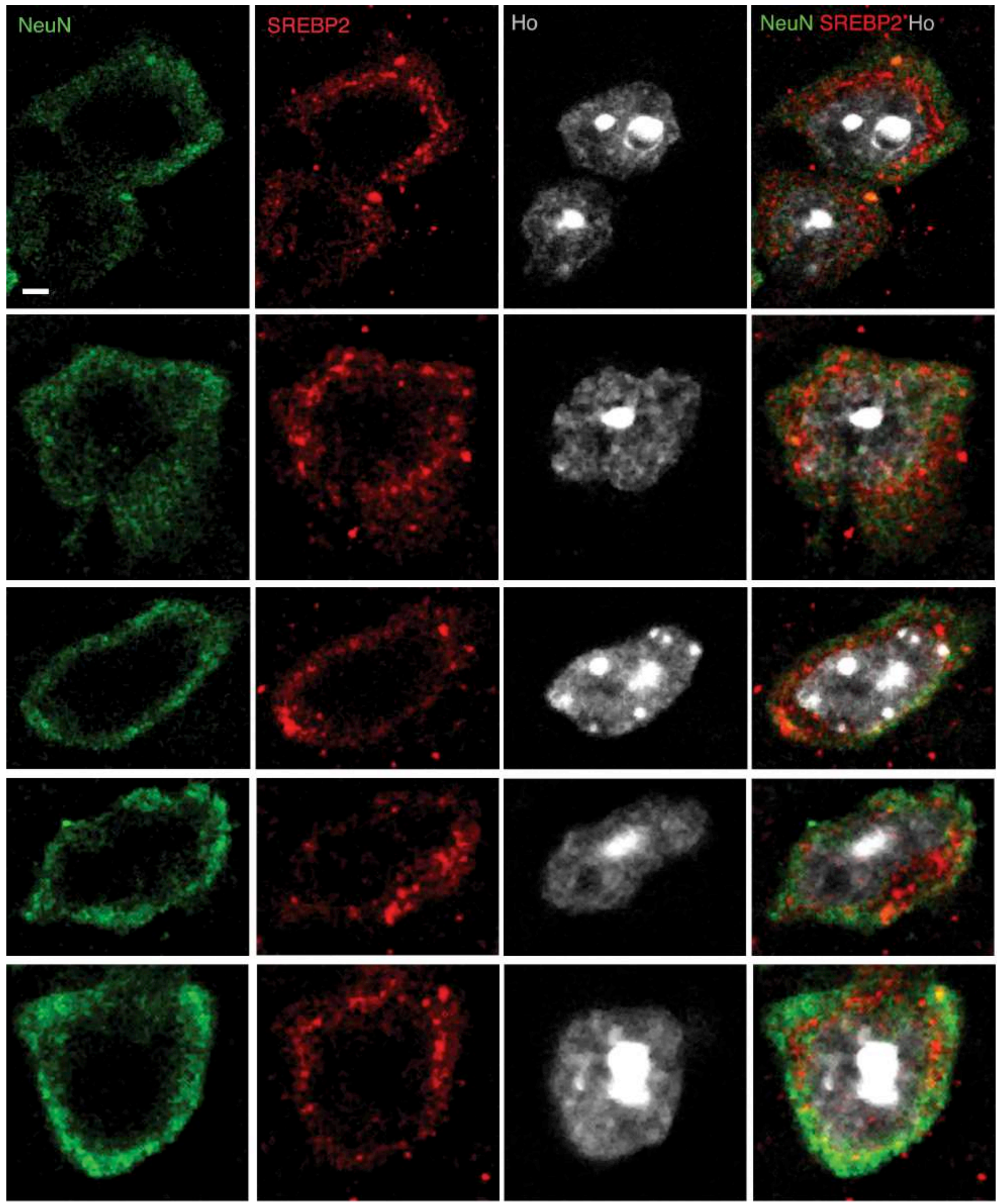


\section{Supplementary Figure 9}

bioRxiv preprint doi: https://doi.org/10.1101/2020.05.13.092742; this version posted May 15, 2020. The copyright holder for this preprint (which was not certified by peer review) is the author/funder, who has granted bioRxiv a license to display the preprint in perpetuity. It is made available under aCC-BY-NC-ND 4.0 International license.

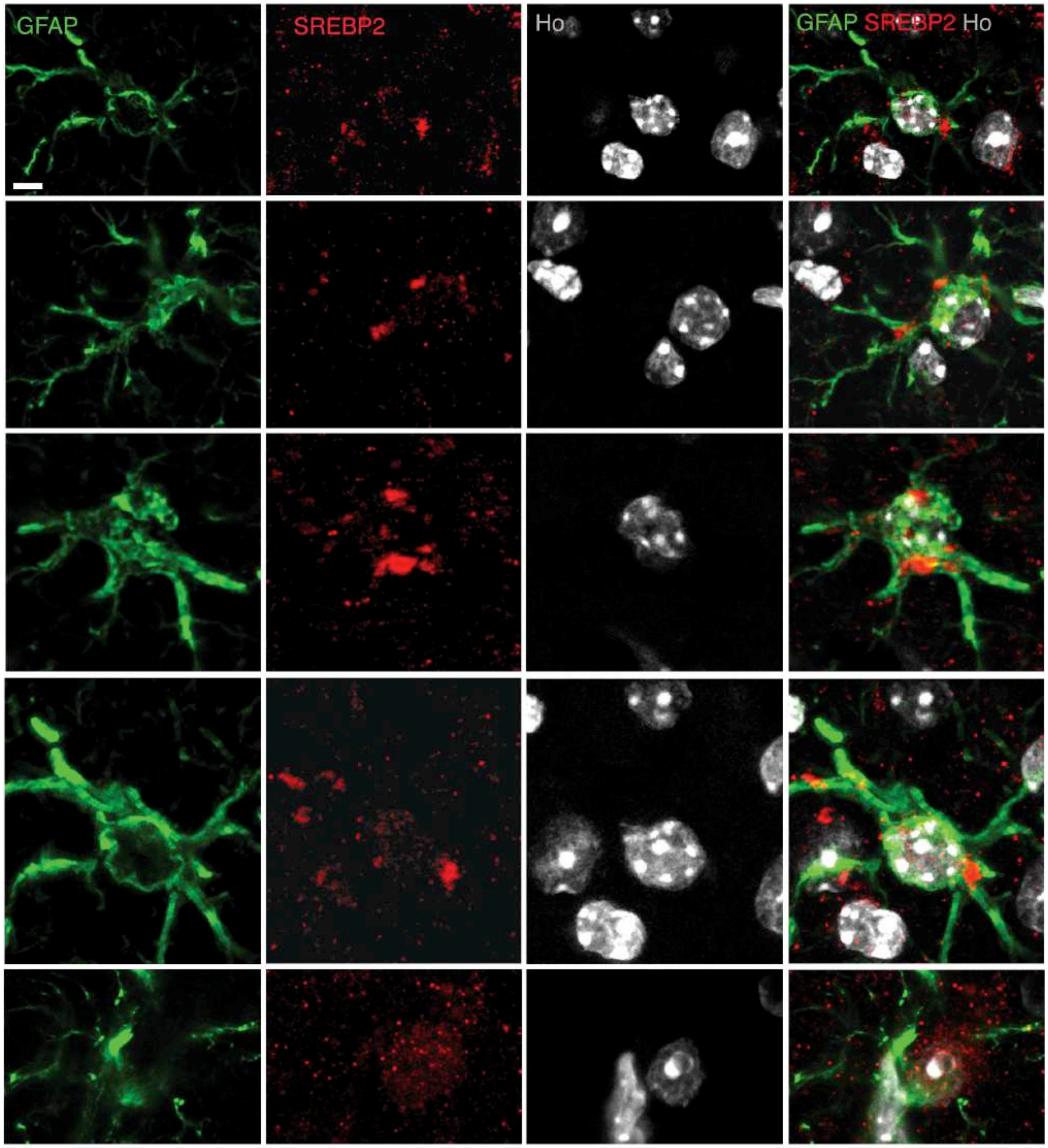




\section{Supplementary Figure 10}

bioRxiv preprint doi: https://doi.org/10.1101/2020.05.13.092742; this version posted May 15, 2020. The copyright holder for this preprint (which

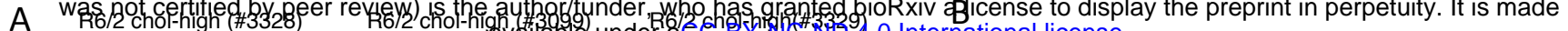
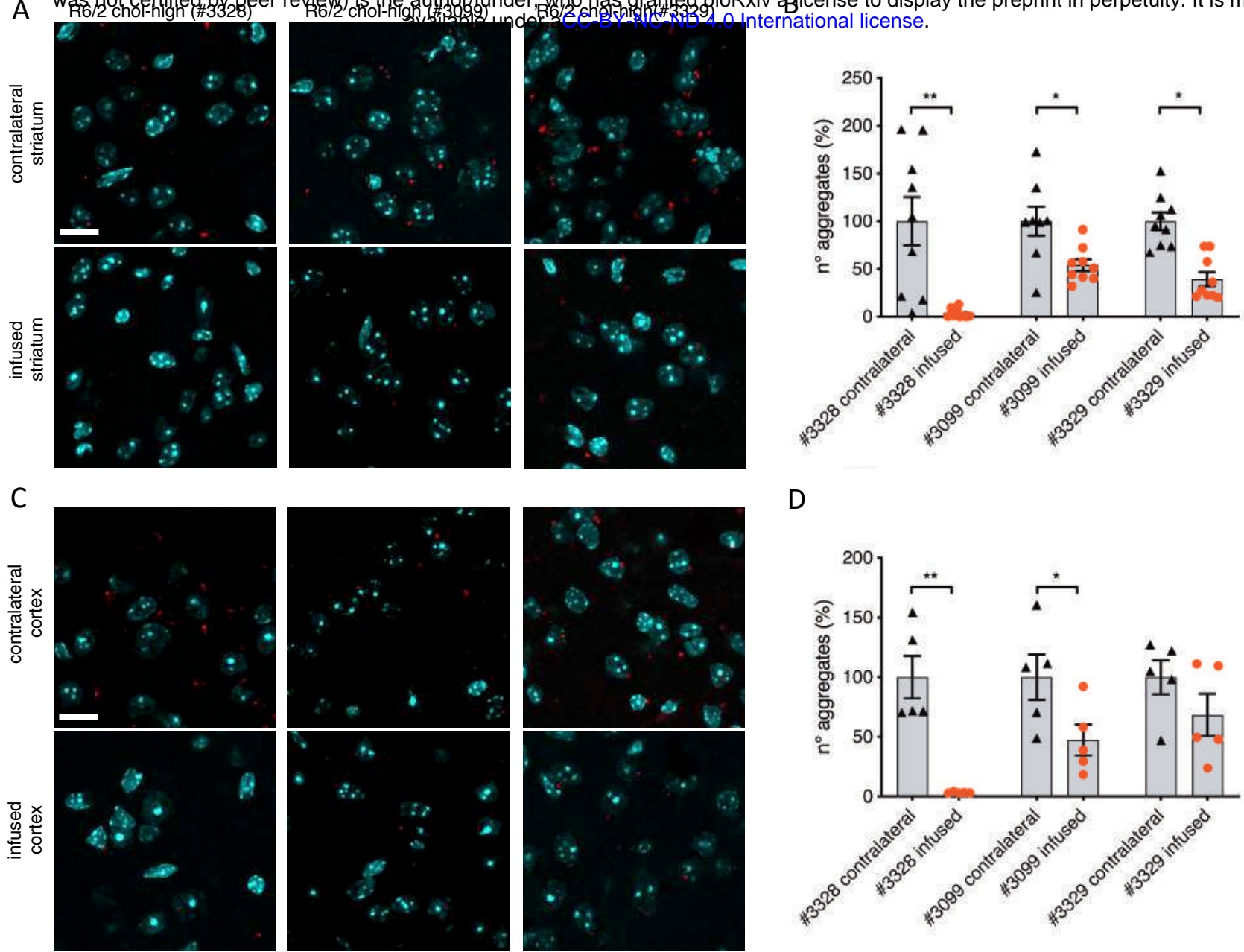

\section{D}
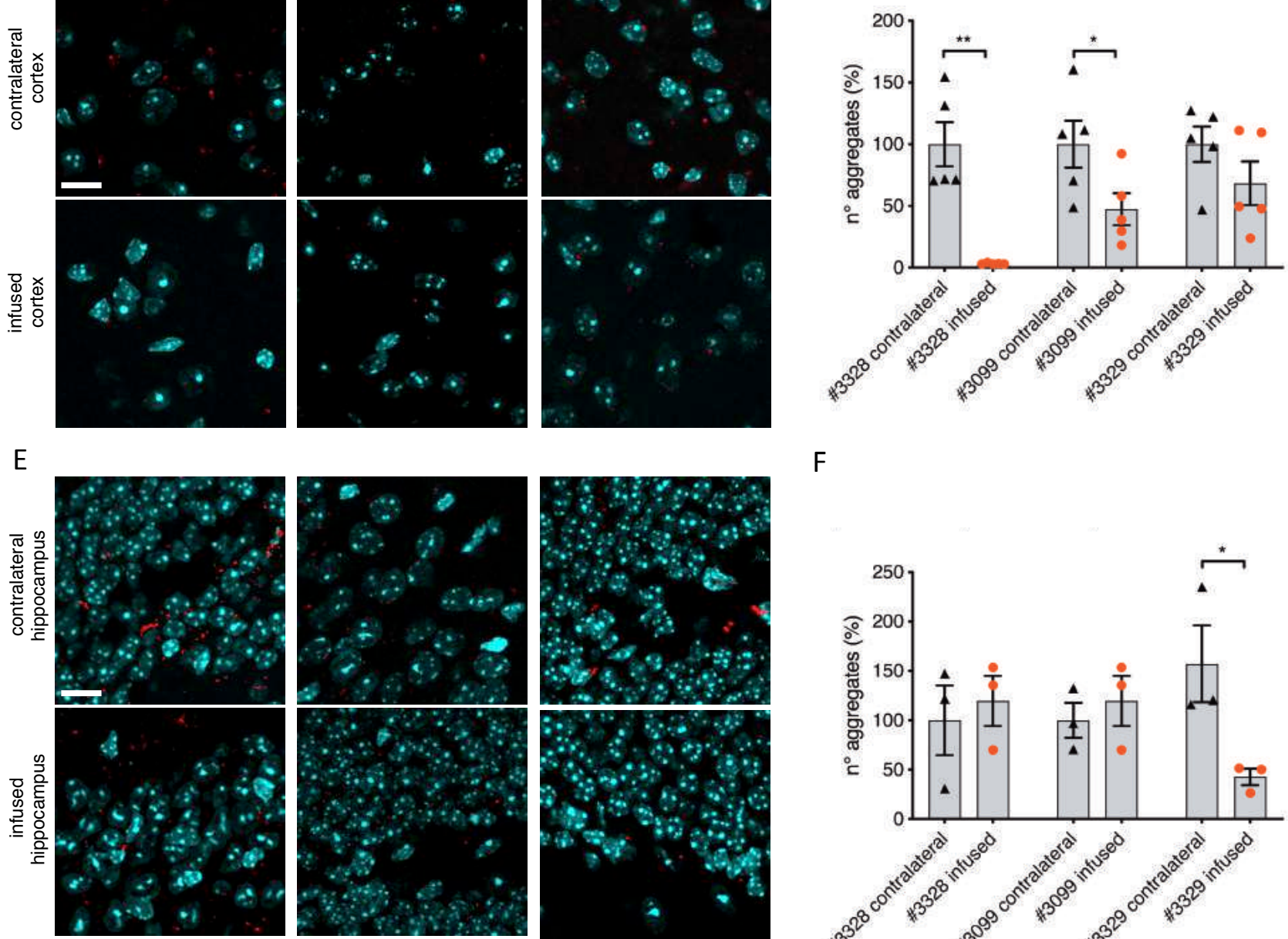

F

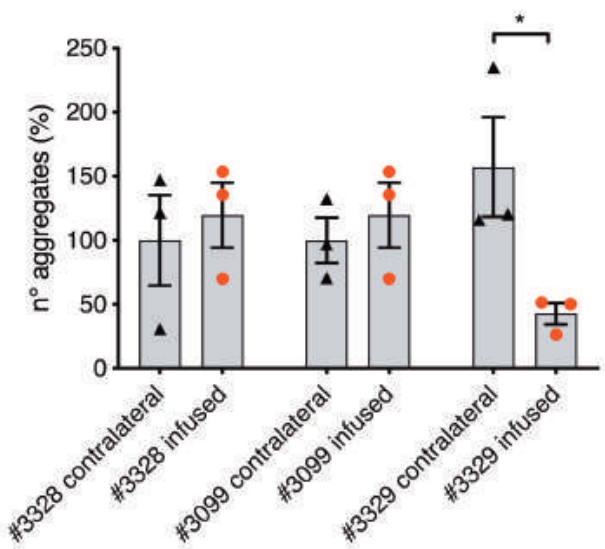


bioRxiv preprint doi: https://doi.org/10.1101/2020.05.13.092742; this version posted May 15, 2020. The copyright holder for this preprint (which was not certified by peer review) is the author/funder, who has granted bioRxiv a license to display the preprint in perpetuity. It is made

Table S1. Dose-dependent effects

\begin{tabular}{|c|c|c|c|}
\hline & R6/2-chol (low) & R6/2-chol (medium) & R6/2-chol (high) \\
\hline \multicolumn{4}{|l|}{ Global Activity } \\
\hline Number of values & 13 & 7 & 16 \\
\hline Mean & 5389 & 6915 & 9921 \\
\hline Std. Error of Mean & 1081 & 582,4 & 958,5 \\
\hline \multicolumn{4}{|l|}{ Distance } \\
\hline Number of values & 12 & 7 & 16 \\
\hline Mean & 3326 & 4753 & 7424 \\
\hline Std. Error of Mean & 1107 & 564,3 & 1132 \\
\hline \multicolumn{4}{|l|}{ Vel. Mean (cm/sec) } \\
\hline Number of values & 12 & 7 & 16 \\
\hline Mean & 0,8167 & 1,771 & 2,013 \\
\hline Std. Error of Mean & 0,2092 & 0,2157 & 0,3271 \\
\hline \multicolumn{4}{|l|}{ Sterotyped mov } \\
\hline Number of values & 12 & 7 & 16 \\
\hline Mean & 418,3 & 552,4 & 767,2 \\
\hline Std. Error of Mean & 62,08 & 63,33 & 62,15 \\
\hline \multicolumn{4}{|l|}{$\mathrm{N}^{\circ}$ rearings } \\
\hline Number of values & 12 & 7 & 16 \\
\hline Mean & 186,3 & 214,1 & 276,4 \\
\hline Std. Error of Mean & 63,41 & 43,93 & 52,78 \\
\hline
\end{tabular}


bioRxiv preprint doi: https://doi.org/10.1101/2020.05.13.092742; this version posted May 15, 2020. The copyright holder for this preprint (which was not certified by peer review) is the author/funder, who has granted bioRxiv a license to display the preprint in perpetuity. It is made Table S2. Passive properties of MSWjable under aCC-BY-NC-ND 4.0 International license.

\begin{tabular}{|l|l|l|}
\hline & Cm (pF) \pm SEM & Rin (M $\mathbf{2}) \pm$ SEM \\
\hline Wt (N = 6) & $68,53 \pm 5,72$ & $119,96 \pm 9,88$ \\
\hline R6/2-ACSF (N = 5) & $51,47 \pm 3,75^{*}$ & $181,05 \pm 20,94^{*}$ \\
\hline R6/2-Chol (N = 7) & $54,13 \pm 8,87$ & $170,48 \pm 15,48^{\S}$ \\
\hline
\end{tabular}

*wt vs R6/2-ACSF (unpaired two-tailed Student's t-test; $\mathrm{p}<0.05$ )

${ }^{\S}$ wt vs R6/2-Chol (unpaired two-tailed Student's t-test; $p<0.05$ ) 
bioRxiv preprint doi: https://doi.org/10.1101/2020.05.13.092742; this version posted May 15, 2020. The copyright holder for this preprint (which was not certified by peer review) is the author/funder, who has granted bioRxiv a license to display the preprint in perpetuity. It is made

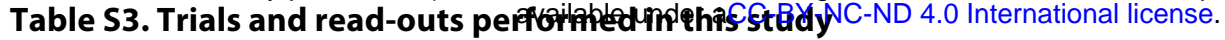

\begin{tabular}{|c|c|c|c|c|c|c|c|c|}
\hline$N^{\circ}$ Trial & Date & Experimental Groups & Behavioral Analysis & MS Analysis & Electrophysiological Analysis & EM Analysis & IHC analysis & TR-FRET Analysis \\
\hline & & & ( $\mathrm{N}$ animals $)$ & ( $\mathrm{N}$ animals) & ( $\mathrm{N}$ animals) & ( $\mathrm{N}$ animals $)$ & ( $\mathrm{N}$ animals) & ( $\mathrm{N}$ animals) \\
\hline \multirow{3}{*}{1} & \multirow{3}{*}{ February-March 2015} & wt & 11 & 2 & & & & \\
\hline & & wt-ACSF & 11 & 3 & & & & \\
\hline & & wt-chol (high) & 7 & 4 & & & & \\
\hline \multirow{3}{*}{2} & \multirow{3}{*}{ June-August 2015} & wt & 5 & & & & & 5 \\
\hline & & R6/2-ACSF & 6 & & & & & 5 \\
\hline & & R6/2-chol (high) & 5 & & & & & 5 \\
\hline \multirow{4}{*}{3} & \multirow{4}{*}{$\begin{array}{l}\text { November 2015- } \\
\text { January } 2016\end{array}$} & $\mathrm{wt}$ & 6 & 2 & & & & 4 \\
\hline & & $\mathrm{R} 6 / 2$ & 6 & & & & & 5 \\
\hline & & R6/2-ACSF & 7 & & & & & 3 \\
\hline & & R6/2-chol (low) & 9 & & & & & 5 \\
\hline \multirow{4}{*}{4} & \multirow{4}{*}{ June-July 2016} & wt & 6 & & & & & 1 \\
\hline & & R6/2-ACSF & 5 & & 5 & & & \\
\hline & & R6/2-chol (low) & 4 & & & & & \\
\hline & & $\mathrm{R} 6 / 2$-chol (high) & 4 & & 4 & & & \\
\hline \multirow{5}{*}{5} & \multirow{5}{*}{ June-July 2016} & wt & 5 & & & & & \\
\hline & & wt-chol (low) & & 5 & & & & \\
\hline & & $\mathrm{R} 6 / 2$ & 3 & & & & & \\
\hline & & R6/2-ACSF & 6 & 4 & & & & 2 \\
\hline & & R6/2-chol (high) & 7 & 2 & & & & 5 \\
\hline \multirow{5}{*}{6} & \multirow{5}{*}{ October-November 2016} & wt & 6 & 3 & & & & \\
\hline & & $\mathrm{R} 6 / 2$ & 6 & 4 & & & & \\
\hline & & R6/2-ACSF & 6 & 3 & & & & \\
\hline & & R6/2-ACSF-M $\beta C D$ & 8 & 4 & & & & \\
\hline & & R6/2-chol (medium) & 6 & 4 & & & & \\
\hline \multirow[b]{2}{*}{7} & \multirow{2}{*}{ August-September 2016} & R6/2-chol (low) & & 4 & & & & \\
\hline & & R6/2-chol (high) & & 2 & & & & \\
\hline \multirow{4}{*}{8} & \multirow{4}{*}{ February-March 2017} & $\mathrm{wt}$ & 3 & & & 3 & & \\
\hline & & $\mathrm{R} 6 / 2$ & 3 & & & 3 & & \\
\hline & & R6/2-ACSF & 6 & & & 3 & 3 & \\
\hline & & R6/2-chol (high) & 6 & & & 3 & 3 & \\
\hline
\end{tabular}


bioRxiv preprint doi: https://doi.org/10.1101/2020.05.13.092742; this version posted May 15, 2020. The copyright holder for this preprint (which was not certified by peer review) is the author/funder, who has granted bioRxiv a license to display the preprint in perpetuity. It is made Supplementary Figures Capfîtiable under aCC-BY-NC-ND 4.0 International license.

\section{Fig. S1 Behavioral characterization of wt mice following striatal infusion of the high dose} of cholesterol.

(A) Latency to fall (seconds) from an accelerating rotarod at 10 weeks of age (3-weeks after cholesterol infusion) in wt $(\mathrm{N}=11)$; wt $\operatorname{ACSF}(\mathrm{N}=11)$ and wt chol-high $(\mathrm{N}=7)$ mice. (B-E) Global motor activity (B), total distance travelled (C), mean velocity (D) and stereotyped movements $(E)$ in an open field at 11 weeks of age (4-weeks after cholesterol infusion) $(w t=11$; wt $\mathrm{ACSF}=10$; wt chol-high=7). (F) Discrimination index (\%) in the novel object recognition test of wt, wt ACSF and wt chol-high mice at 11 weeks of age (4 weeks after cholesterol infusion) ( $w t=11$; wt $\mathrm{ACSF}=10$; wt chol-high=7). DI above zero indicates a preference for the novel object; DI below zero indicates a preference for the familiar object. (G-H) Cholesterol content in the infused striatum $(\mathrm{G})$ and ipsilateral cortex $(\mathrm{H})$ of wt ACSF $(\mathrm{N}=3)$, wt chol-low $(\mathrm{N}=5)$ and wt chol-high $(\mathrm{N}=4)$ mice at 12 weeks of age after 4 week-striatal cholesterol infusion.

The data in A-H are shown as scatterplot graphs with means \pm standard error. Each dot corresponds to the value obtained from each animal. Values in A-D were normalized as \% above the mean of wt ACSF for each independent analysis. Statistics: one-way ANOVA with Newman-Keuls post-hoc test $(* \mathrm{p}<0.05 ; * * \mathrm{p}<0.01 ; * * * \mathrm{p}<0.001)$.

\section{Fig. S2 Behavioral characterization of R6/2 ACSF and R6/2 ACSF complexed with} methyl- $\beta$-cyclodextrin.

(A) Latency to fall (seconds) from an accelerating rotarod at 10 weeks of age (3 weeks after cholesterol infusion) in $\mathrm{R} 6 / 2$ ACSF $(\mathrm{N}=6)$ and $\mathrm{R} 6 / 2$ ACSF-M $\beta C D(\mathrm{~N}=8)$ mice. (B-E) Global motor activity (B), total distance travelled (C), mean velocity (D) and stereotyped movements (E) in an open field at 11 weeks of age (4 weeks after cholesterol infusion) (R6/2 ACSF=6; R6/2 ACSF- 
bioRxiv preprint doi: https://doi.org/10.1101/2020.05.13.092742; this version posted May 15, 2020. The copyright holder for this preprint (which was not certified by peer review) is the author/funder, who has granted bioRxiv a license to display the preprint in perpetuity. It is made

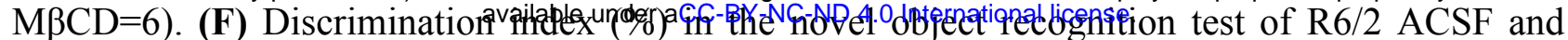

R6/2 ACSF-M $\beta C D$ mice at 11 weeks of age (4 weeks after cholesterol infusion) $(\mathrm{R} 6 / 2-\mathrm{ACSF}=6$; R6/2 ACSF-M $\beta C D=8$ ). DI above zero indicates a preference for the novel object; DI below zero indicates a preference for the familiar object. The data in A-F are shown as scatterplot graphs with means \pm standard error. Each dot corresponds to the value obtained from each animal. Statistics: oneway ANOVA with Newman-Keuls post-hoc test $\left({ }^{*} \mathrm{p}<0.05 ; * * \mathrm{p}<0.01 ; * * * \mathrm{p}<0.001\right)$.

Fig. S3 Cholesterol content in the striatum and cortex of R6/2 mice following striatal infusion of cholesterol.

(A-C) Cholesterol content in the ipsilateral cortex (A), contralateral striatum (B) and contralateral cortex (C) of wt $(N=7), R 6 / 2(N=4), R 6 / 2$ ACSF $(N=6), R 6 / 2$ chol-low $(N=4), R 6 / 2$ chol-medium $(\mathrm{N}=4)$ and $\mathrm{R} 6 / 2$ chol-high $(\mathrm{N}=4)$ mice at 12 weeks of age after 4 week-striatal cholesterol infusion. The data are shown as scatterplot graphs with means \pm standard error. Each dot corresponds to the value obtained from each animal. Statistics: one-way ANOVA with Newman-Keuls post-hoc test $\left({ }^{*} \mathrm{p}<0.05 ; * * \mathrm{p}<0.01 ; * * * \mathrm{p}<0.001\right)$. All values were normalized as $\%$ above the mean of wt for each independent analysis

Fig. S4 Characterization of PSD area and length in wt and R6/2 groups following striatal infusion of the high dose of cholesterol.

(A-B) 60 PSDs were analyzed in 3 mice/group. Data are represented as means \pm standard error and were analyzed by one-way ANOVA with non-parametric Dunn's multiple comparison test.

Fig. S5 Morphometric analysis of synaptic vesicle (SV) density of inhibitory synapse in wt and $\mathbf{R 6 / 2}$ groups.

(A) Representative TEM images of inhibitory striatal synapses in wt, R6/2 and R6/2 chol-high mice. Inhibitory synapses were verified by staining the samples with anti-GABA antibodies 
bioRxiv preprint doi: https://doi.org/10.1101/2020.05.13.092742; this version posted May 15, 2020. The copyright holder for this preprint (which was not certified by peer review) is the author/funder, who has granted bioRxiv a license to display the preprint in perpetuity. It is made

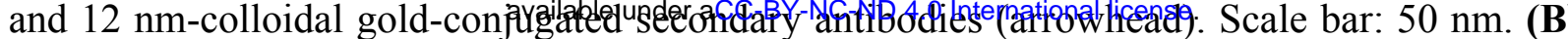

Quantification of SVs density in 30 inhibitory synapses of wt, R6/2 and R6/2 chol-high mice ( $\mathrm{N}=3$ mice/group). Graphs are means \pm standard error.

Fig. S6 Electron microscopy analysis of myelin sheaths in wt and R6/2 groups.

(A) Representative EM images of myelinated fibers taken from the striatum of wt, R6/2, R6/2 ACSF and R6/2 chol-high (Scale bar: $500 \mathrm{~nm}$ ). (B) Scatterplot graph of G-ratios against axonal diameters with linear regression. The slope of the best-fit line was significantly higher for R6/2 compared with wt mice, indicating thinner myelin sheaths in HD mice with and without treatment with cholesterol. (C) Mean G-ratios were higher in R6/2 mice compared with their wt controls, indicating that HD mice had thinner myelin sheaths $(* * * p<0.001)$. At least 300 axons in 3 mice group were subjected to G-ratio analysis. Statistics: one-way ANOVA with Newman-Keuls post-hoc test $\left({ }^{*} p<0.05 ; *^{*} p<0.01 ; * * * p<0.001\right)$. (D) Representative EM images of myelinated fibers taken from the corpus callosum of wt, R6/2, R6/2 ACSF and R6/2 chol-high (Scale bar: $500 \mathrm{~nm}$ ). (E) Scatterplot graph of G-ratios against axonal diameters with linear regression. The slope of the best-fit line was significantly higher for R6/2 compared with wt mice, indicating thinner myelin sheaths in HD mice with and without treatment with cholesterol. (F) Mean G-ratios were higher in R6/2 mice compared with their wt controls, indicating that HD mice had thinner myelin sheaths $(* * * \mathrm{P}<0.001)$. At least 300 axons in 3 mice group were subjected to G-ratio analysis. Error bars represent the standard error of the mean. Statistics: one-way ANOVA with Newman-Keuls post-hoc test $\left({ }^{*} \mathrm{p}<0.05 ;{ }^{*} \mathrm{p}<0.01\right.$; $* * * p<0.001)$. (G) Representative EM images of myelinated fibers and its magnification taken from the striatum of wt mice in which the major dense lines in the myelin sheath are indicated. Periodicity was measured as the mean distance between two major dense lines from at least 45 randomly chosen myelin sheaths in 3 mice group. (Scale bars: $30 \mathrm{~nm}$ and $10 \mathrm{~nm}$ ). (H-I) Quantification of the mean periodicity in wt, R6/2, R6/2 ACSF and R6/2 chol-high mice. Error 
bioRxiv preprint doi: https://doi.org/10.1101/2020.05.13.092742; this version posted May 15, 2020. The copyright holder for this preprint (which was not certified by peer review) is the author/funder, who has granted bioRxiv a license to display the preprint in perpetuity. It is made bars represent the standard eîrof

Keuls post-hoc test $\left({ }^{*} \mathrm{p}<0.05 ; * * \mathrm{p}<0.01 ; * * * \mathrm{p}<0.001\right)$.

Fig. S7 Levels of cholesterol precursors and 24S-OHC in the striatum of wt and R6/2 groups following striatal infusion of cholesterol.

(A-B) 24S-OHC level in the infused striatum of wt ACSF $(\mathrm{N}=3)$, wt chol-low $(\mathrm{N}=5)$, wt cholhigh $(\mathrm{N}=4)(\mathrm{A})$, and in the infused striatum of wt ACSF (N=3), R6/2 ACSF (N=7), R6/2 chollow $(\mathrm{N}=4)(\mathrm{B})$ at 12 weeks of age after 4 week-striatal infusion of cholesterol. (C-D) Lanosterol level in the infused striatum of wt ACSF $(\mathrm{N}=3)$, wt chol-low $(\mathrm{N}=5)$, wt chol-high $(\mathrm{N}=4)(\mathrm{C})$, and in the infused striatum of wt ACSF (N=3), R6/2 ACSF (N=7), R6/2 chol-low $(\mathrm{N}=4)(\mathrm{D})$ at 12 weeks of age after 4 week-striatal infusion of cholesterol. (E-F) Lathosterol level in the infused striatum of wt $\operatorname{ACSF}(\mathrm{N}=3)$, wt chol-low $(\mathrm{N}=5)$, wt chol-high $(\mathrm{N}=4)(\mathrm{E})$, and in the infused striatum of wt ACSF (N=3), R6/2 ACSF $(N=7), R 6 / 2$ chol-low $(N=4)(F)$ at 12 weeks of age after 4 week-striatal infusion of cholesterol. $(\mathbf{G}-\mathbf{H})$ Desmosterol level in the infused striatum of wt ACSF $(\mathrm{N}=3)$, wt chol-low $(\mathrm{N}=5)$, wt chol-high $(\mathrm{N}=4)(\mathrm{G})$, and in the infused striatum of wt ACSF (N=3), R6/2 ACSF (N=7), R6/2 chol-low $(\mathrm{N}=4)(\mathrm{H})$ at 12 weeks of age after 4 week-striatal infusion of cholesterol.

All values were expressed as \% above the mean of wt ACSF. The data of wt ACSF in A, C, E, G are the same shown in B, D, F, H. The data in A-H are shown as scatterplot graphs with means \pm standard error with each dot corresponding to the value obtained from each animal. Statistics: one-way ANOVA with Newman-Keuls post-hoc test $\left({ }^{*} \mathrm{p}<0.05 ;{ }^{* *} \mathrm{p}<0.01\right.$; $* * * \mathrm{p}<0.001)$, and student's t-test $\left({ }^{\#} \mathrm{p}<0.01\right)$ in A.

Fig. S8 Nuclear distribution of SREBP2 in R6/2 MSNs following striatal infusion of the high dose of cholesterol. 
bioRxiv preprint doi: https://doi.org/10.1101/2020.05.13.092742; this version posted May 15, 2020. The copyright holder for this preprint (which was not certified by peer review) is the author/funder, who has granted bioRxiv a license to display the preprint in perpetuity. It is made

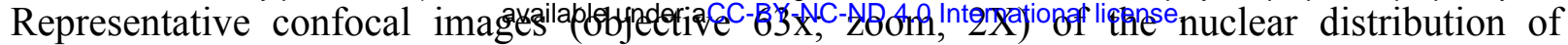

SREBP2 (red) in the infused striatum of R6/2 chol-high mice $(\mathrm{N}=4)$ in MSNs labelled with

DARPP32 (green). Hoechst (Ho, blue) was used to counterstain nuclei. Scale bar is $2 \mu \mathrm{m}$.

Fig. S9 Nuclear distribution of SREBP2 in R6/2 astrocytes following striatal infusion of the high dose of cholesterol.

Representative confocal images (objective 63x; zoom, 2X) of the nuclear distribution of SREBP2 (red) in the infused striatum of R6/2 chol-high mice $(\mathrm{N}=4)$ in astrocytes labelled with GFAP (green). Hoechst (Ho, blue) was used to counterstain nuclei. Scale bar is $5 \mu \mathrm{m}$.

Fig. S10 MuHTT aggregates in the striatum, cortex and hippocampus of R6/2 chol-high mice.

(A-F) Zoom of representative confocal images of immunostaining against EM48 antibody, specific for muHTT aggregates, in the infused and the contralateral striatum (A), cortex (C) and hippocampus $(E)$ of $R 6 / 2$ chol-high mice $(N=3)$ and relative quantification $(B, D, F)$ of number of aggregates. Hoechst (Ho, blue) was used to counterstain nuclei. Scale bars in A, C, E: 10 $\mu \mathrm{m} .18$ images/animal were analyzed from 9 sections throughout the entire striatum; 10 images for each animal were analyzed from 3 sections of the cortex; 6 images for each animal/condition were analyzed from 3 sections of the hippocampus. All values are expressed as $\%$ above the mean of aggregates in the contralateral tissue of R6/2 chol-high mice. The data are shown as scatterplot graphs with means \pm standard. Each dot corresponding to number of aggregates counted in all the images. Statistics: one-way ANOVA with Newman-Keuls posthoc test $(* \mathrm{p}<0.05 ; * * \mathrm{p}<0.01 ; * * * \mathrm{p}<0.001)$. 